\title{
Therapeutic Approaches to Genetic Ion Channelopathies and Perspectives in Drug Discovery
}

Paola Imbrici ${ }^{*}$, Antonella Liantonio ${ }^{1}$, Giulia M. Camerino', Michela De Bellis ${ }^{1}$, Claudia Camerino ${ }^{2}$, Antonietta Mele1, Arcangela Giustino ${ }^{3}$, Sabata Pierno', Annamaria De Luca ${ }^{1}$, Domenico Tricarico ${ }^{1}$, Jean-Francois Desaphy ${ }^{3}$ and Diana Conte ${ }^{1}$

' Department of Pharmacy - Drug Sciences, University of Bari "Aldo Moro", Bari, Italy, ${ }^{2}$ Department of Basic Medical Sciences, Neurosciences and Sense Organs, University of Bari "Aldo Moro", Bari, Italy, ${ }^{3}$ Department of Biomedical Sciences and Human Oncology, University of Bari "Aldo Moro", Bari, Italy

In the human genome more than 400 genes encode ion channels, which are transmembrane proteins mediating ion fluxes across membranes. Being expressed in all cell types, they are involved in almost all physiological processes, including sense perception, neurotransmission, muscle contraction, secretion, immune response, cell proliferation, and differentiation. Due to the widespread tissue distribution of ion channels and their physiological functions, mutations in genes encoding ion channel subunits,

\section{OPEN ACCESS}

Edited by: Maria Cristina D'Adamo, University of Perugia, Italy

Reviewed by:

Mirko Baruscotti,

University of Milano, Italy

Adrien Moreau,

Institut Neuromyogene - École Normale Supérieure de Lyon, France

*Correspondence:

Paola Imbrici

paola.imbrici@uniba.it

Specialty section: This article was submitted to Pharmacology of lon Channels and Channelopathies,

a section of the journal

Frontiers in Pharmacology

Received: 27 February 2016 Accepted: 25 April 2016 Published: 10 May 2016

Citation:

Imbrici P, Liantonio $A$, Camerino GM,

De Bellis M, Camerino C, Mele A, Giustino A, Pierno S, De Luca A, Tricarico D, Desaphy J-F and Conte $D$

(2016) Therapeutic Approaches to Genetic Ion Channelopathies and Perspectives in Drug Discovery.

Front. Pharmacol. 7:121 doi: 10.3389/fphar.2016.00121 or their interacting proteins, are responsible for inherited ion channelopathies. These diseases can range from common to very rare disorders and their severity can be mild, disabling, or life-threatening. In spite of this, ion channels are the primary target of only about $5 \%$ of the marketed drugs suggesting their potential in drug discovery. The current review summarizes the therapeutic management of the principal ion channelopathies of central and peripheral nervous system, heart, kidney, bone, skeletal muscle and pancreas, resulting from mutations in calcium, sodium, potassium, and chloride ion channels. For most channelopathies the therapy is mainly empirical and symptomatic, often limited by lack of efficacy and tolerability for a significant number of patients. Other channelopathies can exploit ion channel targeted drugs, such as marketed sodium channel blockers. Developing new and more specific therapeutic approaches is therefore required. To this aim, a major advancement in the pharmacotherapy of channelopathies has been the discovery that ion channel mutations lead to change in biophysics that can in turn specifically modify the sensitivity to drugs: this opens the way to a pharmacogenetics strategy, allowing the development of a personalized therapy with increased efficacy and reduced side effects. In addition, the identification of disease modifiers in ion channelopathies appears an alternative strategy to discover novel druggable targets.

Keywords: ion channels pharmacology, channelopathies, physiopathology, drug discovery and development, genetics

\section{INTRODUCTION}

Ion channels are membrane proteins that selectively regulate ion fluxes across the membranes of cells and cellular organelles, their gating mechanism depending on changes in membrane voltage, ligand binding or physical and chemical stimuli. The presence of distinct ion channel isoforms and their age-dependent and tissue-specific expression allow the fine regulation of many cellular 
functions, such as cell excitability, contraction, neurotransmitter and hormone release, gene expression, ion and water homeostasis (Hibino et al., 2010; Jan and Jan, 2012; Catterall and Swanson, 2015; Jentsch, 2015; Zamponi et al., 2015).

Given the pivotal roles played by ion channels and their extensive distribution, it is not surprising that mutations in ion channels genes, or their interacting proteins, cause specific inherited ion channelopathies, ranging from relatively common ones, such as idiopathic epilepsies, to very rare diseases (Figure 1). Despite the differences in their genetic origin and clinical setting, ion channelopathies share some common features regarding pathophysiology and therapeutic approach. In general, loss- or gain-of-function mutations translate into a principal "organ-specific" clinical phenotype (Cannon, 2015; Spillane et al., 2016). The clinical manifestation of the disease depends on the type of mutation and functional consequences on channel activity, the cellular and subcellular localization of the channel isoform, and the channel oligomeric assembly (Kullmann and Waxmann, 2010). Since first discovery, the clinical spectrum of most channelopathies has broadened as new carrier families and new mutations have been identified. In some cases, the range of symptoms associated with specific channelopathies are not easily explained at a molecular and functional level and, besides the disease-causing mutation in a particular ion channel gene, they might stem from the interplay of different genes and life conditions acting as disease modifiers (Kullmann and Waxmann, 2010; Kearney, 2011; Furby et al., 2014; Swaggart and McNally, 2014; Portaro et al., 2015). Other channelopathies are further complicated by comorbidity, including seizures, myotonia, neurodevelopmental delay, arrhythmias, or diabetes that led to the definition of multiorgan syndromes. As a consequence of such genetic and clinical complexity and of the rarity of affected patients, a precise diagnosis for several channelopathies is still difficult to be made and a genotype-phenotype correlation cannot be easily defined. This, in turn, can subtsantially affect the choice of the most appropriate therapeutic management. The elevated cost of drug discovery restrains the development of new drugs for these rare diseases that are generally neglected by pharmaceutical companies. Furthermore, as patients' groups are very small, clinical trials of statistical significance are difficult to run. A few channelopathies, such as sodium channel myotonias (SCMs) or neonatal diabetes, may benefit from a targeted pharmacotherapy (Desaphy et al., 2013b; De Franco et al., 2015). In some cases, a pharmacogenetic approach have been explored successfully (Yang et al., 2012; Desaphy et al., 2013b). Yet, most of inherited channelopathies lack specific treatments, and medications for these disorders are often empiric and symptomatic, acting, for instance, to restore membrane excitability or counteract inflammation and pain (Spillane et al., 2016). Notoriously, these drugs are marginally effective and may work inconsistently in different patients.

Today, about $5 \%$ of the available marketed drugs are small molecules able to modulate ion channel activity in a number of diseases. Some of these compounds are also enrolled in the clinical management of channelopathies. $\mathrm{Na}_{\mathrm{v}}$ channels blockers have been successfully employed for decades as anticonvulsants, antiarrhythmics, and local anesthetics (Catterall and Swanson, 2015). Great interest is emerging from the possibility to develop sodium channel inhibitors for the treatment of neuropathic pain and to repurpose marketed blockers for other medical indications (Desaphy et al., 2013a, 2014; Matthews and Hanna, 2014; de Lera Ruiz and Kraus, 2015). KCNQ openers have been placed in clinics for their anticonvulsant effects (Humphries and Dart, 2015) and KATP channels are promptly targeted by sulfonylureas in neonatal diabetes (De Franco et al., 2015). Calcium channels blockers are widely used as symptomatic antiarrhythmics. Conversely, chloride channels represent a relatively underexplored target class for drug discovery (Verkman and Galietta, 2009; Imbrici et al., 2015a; Jentsch, 2015). Unfortunately, several drugs targeting ion channels, such as sodium channel modulators, are not able to discriminate among ion channel isoforms, hence at risk of causing unwanted side effects (Catterall, 2014; Grunnet et al., 2014). With a few exceptions, much-needed specific ion channels modulators are lacking.

Therefore, to guarantee patients suffering from channelopathies a personalized therapy, novel molecules are under development and pharmacological strategies have been explored to identify novel drug targets. In principle, the better understanding of the genetic and functional defects underlying channelopathies will allow to deliver patients a precision medicine specifically targeting the biological effects of the disease-causing mutation, such as a biophysical or folding defect. Drug design and development are being greatly assisted by the recently identified crystal structures of several ion channels, by computer modeling, by high-throughput screening methods, by novel genetic studies and, finally, by transgenic and pharmacologically induced cell and animal models of channelopathies (Feng et al., 2010; Hibino et al., 2010; Jan and Jan, 2012; Tikhonov and Zhorov, 2012; Paşca et al., 2014; Jentsch, 2015; Rubinstein et al., 2015; Zamponi et al., 2015; Zou, 2015). Here we summarize the main pharmacological strategies performed to treat major channelopathies caused by mutations in voltage-gated and inward rectifying ion channels. Although, the involvement of other classes of ion channels and transporters, including neurotransmitter-gated channels (Spillane et al., 2016), cyclic nucleotide-gated channels, volume-regulated and calcium-activated anion channels (Hoffmann et al., 2015) is also well-established in channelopathies, these are not detailed in this review. Finally, although rare, some channelopathies may serve as a useful paradigm for understanding and treatment of more common multifactorial disorders.

\section{MOLECULAR MECHANISMS OF ION CHANNELOPATHIES}

Inherited channelopathies result from loss or gain of function mutations in genes coding for ion channels or their accessory subunits. Genetic variants include small deletions, insertions, frame-shifts, stop codons, missense, splice-site mutations and, recently, also exon deletions or duplications have been reported (Catterall, 2014; Imbrici et al., 2015b; Spillane et al., 2016). The 


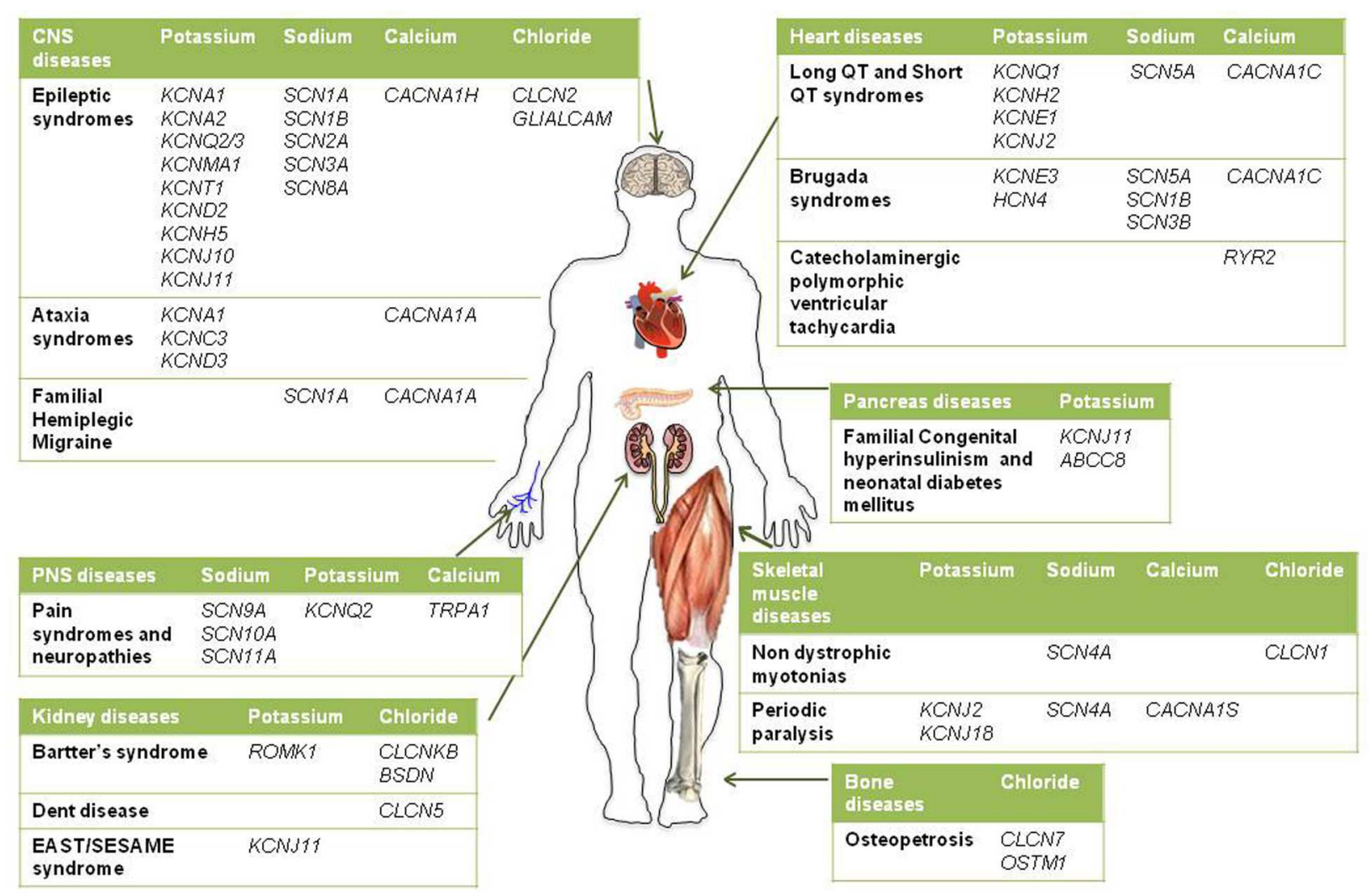

FIGURE 1| Schematic diagram illustrating the main inherited ion channelopathies of CNS, PNS, skeletal muscle, heart, kidney, pancreas, and bone.

majority of inherited mutations alter ion channel biophysical properties, such as voltage-dependent gating, kinetics, single channel conductance, ion selectivity, or modulation by signaling pathways. Some mutations reduce channel surface expression as a consequence of altered synthesis, defective folding and trafficking to the membrane, or increased degradation (Bechi et al., 2015; Mall and Galietta, 2015). In general, loss-of-function mutations in $\mathrm{K}^{++}$or $\mathrm{Cl}^{-}$channels or gain-of-function mutations in $\mathrm{Ca}^{2+}$ or $\mathrm{Na}^{+}$channels lead to hyperexcitability disorders, such as epilepsy or myotonia. However, gain-of-function mutations of neuronal $\mathrm{K}^{+}$channels or loss-of-function mutations of $\mathrm{Na}^{+}$ channels that decrease excitability in inhibitory interneurons can lead to epilepsy as well. Thus, the final effect of a mutation depends on the specific expression pattern, exact stochiometry and functional role of the ion channels involved. This knowledge is fundamental to design appropriate therapies.

\section{CENTRAL NERVOUS SYSTEM CHANNELOPATHIES}

\section{Epilepsy}

Epilepsy is a brain disorder due to abnormal synchronous discharges of neuronal networks in the brain that causes convulsions, muscle spasms, and often loss of consciousness (Spillane et al., 2016). A broad spectrum of epileptic syndromes exists, often comorbid with other clinical features, such as autistic traits and other psychiatric conditions and with cardiac arrhythmias (Splawski et al., 2004; Sicca et al., 2011; Catterall, 2014; Guglielmi et al., 2014). Different classes of ion channels play critical roles in maintaining the balance between excitatory and inhibitory inputs in the brain, thus it is no surprise that gain or loss of function mutations in their genes are associated to epilepsy.

Diverse voltage gated sodium channel subtypes, ensuring action potential generation and propagation in the CNS $\left(\mathrm{Na}_{\mathrm{v}} 1.1\right.$, $\mathrm{Na}_{\mathrm{v}} 1.2, \mathrm{Na}_{\mathrm{v}} 1.3$, and $\left.\mathrm{Na}_{\mathrm{v}} 1.6\right)$ have been associated with multiple seizure disorders (Catterall, 2014). More than 300 mutations in SCN1A $\left(\mathrm{Na}_{\mathrm{v}} 1.1\right)$ are responsible for genetic epilepsy syndromes ranging in severity from simple febrile seizures to Generalized Epilepsy with Febrile Seizures (GEFS+), an autosomal dominant epilepsy disorder associated to missense mutations, to Severe Myoclonic Epilepsy of Infancy (SMEI or Dravet syndrome; prevalence: $<1 / 40,000)$, the most severe form of often intractable epilepsy mainly caused by truncation or deletion mutations in Nav1.1 channels (Catterall, 2014). Dominant mutations in SCN2A encoding $\mathrm{Na}_{\mathrm{v}} 1.2$ channels cause Benign Familial Neonatal-Infantile Seizures (BFNIS; prevalence: $<1 / 1000,000$ ), a 
mild seizure syndrome that responds positively to treatment with anti-epileptic drugs (AEDs), and generally remits by 1 year of age (Berkovic et al., 2004). In addition, de novo mutations in $\mathrm{Na}_{\mathrm{v}} 1.2$ can cause more severe phenotypes including developmental delay and intractable seizures (Ogiwara et al., 2009; Liao et al., 2010). Other epileptic phenotypes have been associated with mutations in SCN3A $\left(\mathrm{Na}_{\mathrm{v}} 1.3\right), S C N 8 A\left(\mathrm{Na}_{\mathrm{V}} 1.6\right)$, and in SCN1B ( $\mathrm{Na}_{\mathrm{v}} 1.1 \beta$ subunits; Vanoye et al., 2013; Larsen et al., 2015; O'Malley and Isom, 2015; Wagnon and Meisler, 2015). Electrophysiological and behavioral studies on mouse models of SMEI and GEFS+ indicated that progressive loss of Nav1.1 activity in inhibitory GABAergic interneurons may cause reduced GABA release and network hyperexcitability in different brain regions, resulting in seizure syndromes of increasing severity (Tang et al., 2009; Catterall, 2014; Rubinstein et al., 2015). Beside epilepsy, impairment in GABAergic interneurons also contributes to autistic-like behavior, hyperactivity and cognitive impairment observed in SMEI patients (Bender et al., 2012; Rubinstein et al., 2015).

Voltage-dependent potassium channels concur to action potential repolarization and resting membrane potential, set the firing frequency of neurons and dampen abnormal excitatory inputs. Moreover, inward rectifier potassium channels contribute to the maintenance of resting potential and to the transport and buffering of $\mathrm{K}^{+}$across membranes. Thus, disruption of $\mathrm{K}^{+}$ channels in specific brain areas is often associated with increased susceptibility to seizures (for reviews see D'Adamo et al., 2015b; Miceli et al., 2015a). Patients affected by episodic ataxia type 1, a form of episodic ataxia with myokymia (see below) caused by loss-of-function mutations in KCN1A (coding for $\mathrm{K}_{\mathrm{v}} 1.1$ channel), often report abnormal EEGs, and several animal models carrying $k c n a 1$ gene defects show an increased susceptibility to seizures (Smart et al., 1998). Loss- and gain-of-function mutations in KCNA2 (encoding the potassium channel $\mathrm{K}_{\mathrm{v}} 1.2$ ) have been identified in patients with epileptic encephalopathy, intellectual disability, delayed speech development and sometimes ataxia (Syrbe et al., 2015). Loss-of-function mutations in KCNQ2 or KCNQ3 (encoding for $\mathrm{K}_{\mathrm{v}} 7.2$ and $\mathrm{K}_{\mathrm{v}} 7.3$ channels) cause Benign Familial Neonatal Convulsions (BFNC; prevalence: 100 reported families), a form of juvenile epilepsy characterized by tonic or clonic episodes spontaneously disappearing during the first year of life (Miceli et al., 2015a). In the brain, heteromeric channels composed of $\mathrm{K}_{\mathrm{v}} 7.2$ and $\mathrm{K}_{\mathrm{v}} 7.3$ subunits underlie the $\mathrm{M}$-current that regulates neuronal excitability in the sub-threshold range for action potential generation and limits repetitive firing (Soldovieri et al., 2011). A decrease in M-current amplitude by $25 \%$ is sufficient to cause neonatal epilepsy of variable clinical severity depending on the extent of $\mathrm{K}^{+}$channel impairment caused by the specific mutation. Remarkably, de novo gain-of-function mutations in $\mathrm{K}_{\mathrm{v}} 7.2$ channels have been found in neonates affected by early-onset epileptic encephalopathy presenting with pharmacoresistant seizures and various degrees of developmental delay (Miceli et al., 2015b). In this case, the gain of potassium current in inhibitory interneurons likely increases the excitability of hippocampal CA1 pyramidal neurons leading, in turn, to epilepsy. Recently, several gain of function mutations in KCNT1 gene (coding for Kca4.1, a sodium-activated potassium channel also named Slo2.2 or SLACK) have been identified in patients with two different types of epilepsy occurring in infancy or childhood: Malignant Migrating Partial Seizures of Infancy (MMPSI; also called Epilepsy of Infancy with Migrating Focal Seizures, EIMFS; prevalence: $<1 / 1000,000)$ and Autosomal Dominant Nocturnal Frontal Lobe Epilepsy (ADNFLE; prevalence: over 100 reported families; Lim et al., 2016; Tang et al., 2016). In these patients, intellectual disability and psychiatric features have also been observed. Gain-of-function mutations in the KCNJ10 gene (coding for the $\mathrm{K}_{\mathrm{ir}} 4.1$ potassium channel) have been reported in children with autistic traits, seizures and intellectual disability (Sicca et al., 2011; Guglielmi et al., 2014). Other genes of potassium channel and their accessory subunits have been implicated in complex epileptic phenotypes, including KCNV2 ( $\left.\mathrm{K}_{\mathrm{v}} 8.2\right)$, KCNMA1 (BK), KCNH5 $\left(\mathrm{K}_{\mathrm{v}} 10.2\right)$, KCNC1 gene $\left(\mathrm{K}_{\mathrm{v}} 3.1\right)$, KCND2 $\left(\mathrm{K}_{\mathrm{v}} 4.2\right.$; Guglielmi et al., 2014; D’Adamo et al., 2015b; Miceli et al., 2015a; Spillane et al., 2016).

Some studies reported polymorphisms or mutations in the chloride channel genes CLCN2 (ClC-2) and CLCN1 (ClC-1) in epileptic patients but the involvement of these channels in epilepsy remains controversial (Saint-Martin et al., 2009; Niemeyer et al., 2010; Chen et al., 2013). One study also showed the unexpected location of ClC-1 mRNA transcripts and protein in several mouse and human brain areas, opening new perspectives to the role of the "skeletal muscle" $\mathrm{ClC}$-1 channels in regulating brain excitability and susceptibility to seizures (Chen et al., 2013). Defects in ClC-2, in the astrocytic membrane protein MLC1 and in the adhesion molecule GlialCAM, underlie human leukoencephalopathies, degenerative disorders affecting the white matter of the brain and associated with myelin and astrocyte vacuolization (Depienne et al., 2013; Hoegg-Beiler et al., 2014). Mutations in both MLC1 and GlialCAM, have been associated with rare megalencephalic leukoencephalopathy with subcortical cysts (MLC1 and 2; prevalence: <1/1000,000), characterized by macrocephaly, developmental delay and seizures that appears in the first years of life (López-Hernández et al., 2011). It has been recently shown that GlialCAM, MLC1 and ClC2 interact in vivo, with GlialCAM targeting both MLC1 and ClC-2 to astrocytes junctions and increasing $\mathrm{ClC}-2$ chloride current, and MLC1 also affecting the localization of ClC-2 and GlialCAM in the glia (Hoegg-Beiler et al., 2014; Brignone et al., 2015). Despite the pathophysiology of MLC remains unclear, studies from different genetic animal models suggest that reduction or change in $\mathrm{ClC}-2$ currents may at least in part account for the impaired glial ion homeostasis in both MLC forms (Blanz et al., 2007).

Gain of function mutations in the calcium channel gene CACNA1C (coding for $\mathrm{Ca}_{\mathrm{v}} 1.2$ channel), is associated with Timothy syndrome (TS; prevalence: $<1 / 1000,000$ ), a rare multiorgan system disorder that comprises long QT syndrome, seizures, autistic traits, dysmorphic features, developmental delay and immunodeficiency (Splawski et al., 2004; Bader et al., 2011; Diep and Seaver, 2015). Children die prematurely mainly for cardiac ventricular fibrillation (Heyes et al., 2015). Gain-offunction mutations in $C A C N A 1 H\left(\mathrm{Ca}_{\mathrm{v}} 3.2\right)$ channels have been 
found in various forms of idiopathic generalized epilepsies, such as absence epilepsy (Eckle et al., 2014; Wang et al., 2015). Studies from an animal model carrying one $\mathrm{Ca}_{\mathrm{v}} 3.2$ mutation associated with childhood absence epilepsy suggest that $\mathrm{Ca}_{\mathrm{v}} 3.2$ mutant channels potentiate NMDA-mediated synaptic transmission via increasing local $\mathrm{Ca}^{2+}$ influx at cortical synapses, thus enhancing the susceptibility to absence-like epilepsy (Wang et al., 2015).

\section{Pharmacology and Drug Therapy}

Common therapeutic strategies adopted to treat different epileptic syndromes include the positive modulation of inhibitory GABAergic transmission, the decrease of excitatory transmission through the inhibition of voltage-gated sodium and calcium channels and other various mechanisms. Regardless of the genetic origin, different AEDs such as benzodiazepines, stiripentol, topiramate, retigabine, and Nav blockers are available on the market and are effective in suppressing the abnormal neuronal firing underlying epileptic seizures (Catterall, 2014; Table 1). Despite the numerous available treatments, a large proportion of patients still present drug-resistant seizures and experience frequent adverse drug reactions. Thus new more effective therapeutic options are evaluated by several research groups and pharmaceutical companies to fulfill the need of a personalized medicine, assisted by advances in understanding disease mechanisms and ion channel structures (Catterall, 2014; Walker et al., 2015).

Phenytoin, carbamazepine, lamotrigine, and valproate are well-known state- and frequency-dependent non-selective Nav inhibitors, binding to the local anesthetic receptor site in the channel pore, according to the modulated receptor hypothesis, and preferentially stabilizing channels in the non-conducting inactivated state (Catterall and Swanson, 2015). Although they lack Nav isoform specificity, these blockers should allow a selective inhibition of action potential generation in the depolarized and rapidly firing cells that are responsible for epilepsy, leaving unaffected normally functioning tissues. These drugs are widely used for partial and generalized epilepsy but not for absence epilepsy (Catterall, 2014). Among sodium channel blockers recently approved as AEDs, it is worth mentioning lacosamide and eslicarbazepine, that shift the slow inactivation curve of the Nav channel to more hyperpolarized potentials and enhance the maximal fraction of channels that are in the slow inactivated state (Rogawski et al., 2015; Soares-da-Silva et al., 2015). In addition, current efforts in sodium channel pharmacology are focused to develop subtype-selective Nav channel ligands with improved safety and efficacy compared to first generation of Nav blockers. Interestingly, several antidepressant drugs have been shown to block sodium channels, and this action may contribute to their anticonvulsant effects (Igelström and Heyward, 2012). Of note, blockade of voltagegated sodium channels also results in inhibition of glutamate release, which is associated with anticonvulsant effect.

In Dravet syndrome, as well as in other SCN1A-related seizure disorders, sodium channel blockers such as carbamazepine, lamotrigine, phenytoin are contraindicated as they may increase frequency and severity of seizures (Catterall, 2014; Miller and Sotero de Menezes, 2014; Schoonjans et al., 2015). In children with SCN1A-related epilepsies, seizure control is particularly critical as they are at high risk for sudden unexplained death in epilepsy. In addition, there are clinical evidences that controlling seizures will reduce the subsequent brain injury and frequent comorbidity with cognitive impairment. In agreement with reduced GABAergic tone in SCN1Arelated seizures, enhancement of GABAergic transmission in inhibitory interneurons would be the most beneficial therapeutic intervention. Indeed, treatment of conditional Scn1 $1 a^{+/-}$mouse model of SMEI with low-dose clonazepam protected against myoclonic and generalized tonic-clonic seizures and completely rescued the abnormal social behaviors and deficits in fear memory (Bender et al., 2012; Oakley et al., 2013). At present, the standard treatment to treat SMEI children in Europe is either the combination of stiripentol, valproate and clobazam, or valproate in combination with topiramate (Miller and Sotero de Menezes, 2014; Schoonjans et al., 2015). Stiripentol has obtained orphan drug status for the treatment of SMEI in Europe (Prunetti and Perucca, 2011). Evidences from an animal model with haploinsufficiency for Scn1a and Scn8a suggested that reduction in the activity of Nav1.6 channels expressed in excitatory neurons might be an alternative useful option for Nav1.1-associated seizures in SMEI (Chen et al., 2008; de Lera Ruiz and Kraus, 2015). Recently, levetiracetam, which binds to the synaptic vesicle protein SV2A, was shown to be effective in GEFS+, as add-on therapy in SMEI, and in a broad range of epilepsy syndromes (Catterall, 2014).

Even though a selective channel opener might be a particularly effective AED for Nav1-associated syndromes due to loss-ofchannel function, no such drug has been developed to date (de Lera Ruiz and Kraus, 2015). Recently, different rescuing approaches have been explored to increase surface expression and restore the correct functioning of sodium channel mutants associated to GEFS+ and SMEI that present folding defects in vitro (Bechi et al., 2015). In addition, although sodium channel $\beta$ subunit-specific drugs have not yet been developed, this protein family is an emerging therapeutic target (O'Malley and Isom, 2015).

Quinidine, an antiarrhythmic and antimalarial drug, proved effective in reversing the increased current of KCNT1 mutants in vitro and in remitting seizures in three patients with KCNT1 mutations resistant to multiple antiepileptic agents (Lim et al., 2016). However, this drug acts on various cardiac potassium channels and could possibly lengthen the QT interval and lead to cardiac arrest. Thus, development of specific KCNT1 channel inhibitors with good blood-brain barrier penetration may provide a safer and more effective alternative in affected patients (Lim et al., 2016).

Another strategy to balance excitation and inhibition in the brain consists in incrementing potassium currents, such as $\mathrm{KCNQ} / \mathrm{K}_{\mathrm{v}} 7$ currents. The first agent proven to enhance $\mathrm{M}$-current activity was retigabine that has recently been approved as a first-in-class AED for the treatment of resistant partial-onset seizures (Humphries and Dart, 2015). Retigabine stabilizes the $\mathrm{K}_{\mathrm{v}} 7$ open channel conformation and induces a hyperpolarizing shift of the activation curve (Grunnet et al., 2014; Miceli et al., 2015a). Yet, the drug shows limited 
TABLE 1 | Central nervous system channelopathies.

\begin{tabular}{|c|c|c|c|}
\hline Disease & Gene (protein) & Pharmacotherapy & $\begin{array}{l}\text { Pharmacological } \\
\text { perspectives }\end{array}$ \\
\hline $\begin{array}{l}\text { Epileptic syndromes including } \\
\text { GEFS+, SMEI, } \\
\text { BFNIS, BFNC, } \\
\text { MPSI, ADNFLE, } \\
\text { MLC, absence epilepsy and } \\
\text { other epileptic } \\
\text { encephalopathies } \\
\text { (see text for abbreviations) }\end{array}$ & $\begin{array}{l}\text { SCN1A (Nav1.1) } \\
\text { SCN2A (Nav1.2) } \\
\text { SCN3A (Nav1.3) } \\
\text { SCN8A (Nav1.6) } \\
\text { SCN1B (Nav2.1) } \\
\text { KCNA1 (Kv1.1) } \\
\text { KCNA2 (Kv1.2) } \\
\text { KCNC3 (Kv3.3) } \\
\text { KCND2 (Kv4.2) } \\
\text { KCND3 (Kv4.3) } \\
\text { KCNQ2 (Kv7.2) } \\
\text { KCNQ3 (Kv7.3) } \\
\text { KCNH5 (Kv10.1) } \\
\text { KCNJ10 (Kir4.1) } \\
\text { KCNJ11 (Kir6.2) } \\
\text { ABCC8 (SUR1) } \\
\text { KCNMA1 (KCa1.1) } \\
\text { KCNT1 (KCa4.1) } \\
\text { CACNA1C (Cav1.2) } \\
\text { CACNA1A (Cav2.1) } \\
\text { CACNA1H (Cav3.2) } \\
\text { CLCN2 (CIC-2) } \\
\text { GLIALCAM }\end{array}$ & $\begin{array}{l}\text { Antiepileptic drugs aim at reducing neuronal } \\
\text { hyperexcitability with different mechanisms: } \\
\text { - Enhancement of GABAergic transmission: } \\
\text { benzodiazepines, phenobarbital, valproate, } \\
\text { stiripentol, topiramate } \\
\text { - Inhibition of glutamatergic transmission: topiramate } \\
\text { - Inhibition of Nav channels: phenytoin, } \\
\text { carbamazepine, lamotrigine, valproate, topiramate, } \\
\text { lacosamide, eslicarbazepine } \\
\text { - Opening of K channels: retigabine, acetazolamide } \\
\text { - Inhibition of T-type Cav channels: ethosuximide } \\
\text { - Inhibition of the synaptic vescicle } 2 A: \text { levetiracetam } \\
\text { - Inhibition of presynaptic Cav2 channels } \alpha 2 \delta \text { auxiliary } \\
\text { subunit: gabapentin, pregabalin } \\
\text { - Inhibition of carbonic anhydrase: topiramate, } \\
\text { acetazolamide }\end{array}$ & $\begin{array}{l}\text { - Development of } \\
\text { subtype-selective Nav } \\
\text { channels ligands with } \\
\text { improved safety and efficacy } \\
\text { - Development of } \\
\text { pharmacological chaperones } \\
\text { for folding defective mutants } \\
\text { of Nav, Kv and ClC channels } \\
\text { - Development of more } \\
\text { selective and safer Kv } \\
\text { openers }\end{array}$ \\
\hline $\begin{array}{l}\text { Episodic and spinocerebellar } \\
\text { ataxias }\end{array}$ & $\begin{array}{l}\text { KCNA1 (Kv1.1) } \\
\text { CACNA1A (Cav2.1) } \\
\text { KCNC3 (Kv3.3) } \\
\text { KCND3 (Kv4.3) }\end{array}$ & $\begin{array}{l}\text { Symptomatic drugs aim at restoring cerebellar } \\
\text { functioning and reducing frequency, duration and } \\
\text { severity of attacks: } \\
\text { - Inhibition of carbonic anhydrase: acetazolamide, in } \\
\text { EA1 and EA2 } \\
\text { - Inhibition of Kv channels: 4-aminopyridine, first } \\
\text { choice in EA2 } \\
\text { - Riluzole: Nav channels blocker and SK and TWIK } \\
\text { channels opener, in cerebellar ataxias }\end{array}$ & $\begin{array}{l}\text { - Opening of SK channels to } \\
\text { restore Purkinje cells } \\
\text { pacemaking: chlorzoxazone } \\
\text { and 1-EBIO, in EA2 animal } \\
\text { models } \\
\text { - Kv1.1 dysinactivators }\end{array}$ \\
\hline Familial hemiplegic migraine & $\begin{array}{l}\text { CACNA1A (Cav2.1) } \\
\text { SCN1A (Nav1.1) }\end{array}$ & $\begin{array}{l}\text { Symptomatic and prophylactic drugs aim at reducing } \\
\text { frequency and painful attacks: } \\
\text { - Tricyclic antidepressants, } \beta \text {-blockers, triptans, Cav } \\
\text { blockers, AEDs, acetazolamide }\end{array}$ & - Botulinum toxin \\
\hline
\end{tabular}

selectivity among all the neuronal $\mathrm{K}_{\mathrm{v}} 7$ channel subtypes and possesses significant activation of $\mathrm{GABA}_{A}$ receptors. Because of short half-life, retigabine requires a high and frequent dosing regimen that, together with the relatively poor selectivity, contributes to relevant adverse effects, including sedation, blue skin discoloration and eye abnormalities. Thus, more selective $\mathrm{K}_{\mathrm{v}} 7.2$ activators are under development (Grunnet et al., 2014).

Among AEDs, ethosuximide is a fist-line treatment of childhood absence seizures (CAE), acting through inhibition of low-threshold T-type calcium channels (comprising $\mathrm{Ca}_{\mathrm{v}} 3.1$, 3.2 , and 3.3 channels) that are generally believed to contribute to increasing seizures susceptibility. Perplexingly, about $50 \%$ of CAE patients did not respond to ethosuximide, and the majority of the non-responders carry $\mathrm{Ca}_{\mathrm{v}} 3.2$ gain-of-function mutations (Chen et al., 2003; Glauser et al., 2013). Recently, studies from the first animal model of $\mathrm{Ca}_{\mathrm{v}}$ 3.2-linked absence epilepsy raised the possibility to reduce slow wave discharges through NMDA and AMPA receptors antagonists but not T-type calcium blockers (Wang et al., 2015).
The gabapentinoid drugs, pregabalin and gabapentin, have emerged in recent years as promising therapeutic options in epilepsy and chronic pain. They target primarily the $\alpha 2 \delta$ auxiliary subunit of the presynaptic $\mathrm{Ca}_{\mathrm{v}} 2$ channels, thereby altering their membrane trafficking and inhibiting excitatory neurotransmission (Catterall and Swanson, 2015).

Current treatment for megalencephalic leukoencephalopathy is only symptomatic, including management of seizures and spasticity with topiramate and carbamazepine (Batla et al., 2011; van der Knaap and Scheper, 2011).

\section{Cerebellar Ataxias and Migraine}

The episodic ataxias are a group of rare autosomal dominant diseases characterized by recurrent attacks of vertigo and cerebellar ataxia (Jen et al., 2007). Episodic ataxia type 1 (EA1) is caused by loss-of-function mutations in the voltagedependent potassium channel gene KCNA1 (D'Adamo et al., 2015b). Affected patients display constant myokymia and short 
episodes of spastic contractions of the skeletal muscles of the head, arms and legs, with loss of both motor coordination and balance. The spectrum of clinical manifestations of the disease also includes cognitive impairments, seizures, blurred vision, neuromyotonia, migraine, short sleep phenotype (Imbrici et al., 2011; D’Adamo et al., 2015b,a). The functional characterization of several $\mathrm{K}_{\mathrm{V}} 1.1$ mutations and the generation of a knock-in animal model of EA1 (Herson et al., 2003), both suggest that increased neuronal excitability and altered GABAergic inputs to cerebellar nuclei likely generate the disease. Episodic Ataxia type 2 (EA2) is the most frequent subtype of episodic ataxia caused by loss-of- function mutations in the CACNA1A gene encoding the alpha1A subunit of $\mathrm{P} / \mathrm{Q}$ type voltage-gated $\mathrm{Ca}^{2+}$ channels $\left(\mathrm{Ca}_{\mathrm{v}} 2.1\right)$ mainly expressed in Purkinje and granule cells in the cerebellum (Jen et al., 2007). EA2 is characterized by longer attacks of ataxia compared to EA1, and is associated with headache and nystagmus both during and between the episodes attacks, but not myokymia (Jen et al., 2007; Graves et al., 2008). The disorder frequently progresses toward a permanent ataxia with cerebellar atrophy. It is generally assumed that ataxia originates from impaired cerebellar neurotransmission (Pietrobon, 2010); emerging data also point to a loss in the precision of cerebellar Purkinje cells (PCs) pacemaking (Walter et al., 2006).

Spinocerebellar ataxias (SCAs) are a very heterogeneous group of autosomal dominant neurological disorders caused by degeneration of the cerebellum and spinal cord. SCAs present a wide range of phenotypes, including cerebellar ataxia, dysarthria, extrapyramidal symptoms, oculomotor disturbance, cognitive impairment, and epilepsy. SCA6 (prevalence: <1/1000,000) is characterized by late onset, slowly progressive cerebellar ataxia (Pietrobon, 2010). It is due to small expansions of a polyglutamine stretch in the C-terminal tail of the $\mathrm{Ca}_{\mathrm{v}} 2.1$ calcium channel, which likely causes an accumulation of $\mathrm{Ca}_{\mathrm{v}} 2.1$ channels in the cytoplasm (Pietrobon, 2010). SCA13 (prevalence: $<1 / 1000,000)$ is caused by point mutations in the KCNC3 gene (encoding $\mathrm{K}_{\mathrm{v}} 3.3$ channels), which affect channel function by gain- and loss-of-function mechanisms (Minassian et al., 2012). This channel is quite exclusively expressed in fast spiking neurons, where its dysfunction affects firing frequency and neurotransmitter release. Loss-of-function mutations in the KCND3 gene $\left(\mathrm{K}_{\mathrm{v}} 4.3\right)$ have been found in patients with SCA19 and SCA22 (prevalence: <1/1000,000; Duarri et al., 2012; Lee et al., 2012).

Familial hemiplegic migraine type 1 (FHM1) is a rare and severe form of migraine with hemiplegic aura associated with cerebellar deficit in about 50\% of patients (Pietrobon and Moskowitz, 2013). FHM1 is due to gain-of-function missense mutations, mostly affecting the pore and the voltage sensor module of the $\mathrm{Ca}_{\mathrm{v}} 2.1$ channel (Pietrobon and Moskowitz, 2013; Jen, 2015). Electrophysiological recordings from cerebellar granule cell of a mouse model of FHM1, bearing the voltage sensor R192Q mutation, showed increased $\mathrm{Ca}_{\mathrm{v}} 2.1$ density and glutamate release and increased susceptibility to cortical spreading depression as the pathophysiologic mechanism underlying migraine with aura (Tottene et al., 2009; Pietrobon, 2010). FHM3 is associated with gain-of-function heterozygous mutations in the SCN1A gene likely leading to hyperexcitability of GABAergic interneurons (Dichgans et al., 2005; Cestèle et al., 2013).

\section{Pharmacology and Drug Therapy}

No specific treatment exists for individuals affected by episodic ataxias type 1 and 2 , as openers of neuronal $\mathrm{K}_{\mathrm{V}} 1.1$ and $\mathrm{P} / \mathrm{Q}$ type calcium channels are dramatically lacking (Table 1). Both EA1 and EA2 patients are often treated with acetazolamide, a carbonic-anhydrase (CA) inhibitor, although with variable effectiveness and notable side effects during chronic treatment (such as nephrocalcinosis, hyperhidrosis, paresthesia, muscle stiffening with easy fatigability, and gastrointestinal disturbances; D'Adamo et al., 2015b, Jen, 2015). The mechanisms of action of this drug are still unclear and may include activation of skeletal muscle $\mathrm{Ca}^{2+}$-activated-K ${ }^{+}(\mathrm{BK})$ channels or $\mathrm{ClC}-1$ channels (see below Eguchi et al., 2006; Tricarico et al., 2006). Today, 4aminopyridine is the treatment of choice for EA2. The drug, at the concentrations used, likely targets the $\mathrm{K}_{\mathrm{V}} 1$ channels, possibly the $\mathrm{K}_{\mathrm{v}} 1.5$ subtype, whereas at higher concentrations it blocks a large array of $\mathrm{K}^{+}$channels and is a proconvulsant. Its efficacy in relieving ataxic gaits with only minor side effects was assessed first in a pilot study for EA2 in humans and confirmed in a prospective randomized, double blind, placebo-controlled crossover study in familial EA with nystagmus. Actually, two randomized controlled trials on EA2 with 4-aminopyridine versus acetazolamide are ongoing (EAT-2-TREAT; Strupp et al., 2015).

An alternative approach for the treatment of EA2 may consist in the activation of the widely- distributed, smallconductance $\mathrm{Ca}^{2+}$-activated-K $\mathrm{K}^{+}$(SK) channels to improve PCs firing. Treatment with 1-ethyl-2-benzimidazolinone or chlorzoxazone, two SK channel activators, efficaciously restored the correct pacemaking activity of PCs and reduced ataxia and dyskinesia in tottering and ducky EA2 mouse models (Walter et al., 2006; Alvina and Khodakhah, 2010a). Actually, also 4AP was shown to restore PC pacemaking and neurotransmitter release in mouse models of EA2 (Alvina and Khodakhah, 2010b).

Compounds that disrupt Kv1.1 N-type inactivation induced by $\beta 1$ subunits have been developed and might be useful for reducing neuronal hyperexcitability in diseases, such as epilepsy and neuropathic pain, but could also be adjuvant in diseases presenting with cognitive symptoms of hippocampal origin (Humphries and Dart, 2015).

No specific treatments have been demonstrated effective in progressive SCA (Table 1). Acetazolamide is used to alleviate episodes of ataxia, and gabapentin may be beneficial to SCA6 patients (Nakamura et al., 2009; Ilg et al., 2014). Repurposing of existing drugs is an approach that is being increasingly explored. A 1-year randomized, double-blind, placebo-controlled trial with riluzole, the only drug licensed for the treatment of amyotrophic lateral sclerosis, in patients with hereditary cerebellar ataxia of different aetiologies suggests the potential efficacy of this drug (Romano et al., 2015). Riluzole blocks sodium channels, opens SK channels, enhances activity of TWIK-related potassium channel1 (TREK-1), and reduces glutamate release, thereby decreasing neuronal hyperexcitability. Longer confirmatory studies on larger and disease-specific populations are, however, needed. 
The available therapy for all FHM types during an episode of hemiplegic migraine is only symptomatic (Table 1). Standard prophylactic drugs for frequent migraine include tricyclic antidepressants, $\beta$-blockers, calcium channel blockers, triptans, AEDs, and acetazolamide, but there is no evidence of clinical efficacy on a large scale for any of these medications (Omata et al., 2011; Diener et al., 2015; Jen, 2015).

\section{PERIPHERAL NERVE CHANNELOPATHIES}

\section{Pain Syndromes}

As in the central nervous system, ion channels play a pivotal role in excitability and communication in the peripheral nervous system (PNS), consisting in the somatic, autonomic, and sensory nervous systems. Genetic ion channelopathies of the PNS encompass gene mutations in the voltage-gated sodium, potassium and transient receptor potential channels (TRP; Miceli et al., 2012; Bennett and Woods, 2014). Many sodium channel subtypes are expressed in the PNS. The $\mathrm{Na}_{\mathrm{v}} 1.3$ channel is expressed mainly during embryogenesis, but de novo expression has been reported after nerve injury and inflammation, suggesting a possible role in neuropathic pain. The $\mathrm{Na}_{\mathrm{v}} 1.1,1.2$, and 1.6 are expressed in both the PNS and CNS, and mutations in these channels result in epileptic diseases (see above), while little is known about possible peripheral symptoms. In contrast, SCNA9 $\left(\mathrm{Na}_{\mathrm{v}} 1.7\right)$, SCNA10 $\left(\mathrm{Na}_{\mathrm{v}} 1.8\right)$, and SCNA11 $\left(\mathrm{Na}_{\mathrm{v}} 1.9\right)$ channels are considered as specific PNS channels (Catterall, 2012). Mutations in these channels cause a series of familial or sporadic pain disorders (Brouwer et al., 2014; Waxman et al., 2014; Habib et al., 2015). Loss of function of Nav1.7 is linked to recessive congenital pain insensitivity or hereditary sensory and autonomic neuropathy (Cox et al., 2006; Yuan et al., 2013). Conversely, gain of function of Nav1.7 leads to a triad of autosomal dominant familial pain syndromes, including inherited erythromelalgia (IEM), paroxysmal extreme pain disorder (PEPD; prevalence $<1 / 1000,000$ ), and painful smallfiber neuropathy (SFN; Yang et al., 2004; Fertleman et al., 2006; Faber et al., 2012a). Functional studies of $\mathrm{Na}_{\mathrm{v}} 1.7$ mutants suggest that IEM mutations essentially enhance channel activation and the channel ramp response, whereas PEPD mutations rather impair fast and/or slow inactivation and produce resurgent currents (Lampert et al., 2014). The SFN mutations induce functional alterations overlapping those of IEM and PEPD. These biophysical defects invariably enhance neuron excitability, which accounts for pain exacerbation. Interestingly, a study recently described a possible link between $\mathrm{Na}_{\mathrm{v}} 1.7$ mutation and the neurodegeneration observed in SFN, because of reverse $\mathrm{Na} / \mathrm{Ca}$ exchanger-induced $\mathrm{Ca}^{2+}$ toxicity (Estacion et al., 2015). Gain of function mutations of the $\mathrm{Na}_{\mathrm{v}} 1.8$ channel also lead to painful SFN, showing faster recovery from inactivation, hyperpolarized activation, or impaired fast inactivation (Faber et al., 2012b; Han et al., 2014). While $\mathrm{Na}_{\mathrm{v}} 1.7$ and Nav1.8 channels allow the rapid upstroke of action potentials in nociceptors, $\mathrm{Na}_{\mathrm{v}} 1.9$ channels have much slower kinetics and are active near the resting potential, thereby lowering the excitability threshold.
Gain of function mutations of $\mathrm{Na}_{\mathrm{v}} 1.9$ were recently reported to cause familial episodic pain (Zhang et al., 2013; Huang et al., 2014; Leipold et al., 2015). Quite surprisingly, another $\mathrm{Na}_{\mathrm{v}} 1.9$ mutation was associated to loss of pain sensation, likely due to the concomitant alteration of channel activation and inactivation resulting in a larger window current that, in turn, causes sustained depolarization and inactivation of nociceptors (Leipold et al., 2013, 2015).

Peripheral nerve hyperexcitability seems also related to mutations in potassium channels underlying the M-current, such as $\mathrm{R} 207 \mathrm{~W} / \mathrm{Q}$ in $\mathrm{K}_{\mathrm{v}} 7.2$ (Wuttke et al., 2007). In some cases the disease is attributable to the generation of gating pore currents (Miceli et al., 2012).

Only one mutation has been found in TRPA1 channel to cause familial episodic pain syndrome type I (Kremeyer et al., 2010). The enhanced activation of mutant channel by endogenous mediators likely accounts for the intense pain experienced by carriers.

In addition, besides the pathogenic mutations, some single nucleotide polymorphisms found in various ion channels, including $\mathrm{Na}_{\mathrm{v}} 1.7$, have been shown to contribute to altered pain sensations in various conditions (Bennett and Woods, 2014; Brouwer et al., 2014).

\section{Pharmacology and Drug Therapy}

The familial pain disorders can be severely disabling and require the use of analgesics in addition to cold compress. At the moment, therapeutic management of these channelopathies is generally very difficult, often requiring combined medication (Table 2). Controlled trials of drug effectiveness are lacking, and the choice of drug relies mainly on physician experience. Acetaminophen and non-steroidal anti-inflammatory drugs may give some pain relief, but a significant number of patients get no response (Estacion et al., 2015; Leipold et al., 2015). In addition, the response to neuropathic pain medications, such as antidepressants and gabapentinoids, is quite variable between individuals. Recently, intrathecal ziconotide, a calcium channel blocker, have proved beneficial in a woman with primary erythromelalgia, with reduction of burning pain and net improvement of lower extremity edema (Russo et al., 2015). Targeting $\mathrm{Na}_{\mathrm{v}}$ channels to modulate chronic/neurpathic pain is a widely used strategy. For example, topical lidocaine patch is considered a first or second-line drug to treat localized neuropathic pain, such as post-herpetic nevralgia or diabetic neuropathy (Finnerup et al., 2015). Also the analgesic effect of the local anesthetic butamben, used through epidural administration to alleviate chronic pain, might be due to modulation of $\mathrm{Na}_{\mathrm{v}}$ channels (Shulman et al., 1998, 2000; McCarthy et al., 2002; Thériault et al., 2014). The use of sodium channel blockers may appear straightforward to reduce nociceptor hyperexcitability due to gain of function $\mathrm{Na}_{\mathrm{v}}$ mutations. A study reported a satisfactory response to lidocaine patch in about one-half of 34 patients suffering from primary erythromelalgia (Davis and Sandroni, 2005). A Na 1.7 mutation was shown to affect the binding of the local anesthetic, which may explain in part the significant proportion of non-responders (Sheets et al., 2007). Only one IEM mutation has been shown to increase $\mathrm{Na}_{\mathrm{v}} 1.7$ 
TABLE 2 | Peripheral nervous system channelopathies.

\begin{tabular}{|c|c|c|c|}
\hline Disease & Gene (protein) & Pharmacotherapy & $\begin{array}{l}\text { Pharmacological } \\
\text { perspectives }\end{array}$ \\
\hline $\begin{array}{l}\text { Painful syndromes } \\
\text { Inherited erythromelalgia (IEM), } \\
\text { paroxysmal extreme } \\
\text { pain disorder (PEPD), painful } \\
\text { small-fiber neuropathy (SFN), } \\
\text { familial episodic pain syndrome } \\
\text { (FEPS) }\end{array}$ & $\begin{array}{l}\text { SCN9A (Nav1.7) } \\
\text { SCN10A (Nav1.8) } \\
\text { SCN11A (Nav1.9) } \\
\text { TRPA1 (Trpa1) }\end{array}$ & $\begin{array}{l}\text { Symptomatic therapy aims at alleviating pain with } \\
\text { different mechanisms of action: } \\
\text { - Tricyclic and SNRI Antidepressants } \\
\text { - Gabapentinoids } \\
\text { - Ziconotide, a calcium channel blocker } \\
\text { - Nav blockers such as lidocaine and carbamazepine } \\
\text { - Acetaminophen and NSAIDS } \\
\text { - Opioids }\end{array}$ & $\begin{array}{l}\text { - Development of potent } \\
\text { and/or selective sodium } \\
\text { channel blockers for } \\
\text { neuropathic and } \\
\text { inflammatory pain } \\
\text { - Capsaicin or lidocaine } \\
\text { patches } \\
\text { - Botulinum toxin } \\
\text { - Cannabinoids }\end{array}$ \\
\hline
\end{tabular}

Painless syndromes

SCN9A (Nav1.7)

No drug available

Congenital insensitivity to pain,

Idiopathic small fiber

neuropathy

channel sensitivity to mexiletine, likely contributing to the favorable response to the drug observed in this specific patient (Choi et al., 2009). Carbamazepine, a sodium channel blocker indicated for trigeminal neuralgia, was reported to be effective in 14 PEPD patients although the response was incomplete (Fertleman et al., 2007). The drug was also effective in an IEM family members carrying a $\mathrm{Na}_{\mathrm{v}} 1.7$ mutation with enhanced carbamazepine sensitivity (Fischer et al., 2009). One may expect that such studies will help to design a pharmacogenetics strategy to identify the most effective drug for each mutation, as predicted by in silico studies (Yang et al., 2012). Nevertheless, treatment of the PNS channelopathies remains in most cases an unmet medical need.

By demonstrating unambiguously the pivotal role $\mathrm{Na}_{\mathrm{v}} 1.7,1.8$ and 1.9 channels in pain sensation, the discovery of PNS $\mathrm{Na}_{\mathrm{V}}$ channelopathies have paved the way for the development of potent and/or selective sodium channel blockers for application in neuropathic and inflammatory pain (Ghelardini et al., 2010; Theile and Cummins, 2011; Bagal et al., 2014; Carbonara et al., 2015). Some of these drugs have entered clinical trials, but whether they will be helpful to treat channelopathies remains to be verified.

\section{SKELETAL MUSCLE CHANNELOPATHIES}

\section{Non-dystrophic Myotonias}

Non-dystrophic myotonias include myotonia congenita (MC; prevalence 1-9/100,000), paramyotonia congenita (PMC) and SCM. They all share a common symptom, myotonia, that is characterized by impaired muscle relaxation after contraction and is evident as typical "myotonic runs" at EMG (Cannon, 2015).

Myotonia congenita is caused by loss-of-function mutations in the CLCN1 gene coding for the skeletal muscle chloride channel ClC-1 (Imbrici et al., 2015b). It can be inherited in a dominant (Thomsen) and recessive (Becker) form, this latter presenting with a more severe myotonic phenotype, frequent transient weakness, and sometimes myopathic signs. Myotonia improves with exercise, according to the so-called "warm-up" phenomenon. Alterations of $\mathrm{ClC}-1$ have been reported also in myotonic dystrophies and in Duchenne muscular dystrophy (De Luca et al., 2003; Cardani et al., 2012); although the underlying mechanisms are different, these alterations can account for common membrane hyperexcitability signs. The $\mathrm{ClC}-1$ channel normally dampens membrane excitability and stabilizes the resting membrane potential after an action potential (Jentsch, 2015). Thus, the reduced chloride conductance resulting from MC mutations predispose the sarcolemma to spontaneous action potential runs or abnormal afterdischarges that hamper muscle relaxation after contraction, causing myotonia.

Dominantly inherited missense mutations in the SCN $4 A$ gene encoding the skeletal muscle voltage-gated sodium channel $\mathrm{Na}_{\mathrm{v}} 1.4$ cause either PMC or SCM (Cannon, 2015). PMC is characterized by early onset muscle stiffness that worsens with cold and exercise (hence paradoxical). Patients often experience muscle weakness that can last several hours. In contrast, SCM presents with different degrees of pure myotonia without weakness. Laryngospasm is a life-threatening symptom reported in neonates carrying some SCM mutations, leading to the description of a new clinical entity called severe neonatal episodic laryngospam (SNEL; Lion-Francois et al., 2010). In heterologous expression systems, sodium channel mutants usually show impaired fast inactivation with enhanced activation or not (Cannon, 2015). Slowed inactivation has been suggested to induce resurgent $\mathrm{Na}$ currents due to re-opening of $\mathrm{Na}^{+}$channels during repolarisation (Jarecki et al., 2010). The net effect of these gain-of-function disturbances is an increase in $\mathrm{Na}^{+}$entry into the muscle fibers, which allows repetitive discharges that persist beyond the duration of the stimulus.

\section{Pharmacology and Drug Therapy}

Today, the sodium channel blocker mexiletine represents the first line therapy for the myotonic syndromes, irrespective of the culprit gene (Table 3). This drug can be effective in reducing stiffness and transient weakness in non-dystrophic myotonias and myotonic dystrophy (Statland et al., 2012; Lo Monaco et al., 2015). Nevertheless its use is limited by 
TABLE 3 | Skeletal muscle channelopathies.

\begin{tabular}{|c|c|c|c|}
\hline Disease & Gene (protein) & Pharmacotherapy & Pharmacological perspectives \\
\hline $\begin{array}{l}\text { Non-dystrophic myotonias } \\
\text { including myotonia congenita } \\
\text { (MC), paramyotonia congenita } \\
\text { (PMC), and sodium channel } \\
\text { myotonia (SCM) }\end{array}$ & $\begin{array}{l}\text { CLCN1 (CIC-1) } \\
\text { SCN4A (Nav1.4) }\end{array}$ & $\begin{array}{l}\text { Symptomatic (MC) and targeted (PMC and SCM) } \\
\text { therapy aims at reducing skeletal muscle } \\
\text { hyperexcitability: } \\
\text { - Mexiletine (first choice), carbamazepine, flecainide, } \\
\text { propafenone are use-dependent Nav channels } \\
\text { blockers } \\
\text { - Charbonic anydrase inhibitors such as } \\
\text { acetazolamide likely increase BK channels activity } \\
\text { and CIC-1 channels open probability }\end{array}$ & $\begin{array}{l}\text { - Enhancement of Nav slow inactivation } \\
\text { with ranolazine and lacosamide } \\
\text { - Repurposing of marketed Nav blockers, } \\
\text { such as riluzole } \\
\text { - Development of more selective and } \\
\text { use-dependent Nav blockers } \\
\text { - Development of CIC-1 channel activators } \\
\text { and pharmacological chaperones for MC } \\
\text { - Development of a pharmacogenetics } \\
\text { approach }\end{array}$ \\
\hline $\begin{array}{l}\text { Periodic paralysis (PP) including } \\
\text { hyperkalemic periodic paralysis } \\
\text { (HyperPP), hypokalemic } \\
\text { periodic paralysis types } 1 \text { and } 2 \\
\text { (HypoPP1 and 2), } \\
\text { Andersen-Tawil syndrome, } \\
\text { tyreotoxic periodic paralysis }\end{array}$ & $\begin{array}{l}\text { SCN4A (Nav1.4) } \\
\text { CACNA1S (Cav1.1) } \\
\text { KCNJ2 (Kir2.1) } \\
\text { KCNJ6 (Kir2.6) }\end{array}$ & $\begin{array}{l}\text { Symptomatic therapy aims at reducing frequency and } \\
\text { severity of paralytic attacks and at restoring serum } \mathrm{K}^{+} \\
\text {levels: } \\
\text { - Carbonic anhydrase inhibitors such as } \\
\text { acetazolamide and dichlorphenamide (orphan drug } \\
\text { for PP) likely increase BK channels activity and CIC-1 } \\
\text { channels open probability } \\
\text { - The } \beta 2 \text {-agonist salbutamol and glucose/insulin } \\
\text { activate Na+/K+-ATPase and restore serum } \mathrm{K}^{+} \\
\text {levels in HyperPP } \\
\text { - Potassium supplements or } \mathrm{K}^{+} \text {sparing diuretics in } \\
\text { HypoPP } \\
\text { - Benzothiazide diuretics such as hydrochlorothiazide } \\
\text { in HyperPP }\end{array}$ & $\begin{array}{l}\text { - Development of guanidinium derivatives } \\
\text { and other /gp blockers in HypoPP } \\
\text { - Development of KATP openers selective } \\
\text { for skeletal muscle channels } \\
\text { - Bumetanide, a loop diuretic that inhibits } \\
\text { the } \mathrm{Na} / \mathrm{K} / 2 \mathrm{Cl} \text { co-transporter, was useful } \\
\text { in a mouse model of HypoPP }\end{array}$ \\
\hline
\end{tabular}

country availability, side effects and limited or null response in some patients (Desaphy et al., 2013b; Matthews and Hanna, 2014; Suetterlin et al., 2015). In vitro and in vivo studies have shown that the variable clinical efficacy of mexiletine in SCM patients may rely on the different sensitivity of specific mutant channels to the drug (Figure 2; Desaphy et al., 2001, 2004, 2013b). Thus, the functional characterization of biophysical defect caused by each mutation could help to predict patients' responsiveness to a drug and to address the more appropriate therapy. Recently, ranolazine and lacosamide, drugs used to treat angina and epilepsy respectively, have been shown to enhance slow inactivation of sodium channels and thus suggested as an alternative to mexiletine in MC nonresponders (Novak et al., 2015). In parallel, other sodium channel blockers on the market for different therapeutic indications, such as riluzole, are under investigation as possible alternatives to mexiletine (Desaphy et al., 2013a, 2014). Finally, a series of structure-activity studies of mexiletine and tocainide derivatives have been performed to develop Nav1.4 channels blockers a 100 times more potent and usedependent than parental compounds, which may prove useful in myotonic conditions (Talon et al., 2001; De Luca et al., 2004; Carocci et al., 2010; De Bellis et al., 2013; Muraglia et al., 2014).

The carbonic anhydrase inhibitor acetazolamide has been used with variable success in myotonia (Benstead et al., 1987; Trudell et al., 1987; Markhorst et al., 2014). One possible mechanism accounting for membrane electrical stabilization by acetazolamide consists in the opening of skeletal muscle BK calcium-activated potassium channels (Tricarico et al., 2006). More recently, the drug was proposed to increase
ClC-1 open probability, probably through a change in $\mathrm{pH}_{\mathrm{i}}$ (Eguchi et al., 2006). It is however possible that the significant percentage of non-responders stems from a reduced sensitivity of some mutant channels to the drug (Desaphy et al., 2013c).

A specific pharmacological treatment for $\mathrm{MC}$ patients is lacking. The ideal drug to treat $\mathrm{ClC}-1$ channelopathy should be one able to increase chloride currents, but this goal is far from being achieved. The $\mathrm{R}(+)$-isomer of $2-(p-$ chlorophenoxy) propionic acid has been shown to increase the skeletal muscle chloride conductance (De Luca et al., 1992). However, a direct effect on heterologously expressed ClC-1 channels has not been observed (Pusch et al., 2000). Insulin-like growth factor-1 or taurine, as well as PKC inhibitors, such as staurosporine or chelerythrine are also able to enhance chloride conductance (Pierno et al., 1994, 2003; De Luca et al., 1998). Although they lack a direct therapeutic interest, compounds able to block $\mathrm{gCl}$, such as 9-anthracen carboxylic acid, clofibric acid derivatives, and niflumic acid can be useful pharmacological tools to develop animal models of myotonia or to investigate $\mathrm{hClC}$-1structurefunction relationship (Liantonio et al., 2007; Desaphy et al., 2014).

\section{Periodic Paralyses}

Opposed to myotonia are the familial periodic paralyses (PP), which are rare $(1 / 100,000)$ autosomal-dominant disorders characterized by transient loss of muscle excitability leading to attacks of flaccid paralysis with weakness (Cannon, 2015; Suetterlin et al., 2015). The PP are classified as hyperkalemic PP (hyperPP; prevalence: 1-9/1000,000), hypokalemic PP (hypoPP; 
A

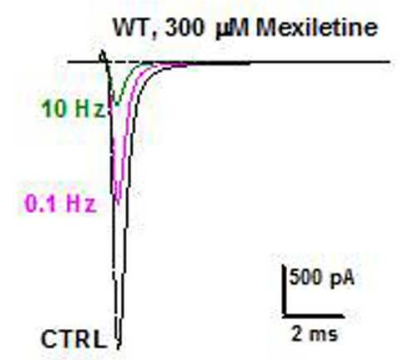

D

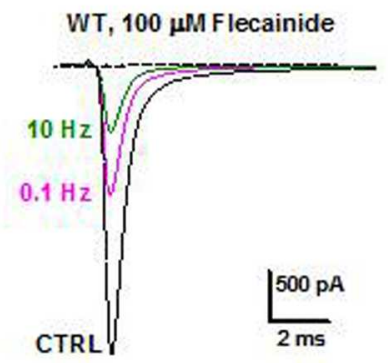

B

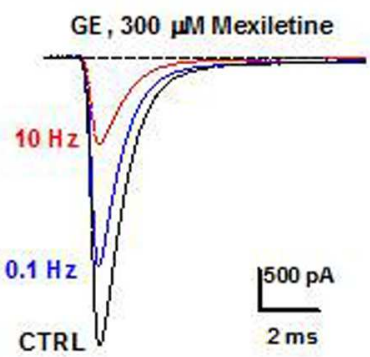

E

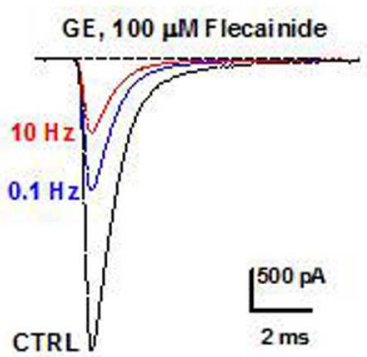

C

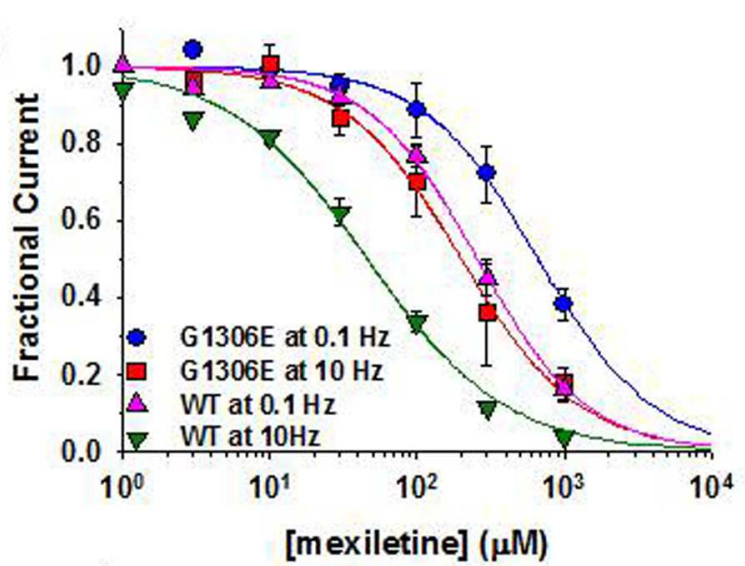

$\mathbf{F}$

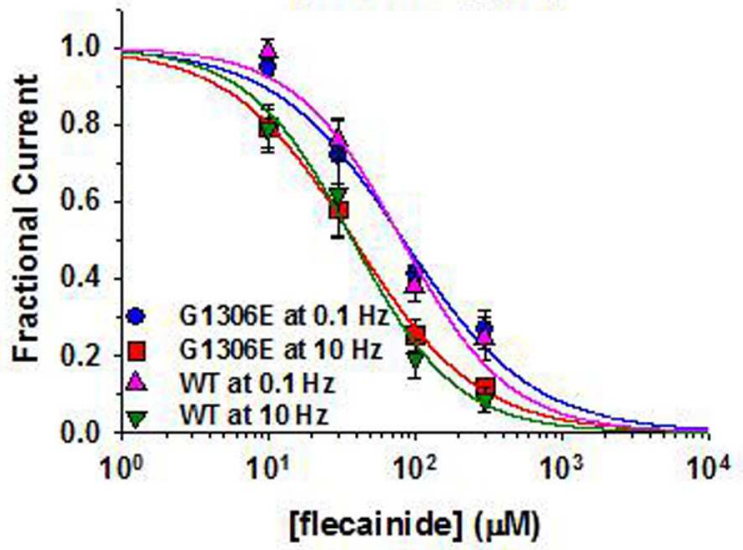

FIGURE 2 | Pharmacogenetics of myotonic sodium channel mutants. (A,B) Representative sodium current traces from hNav1.4 WT channels and myotonic G1306E mutants recorded in transfected cells at steady-state before and during application of mexiletine at 0.1 and $10 \mathrm{~Hz}$ stimulation frequencies.

(C) Concentration-effect relationships for mexiletine on WT and G1306E, fitted to a first-order binding function. (D,E) Effects of flecainide on sodium currents in the same conditions as in (A,B). (F) Concentration-effect relationships for flecainide on WT and G1306E. The G1306E mutation impairs mexiletine inhibition, while leaving flecainide affinity unchanged. Consequently, patients carrying G1306E, who suffer form a severe form of myotonia, obtained significant improvement by shifting treatment from mexiletine to flecainide.

prevalence: 1-9/100,000), or Andersen-Tawil syndrome (ATS), and are caused by mutations of sodium $\left(\mathrm{Na}_{\mathrm{v}} 1.4\right)$, calcium $\left(\mathrm{Ca}_{\mathrm{v}} 1.1\right)$, and several inward-rectifier potassium channels $\left(\mathrm{K}_{\mathrm{ir}} 2.1\right.$, $\mathrm{K}_{\mathrm{ir}} 2.6$, and $\mathrm{K}_{\mathrm{ir}} 3.4$ ). HyperPP is associated with abnormally elevated serum $\mathrm{K}^{+}$ions levels up to $6 \mathrm{mEq} / \mathrm{L}$ triggered by ingestion of potassium-rich food, rest after strenuous exercise, and cold exposure. The pathomechanism in hyperPP is explained by the gain-of-function mutations of $\mathrm{Na}_{\mathrm{v}} 1.4$. The mutant channels display impaired inactivation, resulting in persistent sodium influx and cell depolarization, which in turn inactivates Nav1.4 channel (Cannon, 2015). The depolarization in hyperPP amplifies $\mathrm{K}^{+}$ions efflux from the muscle through $\mathrm{K}^{+}$channels that elevate the serum $\mathrm{K}^{+}$ions concentration contributing to the paralysis (Khogali et al., 2015). In hypoPP, blood potassium concentration decreases below $3.2 \mathrm{mEq} / \mathrm{L}$ triggered by rest after strenuous exercise, by a meal rich in carbohydrates, or by exposure to cold. Familial forms of hypoPP are caused by SCN4A (20\%) and CACNA1S (60\%) mutations of positively charged residues in the channel voltage sensor that create an aberrant permeation pathway for $\mathrm{H}^{+}$or $\mathrm{Na}^{+}$ ions, resulting in depolarizing cation leak currents named gating pore currents (Igp; Moreau et al., 2014). The fiber depolarization in the hypoPP is therefore due to an unbalance between the depolarizing Igp and repolarising $\mathrm{K}_{\mathrm{ir}}$ and sarcoKATP channel currents (Tricarico et al., 2008b). Administration of insulin/glucose activates the $3 \mathrm{Na}^{+} / 2 \mathrm{~K}^{+}$-ATPase causing a marked hypokalemia, which reduces gene expression/activity of $\mathrm{K}_{\mathrm{ir}}$ channels (Tricarico et al., 2003, 2008b). All these factors contribute to the fiber depolarization that inactivates $\mathrm{Na}_{\mathrm{v}} 1.4$ and $\mathrm{Ca}_{\mathrm{v}} 1.1$ channels with paralysis (Tricarico and Camerino, 2011).

Andersen-Tawil syndrome is a multiorgan disease characterized by PP, cardiac arrhythmias, and skeletal malformations (Tawil et al., 1994). Paralysis may occurs with either hyperkalemia or hypokalemia associated with various heart manifestations including long QT syndrome (LQT7, see below). Mutations in KCNJ2 cause the disease by suppressing $\mathrm{K}_{\mathrm{ir}} 2.1$ currents and/or enhancing inward currents, due to dominant negative effects or haplo-insufficiency (Davies et al., 2005). Some KCNJ2 mutations decrease PIP2 sensitivity or 
exaggerate the inhibitory effects of intracellular $\mathrm{Mg}^{2+}$ or proton. A novel mutation of KCNJ5 encoding $\mathrm{K}_{\mathrm{ir}} 3.4$ channel exerts a dominant negative effect on $\mathrm{K}_{\mathrm{ir}} 2.1$ in heart and skeletal muscle of ATS patients (Kokunai et al., 2014).

Thyrotoxic periodic paralysis (TPP), associated to hyperthyroidism, is the most common cause of hypokalemic flaccid muscle paralysis in adults. Mutations of KCNJ18 encoding the $K_{\mathrm{ir}} 2.6$ channel have been found in a few cases of TPP and of sporadic PP (SPP) not necessarily associated to thyrotoxicosis (Ryan et al., 2010; Cheng et al., 2011). The mutants show reduced or no current and exert dominant negative inhibition of wild-type $\mathrm{K}_{\mathrm{ir}} 2.6$ and $\mathrm{K}_{\mathrm{ir}} 2.1$ channels. The $\mathrm{K}_{\mathrm{ir}}$ down-regulation predisposes to hypokalemiainduced paradoxical depolarization during attacks. Other susceptibility genetic variants for TPP and SPP include rs623011 and SUR1Ala1369Ser. The former reduces $\mathrm{K}_{\mathrm{ir}} 2.1$ channel transcription in skeletal muscle independently of thyroid hormone (Jongjaroenprasert et al., 2012), while the latter encodes an auxiliary subunit of KATP channel in pancreatic beta cells, fast twitching muscle fibers and heart (Wheeler et al., 2008; Rolim et al., 2014).

Very recently, the spectrum of muscle channelopathies with pronounced weakness has been widened by the discovery of novel $\mathrm{Na}_{\mathrm{v}} 1.4$ mutations causing congenital myasthenic syndrome with PP or severe fetal hypokinesia (Zaharieva et al., 2015; Habbout et al., 2016).

\section{Pharmacology and Drug Therapy}

Drug therapy of PP can be separated into two categories, treatments used for acute attacks and prophylactic treatments (Table 3). In hyperPP, acute attacks may respond to inhaled salbutamol or glucose/insulin therapy that exert their repolarizing actions by activating the $3 \mathrm{Na}^{+} / 2 \mathrm{~K}^{+}$-ATPase and restoring the serum $\mathrm{K}^{+}$levels. In hypoPP, acute attacks are usually treated with oral potassium chloride glucose-free. The treatment of the hyperkalemia or hypokalemia can be successfully achieved by administrating benzothiazide diuretics (hydrochlorothiazide) or $\mathrm{K}^{+}$sparing diuretics, respectively. The most effective medication for prevention of attacks in both disorders remains the carbonic anhydrase inhibitors, acetazolamide and dichlorphenamide. Dichlorphenamide has been recently designed as orphan drug for the treatment of primary periodic paralyses. A very recent clinical trial demonstrated significant efficiency of dichlorphenamide in hypoPP but not hyperPP (Sansone et al., 2016). These drugs ameliorate paralysis reducing frequency of the attacks and vacuolar myophathy in human and animal models of hypoPP (Tricarico et al., 2006, 2008a; Matthews and Hanna, 2014). One of the main mechanisms responsible for their therapeutic effects relies on their capability to open calcium-activated potassium BK channels in muscle fibers (Tricarico et al., 2006, 2013; Dinardo et al., 2012). Yet, in some hypoPP patients, acetazolamide fails to prevent paralysis and may show detrimental effects. For instance, none of the patients with glycine substitutions, i.e., R528G, R1239G, or R672G, respond satisfactorily to acetazolamide but are still responsive to dichorphenamide (Bendahhou et al., 2001; Sternberg et al., 2001; Kim et al., 2007).
Recently, bumetanide, a loop diuretic that inhibits the $\mathrm{Na}^{+} / \mathrm{K}^{+} / 2 \mathrm{Cl}^{-}$co-transporter, proved effective in preventing weakness attacks in a mouse model of hypoPP, thereby representing a novel symptomatic strategy (Wu et al., 2013).

The treatment of ATS is complicated by the need to address two distinct phenotypes, PP and cardiac arrhythmias (Nguyen et al., 2013). PP therapy includes minimizing known triggers and prophylaxis with acetazolamide. Potassium supplementation may also prevent paralytic attacks while simultaneously shortening the QT interval. Treatment of cardiac arrhythmias forecasts the use of $\beta$-blockers or flecainide. No specific treatment is available to address muscle weakness in TPP. Acetazolamide should not be used in these patients due to risk of adrenergic symptoms aggravation. Drugs targeting KATP and/or $\mathrm{K}_{\mathrm{ir}}$ channels in skeletal muscle may be of interest to treat PP. The available KATP channel openers show a poor tissue selectivity and Kirs openers are not available (Humphries and Dart, 2015). Thus, KATP channel openers have been proposed in PP but their use is limited by the side effects (Tricarico and Camerino, 2011; Tricarico et al., 2012). The search for KATP channel openers acting selectively in skeletal muscle is underway (Rolland et al., 2006; Tricarico et al., 2008a, 2012).

One logical strategy to treat PP may consist in blocking the Igp, without affecting normal channel gating, however no drug is currently available. A few gating pore blockers have been tentatively identified, including divalent and trivalent cations such as gadolinium (Sokolov et al., 2007, 2010; Struyk and Cannon, 2007). Some guanidinium derivatives block Igp but in millimolar concentration range. Differences in the environment surrounding the gating pores may however affect drug responses to this class of compounds (Moreau et al., 2014). In addition, natural toxins can represent interesting lead compounds as Igp blockers, such as those able to stabilize the voltage sensor (Moreau et al., 2014).

\section{HEART CHANNELOPATHIES}

\section{Heart Arrhythmias}

Cardiac channelopathies encompass a large spectrum of heart diseases characterized by arrhythmic events, conduction defects, and cardiomyopathies (Campuzano et al., 2015; Spears and Gollob, 2015). They are among the leading causes of sudden cardiac death (SCD) in young people, with a marked male prevalence. The four principal groups of proarrhythmic channelopathies are long QT syndrome (LQTS; prevalence: $1 / 2,500$ ), short QT syndrome (SQTS), Brugada syndrome (BrS; prevalence: $1 / 3,300$ to $1 / 10,000$ ), and catecholaminergic polymorphic ventricular tachycardia (CPVT; prevalence: $1 / 10,000)$. Besides the four main cardiac channelopathies, ion channel gene mutations have been linked to a plethora of rare familial cases of cardiomiopathies. For instance, SCN5A mutations can cause not only LQT3 and BrS, but also cardiac conduction disease, sick sinus syndrome, atrial fibrillation, or dilated cardiomyopathy (Remme and Wilde, 2014). 
The first heart channelopathy to be discovered was a congenital form of long QT syndrome (LQT1) due to mutations in KCNQ1 encoding the main subunit $\left(\mathrm{K}_{\mathrm{v}} 7.1\right)$ of the $\mathrm{K}$ channel responsible for the slow delayed rectifier current $\left(\mathrm{I}_{K s}\right)$ in cardiomyocytes (Wang et al., 1996). LQT1 mutations induce a loss of function of $\mathrm{K}_{\mathrm{V}} 7.1$, which delays action potential termination and increases the electrocardiogram QT interval longer than $470 / 480 \mathrm{~ms}$ (male/female), thereby increasing the risk of early after discharges (EADs), ventricular arrhythmia, torsades de pointes, seizures, syncope, and sudden death. Since then, at least fifteen genetic subtypes of LQTS have been reported, including nine forms linked to mutations in genes encoding ion channel subunits, while the others are caused by mutations in proteins that secondarily alter ion channel function or calcium signaling (Spears and Gollob, 2015). LQTS mutations induce either loss of function of $\mathrm{K}^{+}$channel subunits or gain of function of $\mathrm{Na}^{+}$or $\mathrm{Ca}^{2+}$ channels.

Conversely, gain of function of $\mathrm{K}^{+}$channels or loss of function of $\mathrm{Ca}^{2+}$ channels accelerates the action potential termination, thereby shortening the QT duration (Brugada et al., 2004; Betzenhauser et al., 2015). SQTS is a rare but very severe condition characterized by a QT interval minor to $350 / 360 \mathrm{~ms}$, which eventually leads to SCD during rest, sleep, or exercise at an early age. Very recently, carnitine deficiency due to mutations in the SLC22A5 gene encoding the ubiquitary membrane carnitine transporter OCTN2, have been associated to SQT, likely due to secondarily increased $\mathrm{K}^{+}$channel activity (Roussel et al., 2016).

The BrS is characterized by various ECG alterations, especially an elevation of the ST segment followed by a negative T wave (Havakuk and Viskin, 2016). The more frequent mutations are found in $S C N 5 A$ gene encoding $\mathrm{Na}_{\mathrm{v}} 1.5$ sodium channel (Chen et al., 1998). Mutations in SCN5A as well as SCN1B or $S C N 3 B$, both encoding auxiliary $\beta$-subunits, all reduced $\mathrm{Na}^{+}$currents. A reduction of $\mathrm{I}_{\mathrm{Na}}$ is also involved in $\mathrm{BrS}$ due to mutations of the glycerol-3-phosphate dehydrogenase GPD1L gene. Loss of function mutations are found in genes coding for the L-type $\mathrm{Ca}^{2+}$ channel in individuals showing overlapping BrS and SQT. Familial dysfunction of the sinoatrial and atrioventricular nodes has been also associated with mutations in HCN4 channels, cationic channels involved in pacemaker activity (Milanesi et al., 2015). Loss of function in HCN4 have been observed in rare BrS cases. One gainof-function mutation in the same channel, R504Q, has been found in a family with inappropriate sinus tachycardia (IST), a syndrome characterized by abnormally fast sinus rate and multisystem symptoms (Baruscotti et al., 2015). Gain of function of the KCNE3 $\beta$-subunit of $\mathrm{K}^{+}$channels responsible for the transient outward current $\mathrm{I}_{\text {to }}$ are found in less than $1 \%$ of $\mathrm{BrS}$ cases.

The CPVT is characterized by ventricular arrhythmias triggered by physical exercise, emotional stress, or catecholamine administration, in the absence of structural heart disease. Without treatment, CPVT has a high mortality rate. Mutations in the RyR2 ryanodine receptor, an intracellular calcium channel, were the first identified to cause CPVT (Priori et al., 2002). Mutations in other proteins involved in $\mathrm{Ca}^{2+}$ handling, including calsequestrin-2, triadin, and calmodulin, have been also reported.
It is also worth to note that some of these channelopathies can affect different organs; for instance, LQT7 syndrome caused by KCNJ2 mutations corresponds to Andersen-Tawil syndrome, which is characterized by a triad of ventricular arrhythmias, periodic paralysis, and dysmorphic features (see above). Similarly, CACNA1C mutations cause LQT8 in Timothy syndrome.

\section{Pharmacology and Drug Therapy}

In cardiac channelopathies, syncope is often the first presenting symptom and the risk of SCD is very high. The genetic testing can give invaluable information to support diagnosis in the patient and prognosis in familiars, and to address treatment in both. The management of syncope survivors and relatives at high risk often consists in the use of an implantable cardioverter defibrillator (ICD) to correct or interrupt life-threatening arrhythmias.

In some cases, such as SQTS and BrS, ICD is the only proven therapy. Only a preliminary study suggests that quinidine may be effective in SQT1, likely due to its ability to block open Herg channels (Gaita et al., 2004). In BrS, either quinidine or isoproterenol, which increases the L-type calcium current, may be used to manage refractory and acute arrhythmias, but data are lacking to recommend these drugs as ICD alternative (Priori et al., 2013). Intravenous class 1 antiarrhythmic drugs, such as flecainide or ajmaline, are used as provocative tools of ST elevation for BrS diagnosis.

In both LQTS and CVPT, emotional stress and intense exercise play a prominent role in triggering ventricular arrhythmias. Thus the main pharmacological approach consists in the use of $\beta$-adrenoceptor antagonists to reduce sympathetic or adrenergic stimulation. The preferred drug in CPVT is nadolol, a long acting $\beta$-blocker lacking intrinsic sympathomimetic activity (Priori et al., 2013). To obtain a better response, high dosage and strict compliance to therapy are required, together with exercise restriction. Flecainide, an antiarrhythmic with mixed action on $\mathrm{Na}_{\mathrm{v}} 1.5$ and RyR2 channels, may be added to prevent breakthrough arrhythmias on $\beta$-blockers. An integrated approach to the diagnosis, risk stratification, and genotypeand phenotype-guided management of patients with LQTS has been recently provided for by Giudicessi and Ackerman (2013). Nadolol and propranolol are recommended for the treatment of all LQTS subtypes. Blockers of late Na current, such as mexiletine or ranolazine, may be used as add-on therapy for LQT3 (Ruan et al., 2007; Moss et al., 2008). However, some SCN5A mutations impair mexiletine effects and the drug may favor $\mathrm{Na}$ channel trafficking to the membrane, thus raising concerns about the indiscriminate use of sodium channel blockers in LQT3 without careful individual testing (Ruan et al., 2007, 2010). In case of unsatisfactory response or non-compliance to $\beta$-blockers, the left cardiac sympathetic denervation (LCSD) may prove useful in both CPVT and LQTS, although randomized control trials to evaluate the risk/benefit of this treatment are lacking.

No gene mutation have been identified in most cases of SCD, thus it is likely that the number of cardiac channel mutations will continue to increase. Despite the large number of ion channels causing cardiac arrhythmias, the therapeutic options are limited and based mostly on symptomatic treatments, with only rare 
exceptions (Table 4). It is expected that future studies will be dedicated to the search of gene- or mutation-specific approaches (El-Sherif and Boutjdir, 2015).

\section{KIDNEY CHANNELOPATHIES}

\section{Bartter's Syndrome}

Bartter's syndromes (BS; prevalence: 1/1000,000) are a heterogeneous group of rare salt loosing tubulopathies confined mainly at the level of thick ascending limb (TAL) of Henle's loop (Loudon and Fry, 2014). BS type III is due to loss of function mutations of CLCNKB gene and is characterized by polyuria, polydipsia, hypokalemia, alkalosis, hypercalciuria and frequently nephrocalcinosis (Simon et al., 1997; Krämer et al., 2008). CLC-Kb chloride channels are expressed, together with their accessory subunit, barttin, at the basolateral membrane of TAL and distal convoluted tubule (DCT), where they permit $\mathrm{NaCl}$ reabsorption, and in the stria vascularis of the inner ear, where they contribute to the mechanism for $\mathrm{K}^{+}$secretion into endolymph (Estévez et al.,
2001). Deletion, nonsense, and missense CLCNKB mutations have been reported, which usually cause a disruption of channel trafficking to the plasma membrane or a reduction of channel open probability (Andrini et al., 2015). Missense and nonsense mutations in BSDN, encoding barttin, result in antenatal BS type IV, the most severe BS form, characterized by excessive polyhydramnios and prematurity with early failure to thrive and sensorineural deafness (Janssen et al., 2009; de Pablos et al., 2014). In addition, impaired palmitoylation of some barttin mutants may play a role in chloride channel dysfunction (Steinke et al., 2015). Conversely, gain-of-function polymorphisms in CLCNK genes have been reported to be associated with salt retention and hypertension (Barlassina et al., 2007).

The $\mathrm{K}_{\mathrm{ir}} 1.1$ (or ROMK) channel encoded by KCNJ1 is the major secretory channel in the kidney (Welling and Ho, 2009). ROMK loss-of-function mutations cause BS type II, characterized by antenatal presentation of polyhydramnios, premature delivery, profound postnatal polyuria, hypokalaemia, hyponatraemia and hypercalciuria, as well as secondary nephrocalcinosis later in life (Simon et al., 1996; Brochard et al., 2009). The defective

TABLE 4 | Heart channelopathies.

\begin{tabular}{|c|c|c|c|}
\hline Disease & Gene (protein) & Pharmacotherapy & $\begin{array}{l}\text { Pharmacological } \\
\text { perspectives }\end{array}$ \\
\hline Long QT syndrome (LQTS) & $\begin{array}{l}\text { KCNQ1 (Kv7.1) } \\
\text { KCNH2 (HERG) } \\
\text { KCNE1 (Mink) } \\
\text { KCNE2 (MiRP1) } \\
\text { KCNJ2 (Kir2.1) } \\
\text { KCNJ5 (Kir3.4) } \\
\text { SCN5A (Nav1.5) } \\
\text { SCN4B (Nav2.4) } \\
\text { CACNA1C (Cav1.2) } \\
\text { Non-channel: } \\
\text { AKAP9 (yatio) } \\
\text { CALM1 (calmodulin) } \\
\text { CALM2 (calmodulin) } \\
\text { CAV3 (caveolin) } \\
\text { SNTA1 (syntrophin a1) } \\
\text { ANKB (ankyrin B) }\end{array}$ & $\begin{array}{l}\text { Symptomatic therapy aims at restoring normal heart } \\
\text { rhythm: } \\
\text { - } \text { Implantable cardioverter defibrillator (ICD) } \\
\text { - } \beta \text {-adrenoceptor antagonists, such as nadolol and } \\
\text { propranolol, plus flecainide. } \\
\text { - Mexiletine or ranolazine can be used as add-on } \\
\text { therapy in LQT3 } \\
\text { - Left cardiac sympathetic denervation (LCSD) when } \\
\beta \text {-blockers fail }\end{array}$ & $\begin{array}{l}\text { Gene- and mutation- specific } \\
\text { drugs }\end{array}$ \\
\hline Short QT syndrome (SQTS) & $\begin{array}{l}\text { KCNH2 (HERG) } \\
\text { KCNQ1 (Kv7.1) } \\
\text { KCNJ2 (Kir2.1) }\end{array}$ & $\begin{aligned} & \text { - } \text { Implantable cardioverter defibrillator (ICD) } \\
& \text { - Quinidine, a class I antiarrhythmic, in SQT1 owing to } \\
& \text { HERG channels block }\end{aligned}$ & \\
\hline Brugada syndrome (BrS) & $\begin{array}{l}\text { SCN5A (Nav1.5) } \\
\text { SCN1B (Nav2.1) } \\
\text { SCN3B (Nav2.3) } \\
\text { KCNE3 (MiRP2) } \\
\text { CACNA1C (Cav1.2) } \\
\text { CACNB2 (CavB2) } \\
\text { HCN4 (HCn4) }\end{array}$ & $\begin{array}{l}\text { Symptomatic therapy aims at restoring normal heart } \\
\text { rhythm: } \\
\text { _ Implantable cardioverter defibrillator (ICD) is the only } \\
\text { available option } \\
\text { _ Quinidine (K channel blocker) or isoproterenol (L-type } \\
\text { calcium current activator) are used for acute } \\
\text { arrhythmias. Their use as an alternative to ICD } \\
\text { remains to be verified }\end{array}$ & $\begin{array}{l}\text { Gene- and mutation-specific } \\
\text { therapy }\end{array}$ \\
\hline $\begin{array}{l}\text { Catecholaminergic polymorphic } \\
\text { ventricular tachycardia (CPVT) }\end{array}$ & $\begin{array}{l}\text { RYR2 (RyR2) } \\
\text { Non-channel: } \\
\text { CASQ2 } \\
\text { (calsequestrin-2) } \\
\text { CALM1 (calmodulin-1) } \\
\text { TRDN (triadin) }\end{array}$ & $\begin{array}{l}\text { Symptomatic therapy aims at restoring normal heart } \\
\text { rhythm: } \\
\text { - } \text { high doses of } \beta \text {-blockers, such as nadolol, plus } \\
\text { flecainide } \\
\text { - } \text { Left cardiac sympathetic denervation (LCSD) where } \\
\quad \beta \text {-blockers fail }\end{array}$ & $\begin{array}{l}\text { - Gene- and mutation- } \\
\text { specific drugs } \\
\text { - Gene therapy in mouse } \\
\text { models }\end{array}$ \\
\hline
\end{tabular}


function of ROMK channel mutants impairs $\mathrm{K}^{+}$movement from intracellular compartment to TAL lumen (Boim et al., 1995).

\section{Pharmacology and Drug Therapy}

Management of patients with BS is oriented toward acute and chronic therapy of presenting complications and abnormalities (Nascimento et al., 2014; Table 5). Fluid and electrolyte replacement led to an immediate amelioration of the symptoms. Long-term treatment in BS consists of a high-salt diet, potassium and magnesium replacement, and potassium-sparing diuretics, such as spironolactone/eplerenone and amiloride. In addition, volume depletion leads to upregulation of prostaglandin E2 by both renal and non-renal mechanisms. Indomethacin, a cyclooxygenase inhibitor, has been used extensively in the treatment of BS and proved efficient in increasing height and body weight, and reducing hyperfiltration. It can frequently induce gastrointestinal complications, such as gastritis, bleeding ulcers, and necrotizing enterocolitis, especially in infants. Definitely, BS therapy remains empirical with one limiting factor represented by the drug-induced risk of progressive renal damage, which can lead to chronic renal failure (Unwin and Capasso, 2006). The identification of therapy of targeting the molecular defect is therefore urgently needed.

NFA, a non-steroidal anti-inflammatory drug belonging to fenamate, resulted the unique molecule able to activate CLC-K channel expressed in Xenopus oocytes (Liantonio et al., 2008). Although this effect was not reproduced in mammalian cells (Imbrici et al., 2014), NFA may represent a lead compound to create novel optimized ligands to treat BS types III and IV. Despite the lack of CLC-K openers, CLC-K selective blockers exist and may have a therapeutic potential in hypertension
(Figure 3). Preclinical studies performed in normotensive and hypertensive rats showed that in vivo administration of smallmolecules inhibitors of CLC-K channels induced diuretic and antihypertensive effects with no toxic effect (Liantonio et al., 2012, 2016; Imbrici et al., 2014).

Similarly to CLC-K, molecular pharmacology of $\mathrm{K}_{\mathrm{ir}} 1.1$ (ROMK) remains quite limited. No $\mathrm{K}_{\mathrm{ir}}$ channel opener is known (Humphries and Dart, 2015). Since ROMK is expressed in both TAL and CCD, inhibitors may provide superior diuretic/natriuretic efficacy as compared to loop diuretics, which exert their effects in TAL only. A high throughput screening study identified 1,4-bis(4nitrophenethyl)piperazine derivatives as potent ROMK inhibitors (Garcia and Kaczorowski, 2014). In normotensive animals, short-term oral administration of one of these derivatives caused concentration-dependent diuresis and natriuresis that were comparable to hydrochlorothiazide (Garcia et al., 2014).

\section{Dent's Disease}

Mutations in CLCN5 gene cause a subtype of Dent's disease type 1 (prevalence: 250 reported families), a renal tubular disorders characterized by low molecular weight proteinuria, hypercalciuria, nephrolithiasis, nephrocalcinosis, and progressive renal failure (Lloyd et al., 1997; Hodgin et al., 2008). CLCN5 encodes the CLC-5 protein, which functions as an electrogenic $2 \mathrm{Cl}^{-} / \mathrm{H}^{+}$antiporter (Picollo and Pusch, 2005). In human kidney, CLC-5 is expressed in proximal tubule (PT), thick ascending limb, and intercalated cells of collecting ducts. In PT cells, CLC-5 co-distributes with the vacuolar $\mathrm{H}^{+}$-ATPase in early endosomes, which are responsible for the reabsorption and processing of albumin and low molecular weight proteins filtered by the glomerulus. Thus, the disease is essentially due to defective

TABLE 5 | Kidney channelopathies.

\begin{tabular}{|c|c|c|c|}
\hline Disease & Gene (protein) & Pharmacotherapy and mechanisms of action & Pharmacological perspectives \\
\hline $\begin{array}{l}\text { Bartter's syndrome (BS) } \\
\text { including types II-IV }\end{array}$ & $\begin{array}{l}\text { CLCNKB (ClC-Kb), BSDN } \\
\text { (Barttin), ROMK1 (Kir1.1) }\end{array}$ & $\begin{array}{l}\text { Symptomatic therapy aims at restoring electrolyte } \\
\text { balance: } \\
\text { - Potassium-sparing diuretics such as } \\
\text { spironolactone/eplerenone and amiloride restore } \\
\text { serum } \mathrm{K}^{+} \text {concentrations } \\
\text { - Indomethacin, a COX inhibitor, reduces PGE2 } \\
\text { production } \\
\text { - Potassium and magnesium supplements restore } \\
\text { electrolyte balance }\end{array}$ & $\begin{array}{l}\text { - Development of selective channel openers } \\
\text { through a pharmacogenetic approach } \\
\text { - Development of pharmacological } \\
\text { chaperones }\end{array}$ \\
\hline Dent disease type 1 & CLCN5 (ClC-5) & $\begin{array}{l}\text { Symptomatic therapy aims at restoring electrolyte } \\
\text { balance: } \\
\text { - Thiazide diuretics ameliorate hypercalciuria } \\
\text { - High citrate and fluid intake control hypercalciuria } \\
\text { - Vitamin D counteracts rickets in clinical cases with } \\
\text { additional bone disease }\end{array}$ & $\begin{array}{l}\text { - Development of CLC-5 activators } \\
\text { - Development of pharmacological } \\
\text { chaperones }\end{array}$ \\
\hline
\end{tabular}

EAST/SESAME syndrome KCNJ11 (Kir4.1)

Symptomatic therapy aims at restoring electrolyte

balance and remitting seizures:

- Antiepileptic drugs

- Indometacin

- Oral potassium 
A
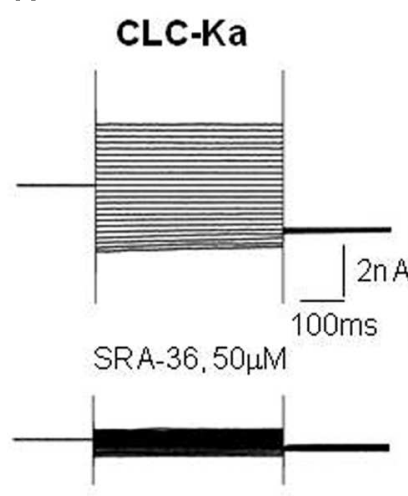

B

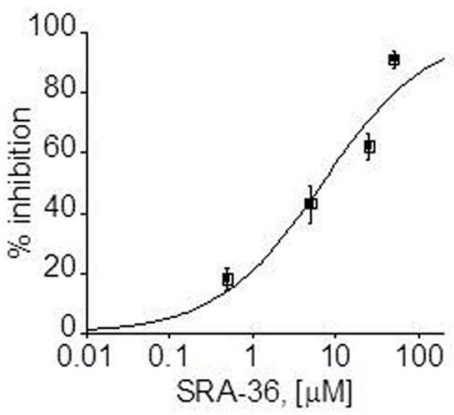

C

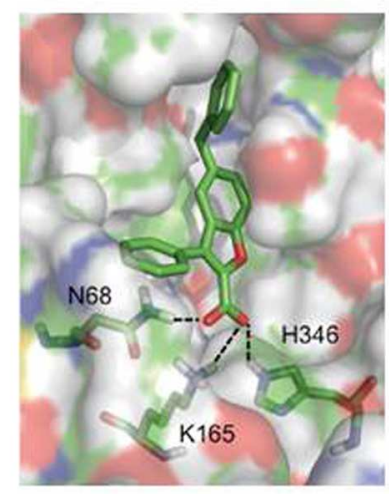

FIGURE 3 | Electrophysiological drug testing on expressed chloride channels and docking simulation. (A) Representative CLC-Ka patch-clamp recordings from transfected HEK293 cells, before and after the application of a synthetic compound, SRA-36. (B) Dose-response curve of CLC-Ka current inhibition by SRA-36 measured at $+60 \mathrm{mV}$. (C) Model of the SRA-36 top-scored docking pose resulting from Induced Fit Docking simulations using a homology model of CIC-Ka modeled on the crystal structure of CIC-ec1.

receptor-mediated endocytosis causing a generalized dysfunction of PT cells. The two constitutive CLC-5 knock-out mouse models (Piwon et al., 2000; Wang et al., 2000), both exhibit the most common features of Dent's disease, but differ in other characteristics, potentially reflecting the phenotype variability observed in patients. The use of a knock-in mouse harboring a point mutation that converts the exchanger into an uncoupled $\mathrm{Cl}^{-}$channel discloses the importance of chloride concentration for organelle physiology (Novarino et al., 2010). The recent analysis of a large cohort of patients confirmed that CLCN5 mutations can be divided into three different functional classes affecting the dimerization process, helix stability or ions transport (Mansour-Hendili et al., 2015; Pusch and Zifarelli, 2015).

\section{Pharmacology and Drug Therapy}

The current care of patients with Dent's disease is supportive, focusing on the prevention of nephrolithiasis relying mainly on generous liquid intake (Table 5). Thiazide diuretics can be used to treat hypercalciuria, although significant adverse events, including hypovolemia and hypokalemia related to primary tubulopathy have been reported (Raja et al., 2002). Similarly, treatment with vitamin $\mathrm{D}$ must be cautious since it may increase hypercalciuria. Studies performed on CLC-5 deficient mice suggest that a high-citrate diet can preserve renal function and slow progression of renal disease (Cebotaru et al., 2005). A major future challenge will be to search for specific molecules able to restore CLC-5 mutant function in Dent's disease patients, but CLC-5 ligands are lacking. Available ligands for other CLC family members could serve as starting molecular structures to reach such an objective.

\section{EAST/SeSAME Syndrome}

EAST/SeSAME syndrome (seizures, sensorineural deafness, ataxia, mental retardation, and electrolyte imbalance syndrome; prevalence: $<1 / 1000,000)$ is a multiorgan disorder that presents with a unique set of symptoms including epilepsy, ataxia, mental retardation, hearing loss, and electrolyte imbalance related to renal salt loss (Bockenhauer et al., 2009). It is caused by missense or deletion mutations in KCNJ10 ( $\mathrm{K}_{\mathrm{ir}} 4.1$ channels) that compromise the function of homomeric $\mathrm{K}_{\mathrm{ir}} 4.1$ expressed in kidney DCT, glial cells in the brain and spinal cord, and in the inner ear (Sala-Rabanal et al., 2010; Cross et al., 2013).

\section{Pharmacology and Drug Therapy}

No specific therapy exists for affected patients (Table 5). Seizure control is achieved with typical AEDs. Potassium supplementation accompanied by indometacin administration has also been reported (Cross et al., 2013).

\section{ENDOCRINE CHANNELOPATHIES}

\section{Neonatal Diabetes Mellitus and Congenital Hyperinsulinism}

In pancreatic beta cells, the main ATP-sensitive $\mathrm{K}^{+}$channel (KATP) complex is formed by the assembly of Kir6.2/SUR1 subunits (Babenko et al., 2000). This channel regulates insulin secretion in response to glucose challenge, and is involved in genetic diseases associated with insulin/glucose dismetabolism. Loss-of-function mutations in KCNJ11 and ABCC8 genes underlie familial congenital hyperinsulinism, while gain-offunction mutations and metabolic uncoupling are associated to neonatal diabetes mellitus (prevalence: 1/300,000-400,000) and DEND syndrome with developmental delay, epilepsy and neonatal diabetes (McTaggart et al., 2010; Arnoux et al., 2011).

\section{Pharmacology and Drug Therapy}

It is known that SUR1 subunit carries the binding sites for the KATP channel blockers, such as glibenclamide, tolbutamide, glimepiride, repaglinide, and nateglinide, acting as insulinreleasing agents in diabetes therapy, and for the KATP channel opener diazoxide used as a hyperglycaemic drug (Babenko et al., 2000). The most used medications in the treatment of congenital hyperinsulinism are diazoxide and somatostatin analogs (Welters 
et al., 2015; Table 6). While insulin therapy is commonly prescribed in neonatal diabetes, glibenclamide is effective in resolving the CNS and peripheral symptoms in patients carrying KCNJ11 and ABCC8 mutations replacing insulin therapy (De Franco et al., 2015). However, patients carrying the Gly334Val KCNJ11 mutation, are not responsive to this drug (Lau et al., 2015).

\section{Osteopetrosis and Other Bone Abnormalities}

Osteopetrosis (OP; prevalence: $1 / 250,000$ ) is a heterogeneous genetic condition characterized by increased skeletal mass and results from reduced function of osteoclasts and impairment of bone resorption. Defects in TCIRG1, encoding a vacuolar-ATPase subunit, account for nearly $50 \%$ of all patients with OP and cause an impairment of vesicle trafficking and lysosomal acidification in osteoclasts leading to bone resorption defect (Sobacchi et al., 2013). More rarely, dominant or recessive mutations are found in CLCN7 or OSTM1 genes, encoding the lysosomal $2 \mathrm{Cl}^{-} / \mathrm{H}^{+}$transporter CLC-7 or its auxiliary subunit Ostm1 (Kornak et al., 2001; Kasper et al., 2005; Leisle et al., 2011). Most CLC-7 mutations induce a loss of channel function; several dominant mutations were shown to accelerate the voltage gating of CLC-7. In mice, the disruption of CLC-7 mimics severe OP with retinal and CNS degeneration as in the recessive form of human OP (Kornak et al., 2001; Weinert et al., 2014). Skeletal dysplasia and defects in bone ossification are associated with gain of function mutations in the calcium-permeable TRPV4 ion channel gene, which result in an increased basal intracellular $\mathrm{Ca}^{2+}$ levels (Nilius and Voets, 2013).

\section{Pharmacology and Drug Therapy}

As osteoclasts are of hematopoietic origin, hematopoietic stem cell transplantation (HSCT) is the only curative treatment for various forms of recessive osteopetrosis in early life, but this is associated with a high incidence of adverse effects such as graft failure, hepatic and pulmonary toxicity, and veno-occlusive disease (Orchard et al., 2015). Otherwise, OP treatment is mainly supportive (Table 6). Calcitriol, by modulating blood calcium level, increases osteoclasts activity and interferon $\gamma$ increases bone resorption, causing a reduction in trabecular bone area and an increase in bone marrow space (Key et al., 1995).
Undergoing research aims at identifying selective compounds able to open/activate CLC-7 or to slow the accelerated activation of CLC-7 observed in several patients, and siRNA against specific CLC-7 mutants can be feasible in some therapeutically neglected form of osteopetrosis (Capulli et al., 2015). Conversely, CLC7 inhibitors as well as anti-CLC-7 antibodies could be used to reduce bone resorption in osteoporosis (Zhao et al., 2009; Ohgi et al., 2011). Proof of concept of gene therapy efficacy has been obtained in mice, in which neonatal transplantation of genetically modified stem cell, using a lentiviral vector expressing murine TCIRG1, led to improved bone resorption (Moscatelli et al., 2013). Encouraging preclinical treatments for OP include in utero stem cell treatment, RANK ligand replacement therapy, and denosumab for post-HSCT hypercalcaemia (Sobacchi et al., 2013). A pharmacological block of TRPV4 has been also proposed as a potential therapeutic strategy (Nilius and Voets, 2013).

\section{FUTURE PERSPECTIVE IN DRUG DISCOVERY}

The pharmacotherapy of ion channelopathies is a challenging issue in clinical management. To date, only a few channelopathies can benefit from a targeted therapy while, in the majority of cases, the current approaches rely on symptomatic and often empiric medications limited by extensive drug resistance and adverse events (Desaphy et al., 2013b; Lo Monaco et al., 2015). Deciphering the exact pathogenetic mechanism for every channelopathy is fundamental to design therapies tailored upon patients' requirements. The improvement and generation of disease-related cell and animal models as well as the development of innovative pharmacological strategies greatly help to fulfill this aim. Below, we report some examples of the most remarkable attempts in this direction (Figure 4).

\section{Disease-related Models}

Animal models that recapitulate human channelopathies have been pivotal for understanding the underlying pathophysiology and for subsequent preclinical studies (De Luca, 2012; Desaphy et al., 2014; Fratta and Hanna, 2015; Rubinstein et al., 2015; Zou, 2015). When possible, human cell-based approaches, such

TABLE 6 | Endocrine channelopathies.

\begin{tabular}{|c|c|c|c|}
\hline Disease & Gene (protein) & Pharmacotherapy & Pharmacological perspectives \\
\hline $\begin{array}{l}\text { Familial congenital } \\
\text { hyperinsulinism }\end{array}$ & $\begin{array}{l}\text { KCNJ11 (Kir6.2) } \\
\text { ABCC8 (SUR1) }\end{array}$ & $\begin{array}{l}\text { Diazoxide, a hyperglycaemic drug that opens KATP } \\
\text { channels, and somatostatin analogs reduce insulin } \\
\text { release in congenital hyperinsulinism }\end{array}$ & \\
\hline $\begin{array}{l}\text { Neonatal diabetes } \\
\text { mellitus and DEND } \\
\text { syndrome }\end{array}$ & $\begin{array}{l}\text { KCNJ11 (Kir6.2) } \\
\text { ABCC8 (SUR1) }\end{array}$ & $\begin{array}{l}\text { Insulin and glibenclamide, a hypoglycaemic drug that } \\
\text { blocks KATP channels, increase insulin levels in } \\
\text { neonatal diabetes mellitus }\end{array}$ & \\
\hline Osteopetrosis & $\begin{array}{l}\text { CLCN7 (CIC-7) } \\
\text { OSTM1 (CIC-7 } \\
\text { accessory subunit } \\
\text { Ostm1) }\end{array}$ & $\begin{array}{l}\text { Therapy aims at increasing bone resorption: } \\
\text { - Hematopoietic stem cell transplantation } \\
\text { - Calcitriol and interferon } \gamma \\
\text { - Corticosteroids }\end{array}$ & $\begin{array}{l}\text { Development of selective compounds } \\
\text { able to open/activate CIC- } 7 \text { or to slow } \\
\text { the accelerated activation of some } \\
\text { CIC- } 7 \text { mutants }\end{array}$ \\
\hline
\end{tabular}




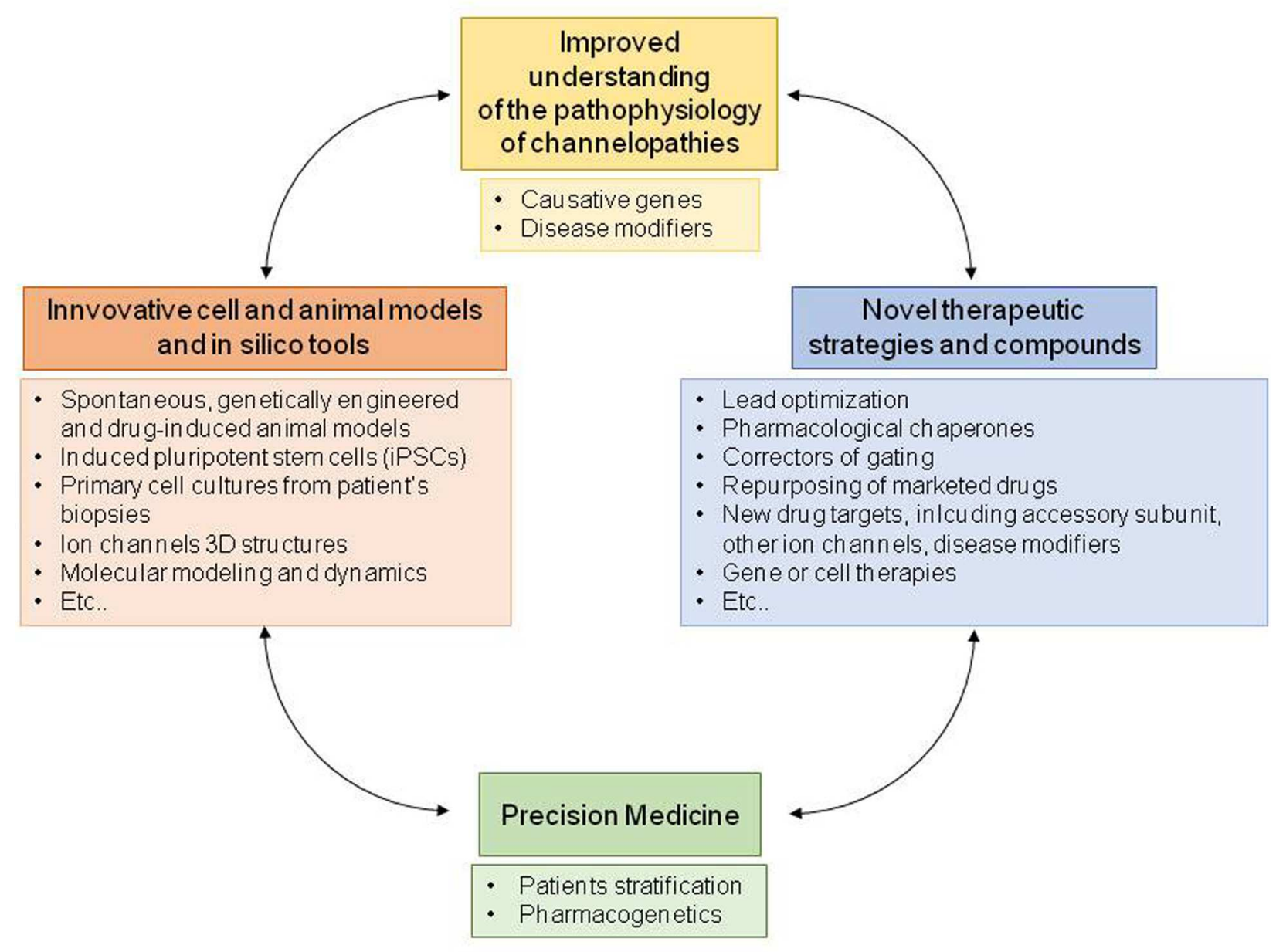

FIGURE 4 | Schematic diagram illustrating the process of drug discovery, from the analysis of disease pathophysiology to development of a precision medicine.

as primary cell culture from patients' biopsies and induced pluripotent stem cells (iPSCs), may represent another fascinating opportunity to understand human diseases, properly identify disease pathways and conduct high-throughput drug screening. Patients' muscle biopsies have been recently employed to investigate the mechanisms of the variable expressivity of myotonia congenita phenotypes (Portaro et al., 2015). In a gene expression study on myotonic patients' biopsies, the greater expression of the $\mathrm{Na}^{+}$channel $\beta 1$ subunit and the total lack of potassium channel subunit MiRP2 were correlated with the clinical severity of the Becker myotonic phenotype of the affected individuals (Portaro et al., 2015). This study not only provides evidence for a role of KCNE3 and $S C N 1 B$ genes as interesting predictors of myotonic phenotype, but also suggests new targets for drug development. As the availability of patients' biopsies is often poor, the possibility to reprogram somatic cells derived from patients into pluripotent stem cells that can be differentiated in vitro is emerging as an appealing opportunity for modeling channelopathies. Recently, human skin cells from Timothy syndrome (TS) patients were reprogrammed into iPSCs and subsequently differentiated into cardiac muscle cells or neurons (Krey et al., 2013; Yazawa and Dolmetsch, 2013; Paşca et al., 2014). Results from these studies showed that TS ventricular-like cardiomyocytes exhibited deficits in contraction, electrical signaling and calcium handling, and that the cyclin-dependent kinase inhibitor and atypical Cav channel blocker roscovitine could successfully rescue this cellular phenotype. Similarly, roscovitine proved efficacious in restoring the neuronal phenotype in cortical neurons derived from TS patients using the same approach (Krey et al., 2013). In vitro iPSCs-based models of cerebellar ataxia and AndersenTawil syndrome have also been established to recapitulate the complex in vivo events underlying these dysfunctions (Watson et al., 2015; Pini et al., 2016). Although fascinating, iPSCs 
technology is still challenging, one of the most crucial issue being the need to establish a reliable disease phenotype that can be reproduced in quite large quantities in vitro. However, once established, it could provide an invaluable resource for drug target identification and drug screening (Skalova et al., 2015; Watson et al., 2015).

\section{Pharmacological Chaperones}

One promising approach to treat protein-misfolding channelopathies is based on pharmacological chaperones. These molecules stabilize protein correct folding, limit premature ERassociated degradation and promote protein delivery to the cell surface. Ivacaftor and lumacaftor, correctors of specific CFTR folding defective mutants, have been successfully used to rescue CFTR dysfunction in patients affected by cystic fibrosis (Mall and Galietta, 2015). Different proof-of-principle strategies have been tested to restore in vitro functioning Nav channels in GEFS+, such as the incubation of mutant sodium channels at low temperature, the interactions with different co-expressed proteins (such as $\beta 1$ subunit, calmodulin, ankyrin G), the exposure to sodium channel blockers such as phenytoin (Rusconi et al., 2007; Cestèle et al., 2013; Bechi et al., 2015). Typical pharmacological chaperones are reversible high affinity ion channels inhibitors, so their application in rescuing misfolded mutants might be limited by the possible block of the rescued channels correctly inserted in the membrane. To overcome these drawbacks in GEFS+, beta scorpion toxins peptidic derivatives were recently engineered to bind Nav channels with high affinity and to target the ER, and appeared more effective pharmacological chaperones than phenytoin in vitro (Bechi et al., 2015).

\section{Voltage Sensor Domain (VSD) Modulators}

Voltage sensitivity is provided in voltage gated ion channels by voltage sensor domains, that allow voltage-induced conformational changes leading to channel opening through the interaction of highly conserved charged residues. Most drugs targeting ion channels bind their central alpha pore. Interestingly, disruption of VSDs, mainly due to mutations of arginine residues has been shown to generate gating pore currents that underlie different channelopathies, including hypoPP, peripheral nerve hyperexcitability, epilepsy and arrhythmias (Moreau et al., 2014; Miceli et al., 2015a). Thus, compounds modulating VSDs could be used as research tools and could represent a very promising pharmacological strategy for many pathologies and biophysical defects. Examples of existing VSD modulators are compounds blocking selectively neuronal $\mathrm{Na}_{\mathrm{v}} 1.1 / 1.3 / 1.7$ channels, specific small molecule openers or blockers of $\mathrm{K}_{\mathrm{v}} 7.2$ channel (Peretz et al., 2010; McCormack et al., 2013), or guanidinium derivatives blocking the gating currents from mutant Nav1.4 channels (Sokolov et al., 2010). Recently, the small molecule ztz240, selected after a wide and sophisticated screening, has been shown to open $\mathrm{K}_{\mathrm{v}} 7.2$ channels by binding to the F137 residue in the gating charge pathway, and be valuable in the treatment of epilepsy (Kornilov et al., 2013; Li et al., 2013). In addition, gating modifier toxins that target and stabilize the VSD in the resting or activated state, can be useful research tools for structure-function investigations (Moreau et al., 2014; Miceli et al., 2015a).

\section{Pharmacogenetics}

In some channelopathies, the observation that the drug sensitivity of an ion channel in vitro depends on the specific biophysical defects carried by single disease-associated ion channel mutations provided the basis for the development of a pharmacogenetic approach. In particular, studies on SCMs demonstrated that sodium channel mutations with a negative shift of the voltage dependence of inactivation showed increased sensitivity to mexiletine, and the corresponding myotonic carriers responded well to this drug. Conversely, mutations that right shifted the inactivation voltage dependence were less sensitive to mexiletine and were preferentially blocked by flecainide (Desaphy et al., 2001, 2004). In the respective mutation carriers, flecainide exhibited greater benefit than mexiletine (Desaphy et al., 2013b). In addition, mutations located close to the binding site for mexiletine can modify sensitivity to the drug (Takahashi and Cannon, 2001). These evidences support the idea that the pharmacological characterization of mutant channels in vitro is fundamental to predict drug response in vivo and address the carrier of a specific mutation toward the appropriate therapy.

\section{Marketed Drugs Repurposing}

One recent direction of pharmacological research is based on repurposing of existing drugs, that represents a time- and costsparing strategy. Nav channel blockers that are already on the market for another indication and can be selected as an alternative to mexiletine to treat neuromuscular channelopathies or cerebellar ataxias represent an example (Desaphy et al., 2014; Matthews and Hanna, 2014; Romano et al., 2015). Importantly, the repurposing of marketed drugs will avoid the need of trials on safety, and, if positive results are obtained in cell and animal models, these drugs will be entered in a phase II clinical trials.

Among novel strategies to discover ion channels selective ligands, it is worth mentioning the search of pharmacovigilance databases to pick commercial drugs inducing a side effect that is endorsed to an ion channel block. Recently this strategy has been used to monitor drug-induced atrophy that in vitro resulted from KATP channel block using the Food and Drug AdministrationAdverse Effects Reporting System (FDA-AERS) database (Mele et al., 2014). This database is a passive surveillance system that collects spontaneous reports of adverse events regarding any US licensed drugs from providers, health care workers, and the public. Although AERS cannot usually prove causal associations between drugs and adverse events, it can help to obtain helpful information on drug activity that can be validated in vitro.

\section{Novel Targets}

Improved understanding of the disease pathways leads to the selection of alternative drug targets apart from the causative ion channel. Indeed, many disorders reflect dysfunctions in regulatory proteins that may alter ion channel biophysical properties, synthesis, membrane trafficking and/or posttranslational modifications and/or can modulate the phenotypic variability observed in affected families. These proteins are 
emerging as attractive opportunities for drug development (Bechi et al., 2015; Brignone et al., 2015). Pharmacological correction of an ion channel defect by targeting an alternative ion channel that may compensate for the primary dysfunction is considered another possible approach to treat channelopathies. Recently, activators of the epithelial $\mathrm{Ca}^{2+}$-activated $\mathrm{Cl}^{-}$channels TMEM16A, also known as anoctamin-1 (ANO1), proved useful in reducing sustained inflammation in cystic fibrosis lung disease (Mall and Galietta, 2015). SK channel activators fulfilled this scope in episodic and progressive ataxias (Walter et al., 2006; Romano et al., 2015). Novel ion channels classes, besides classical voltage-gated channels, have emerged as having therapeutic potential, due to their wide distribution and implication in the pathophysiology of several disorders. TRPV channels modulators, for instance, are being developed in inflammatory and neuropathic pain, migraine, focal and segmental glomerulosclerosis, bone abnormalities and other disorders (Kaneko and Szallasi, 2014). Recently, the muchneeded molecular identity of volume-regulated anion channel (VRAC) composed of LRRC8 heteromers has been disclosed (Pedersen et al., 2016). Given the pivotal role played in cell volume regulation in all cell types and evidences suggesting the involvement in several pathophysiological processes, VRAC would represent a new promising target in diseases such as cardiac hypertrophy, megalencephalic leukoencephalopathy with subcortical cysts, cerebral ischemia and cancer (Yamamoto et al., 2011; Brignone et al., 2015; Pedersen et al., 2016). In addition, ivabradine, the first hyperpolarization-activated cyclic nucleotide-gated $(\mathrm{HCN})$ channel inhibitor, has been clinically approved for the treatment of chronic stable angina pectoris and heart failure (Cao et al., 2015). Moreover, modulators of acidsensing ion channels (ASIC) activity are potential candidates for new effective analgesic and neuroprotection drugs (Baron and Lingueglia, 2015).

\section{REFERENCES}

Alvina, K., and Khodakhah, K. (2010a). KCa channels as therapeutic targets in episodic ataxia type-2. J. Neurosci. 30, 7249-7257. doi: 10.1523/JNEUROSCI.6341-09.2010

Alvina, K., and Khodakhah, K. (2010b). The therapeutic mode of action of 4-aminopyridine in cerebellar ataxia. J. Neurosci. 30, 7258-7268. doi: 10.1523/JNEUROSCI.3582-09.2010

Andrini, O., Keck, M., Briones, R., Lourdel, S., Vargas-Poussou, R., and Teulon, J. (2015). ClC-K chloride channels: emerging pathophysiology of Bartter syndrome type 3. Am. J. Physiol. Renal. Physiol. 308, F1324-F1334. doi: 10.1152/ajprenal.00004.2015

Arnoux, J. B., Verkarre, V., Saint-Martin, C., Montravers, F., Brassier, A., Valayannopoulos, V., et al. (2011). Congenital hyperinsulinism: current trends in diagnosis and therapy. Orphanet J. Rare Dis. 6, 63. doi: 10.1186/17501172-6-63

Babenko, A. P., Gonzalez, G., and Bryan, J. (2000). Pharmaco-topology of sulfonylurea receptors. Separate domains of the regulatory subunits of K(ATP) channel isoforms are required for selective interaction with $\mathrm{K}(+)$ channel openers. J. Biol. Chem. 275, 717-720. doi: 10.1074/jbc.275.2.717

Bader, P. L., Faizi, M., Kima, L. H., Owen, S. F., Tadross, M. R., Alfa, R. W., et al. (2011). Mouse model of Timothy syndrome recapitulates triad of autistic traits. Proc. Natl. Acad. Sci. U.S.A. 108, 15432-15437. doi: 10.1073/pnas.1112667108

\section{Cell and Gene Therapy}

Finally, the possibility to manipulate the expression of ion channels by viral gene therapy is another strategy exploited in neurological channelopathies such as pain, epilepsy and muscular dystrophy, where a high percentage of non-responders to traditional pharmacotherapy have been encountered. This challenging approach ranges from the up- or down-regulation of ion channels that control excitability endogenously, to optogenetics and chemogenetics (Snowball and Schorge, 2015).

As additional ion channels are identified and characterized, new channelopathies emerge that would deserve precision medicine. The key to success in the clinical management of ion channelopathies will be the discovery of more potent and selective ion channel modulators to improve efficacy and safety on a larger clinical scale with respect to existing treatment options.

\section{AUTHOR CONTRIBUTIONS}

PI, DC, and J-FD conceived, coordinated and wrote the paper. $\mathrm{AL}$ and GC reviewed kidney channelopathies; $\mathrm{MB}$ and $\mathrm{AM}$ reviewed skeletal muscle channelopathies; SP, CC, and DT reviewed endocrine channelopathies; J-FD reviewed heart and PNS channelopathies; PI and AG reviewed CNS channelopathies; PI and GC made figures and table; AD edited the paper. All authors approved the final version of the manuscript.

\section{ACKNOWLEDGMENTS}

This work was supported by the Italian Health Ministry (grant GR-2009-1580433 to PI), Telethon-Italy (grant GGP14096 to DC), and AFM-Telethon France (grant 19027 to J-FD).

Bagal, S. K., Chapman, M. L., Marron, B. E., Prime, R., Storer, R. I., and Swain, N. A. (2014). Recent progress in sodium channel modulators for pain. Bioorg. Med. Chem. Lett. 24, 3690-3699. doi: 10.1016/j.bmcl.2014.06.038

Barlassina, C., Dal Fiume, C., Lanzani, C., Manunta, P., Guffanti, G., Ruello, A., et al. (2007). Common genetic variants and haplotypes in renal CLCNKA gene are associated to salt-sensitive hypertension. Hum. Mol. Genet. 16, 1630-1638. doi: $10.1093 / \mathrm{hmg} / \mathrm{ddm} 112$

Baron, A., and Lingueglia, E. (2015). Pharmacology of acid-sensing ion channels - Physiological and therapeutical perspectives. Neuropharmacology 94, 19-35. doi: 10.1016/j.neuropharm.2015.01.005

Baruscotti, M., Bucchi, A., Milanesi, R., Paina, M., Barbuti, A., GnecchiRuscone, T., et al. (2015). A gain-of-function mutation in the cardiac pacemaker HCN4 channel increasing cAMP sensitivity is associated with familial Inappropriate Sinus Tachycardia. Eur. Heart J. pii: ehv582. doi: 10.1093/eurheartj/ehv582 [Epub ahead of print].

Batla, A., Pandey, S., and Nehru, R. (2011). Megalencephalic leukoencephalopathy with subcortical cysts: a report of four cases. J. Pediatr. Neurosci. 6, 74-77. doi: 10.4103/1817-1745.84416

Bechi, G., Rusconi, R., Cestèle, S., Striano, P., Franceschetti, S., and Mantegazza, M. (2015). Rescuable folding defective NaV1.1 (SCN1A) mutants in epilepsy: properties, occurrence, and novel rescuing strategy with peptides targeted to the endoplasmic reticulum. Neurobiol. Dis. 75, 100-114. doi: 10.1016/j.nbd.2014.12.028 
Bendahhou, S., Cummins, T. R., Griggs, R. C., Fu, Y. H., and Ptácek, L. J. (2001). Sodium channel inactivation defects are associated with acetazolamideexacerbated hypokalemic periodic paralysis. Ann. Neurol. 50, 417-420. doi: 10.1002/ana.1144

Bender, A. C., Morse, R. P., Scott, R. C., Holmes, G. L., and Lenck-Santini, P. P. (2012). SCN1A mutations in Dravet syndrome: impact of interneuron dysfunction on neural networks and cognitive outcome. Epilepsy Behav. 23, 177-186. doi: 10.1016/j.yebeh.2011.11.022

Bennett, D. L. H., and Woods, C. G. (2014). Painful and painless channelopathies. Lancet Neurol. 13, 587-599. doi: 10.1016/S1474-4422(14)70024-9

Benstead, T. J., Camfield, P. R., and King, D. B. (1987). Treatment of paramyotonia congenita with acetazolamide. Can. J. Neurol. Sci. 14, 156-158.

Berkovic, S. F., Heron, S. E., Giordano, L., Marini, C., Guerrini, R., Kaplan, R. E., et al. (2004). Benign familial neonatal-infantile seizures: characterization of a new sodium channelopathy. Ann. Neurol. 55, 550-557. doi: 10.1002/ana.20029

Betzenhauser, M. J., Pitt, G. S., and Antzelevitch, C. (2015). Calcium channel mutations in cardiac arrhythmia syndromes. Curr. Mol. Pharmacol. 8, 133-142. doi: 10.2174/1874467208666150518114857

Blanz, J., Schweizer, M., Auberson, M., Maier, H., Muenscher, A., Hübner, C. A., et al. (2007). Leukoencephalopathy upon disruption of the chloride channel ClC-2. J. Neurosci. 27, 6581-6589. doi: 10.1523/JNEUROSCI.0338-07. 2007

Bockenhauer, D., Feather, S., Stanescu, H. C., Bandulik, S., Zdebik, A. A., Reichold, M., et al. (2009). Epilepsy, ataxia, sensorineural deafness, tubulopathy, and KCNJ10 mutations. N. Engl. J. Med. 360, 1960-1970. doi: 10.1056/NEJMoa0810276

Boim, M. A., Ho, K., Shuck, M. E., Bienkowski, M. J., Block, J. H., Slightom, J. L., et al. (1995). ROMK inwardly rectifying ATP-sensitive $\mathrm{K}^{+}$channel. II. Cloning and distribution of alternative forms. Am. J. Physiol. 268, F1132-F1140.

Brignone, M. S., Lanciotti, A., Camerini, S., De Nuccio, C., Petrucci, T. C., Visentin, S., et al. (2015). MLC1 protein: a likely link between leukodystrophies and brain channelopathies. Front. Cell. Neurosci. 9:66. doi: $10.3389 /$ fncel.2015.00106

Brochard, K., Boyer, O., Blanchard, A., Loirat, C., Niaudet, P., Macher, M. A., et al. (2009). Phenotype-genotype correlation in antenatal and neonatal variants of Bartter syndrome. Nephrol. Dial. Transplant. 24, 1455-1464. doi $10.1093 / \mathrm{ndt} / \mathrm{gfn} 689$

Brouwer, B. A., Merkies, I. S., Gerrits, M. M., Waxman, S. G., Hoeijmakers, J. G., and Faber, C. G. (2014). Painful neuropathies: the emerging role of sodium channelopathies. J. Peripher. Nerv. Syst. 19, 53-65. doi: 10.1111/jns5. 12071

Brugada, R., Hong, K., Dumaine, R., Cordeiro, J., Gaita, F., Borggrefe, M., et al. (2004). Sudden death associated with short-QT syndrome linked to mutations in HERG. Circulation 109, 30-35. doi: 10.1161/01.CIR.0000109482.92774.3A

Campuzano, O., Sarquella-Brugada, G., Brugada, R., and Brugada, J. (2015). Genetics of channelopathies associated with sudden cardiac death. Global Cardiol. Sci. Pract. 2015:39. doi: 10.5339/gcsp.2015.39

Cannon, S. C. (2015). Channelopathies of skeletal muscle excitability. Compr. Physiol. 5, 761-790. doi: 10.1002/cphy.c140062

Cao, Y., Pang, J., and Zhou, P. (2015). HCN channels as therapeutic targets for heart failure and pain. Curr. Top. Med. Chem. doi: 10.2174/1568026616666151215104058 [Epub ahead of print].

Capulli, M., Maurizi, A., Ventura, L., Rucci, N., and Teti, A. (2015). Effective Small Interfering RNA Therapy to Treat CLCN7-dependent Autosomal Dominant Osteopetrosis Type 2. Mol. Ther. Nucleic Acids 4:e248. doi: 10.1038/mtna.2015.21

Carbonara, R., Carocci, A., Roussel, J., Crescenzo, G., Buonavoglia, C., Franchini, C., et al. (2015). Inhibition of voltage-gated sodium channels by sumatriptan bioisosteres. Front. Pharmacol. 6:155. doi: 10.3389/fphar.2015.00155

Cardani, R., Giagnacovo, M., Botta, A., Rinaldi, F., Morgante, A., Udd, B., et al. (2012). Co-segregation of DM2 with a recessive CLCN1 mutation in juvenile onset of myotonic dystrophy type 2. J. Neurol. 259, 2090-2099. doi: 10.1007/s00415-012-6462-1

Carocci, A., Catalano, A., Bruno, C., Lentini, G., Franchini, C., De Bellis, M. et al. (2010). Synthesis, and in vitro sodium channel blocking activity evaluation of novel homochiral mexiletine analogue. Chirality 22, 299-307. doi: $10.1002 /$ chir.2074
Catterall, W. A. (2012). Voltage-gated sodium channels at 60: structure, function and pathophysiology. J. Physiol. 590, 2577-2589. doi: 10.1113/jphysiol.2011.224204

Catterall, W. A. (2014). Sodium channels, inherited epilepsy, and antiepileptic drugs. Annu. Rev. Pharmacol. Toxicol. 54, 317-338. doi: 10.1146/annurevpharmtox-011112-140232

Catterall, W. A., and Swanson, T. M. (2015). Structural basis for pharmacology of voltage-gated sodium and calcium channels. Mol. Pharmacol. 88, 141-150. doi: 10.1124/mol.114.097659

Cebotaru, V., Kaul, S., Devuyst, O., Cai, H., Racusen, L., Guggino, W. B., et al. (2005). High citrate diet delays progression of renal insufficiency in the ClC5 knockout mouse model of Dent's disease. Kidney Int. 68, 642-652. doi: 10.1111/j.1523-1755.2005.00442.x

Cestèle, S., Schiavon, E., Rusconi, R., Franceschetti, S., and Mantegazza, M. (2013). Nonfunctional Nav1.1 familial hemiplegic migraine mutant transformed into gain of function by partial rescue of folding defects. Proc. Natl. Acad. Sci. U.S.A. 110, 17546-17551. doi: 10.1073/pnas.13098 27110

Chen, Q., Kirsch, G. E., Zhang, D., Brugada, R., Brugada, J., Brugada, P., et al. (1998). Genetic basis and molecular mechanism for idiopathic ventricular fibrillation. Nature 392, 293-296. doi: 10.1038/33305

Chen, T. T., Klassen, T. L., Goldman, A. M., Marini, C., Guerrini, R., and Noebels, J. L. (2013). Novel brain expression of ClC-1 chloride channels and enrichment of CLCN1 variants in epilepsy. Neurology 80, 1078-1085. doi: 10.1212/WNL.0b013e31828868e7

Chen, Y., Lu, J., Pan, H., Zhang, Y., Wu, H., Xu, K., et al. (2003). Association between genetic variation of CACNA1H and childhood absence epilepsy. Ann. Neurol. 54, 239-243. doi: 10.1002/ana.10607

Chen, Y., Yu, F. H., Sharp, E. M., Beacham, D., Scheuer, T., and Catterall, W. A. (2008). Functional properties and differential neuromodulation of $\mathrm{Na}(\mathrm{v}) 1.6$ channels. Mol. Cell. Neurosci. 38, 607-615. doi: 10.1016/j.mcn.2008. 05.009

Cheng, C. J., Lin, S. H., Lo, Y. F., Yang, S. S., Hsu, Y. J., Cannon, S. C., et al. (2011). Identification and functional characterization of Kir2.6 mutations associated with non-familial hypokalemicperiodic paralysis. J. Biol. Chem. 286, 27425-27435. doi: 10.1074/jbc.M111.249656

Choi, J. S., Zhang, L., Dib-Hajj, S. D., Han, C., Tyrrell, L., Lin, Z., et al. (2009). Mexiletine-responsive erythromelalgia due to a new Nav1.7 mutation showing use-dependent current fall-off. Exp. Neurol. 216, 383-389. doi: 10.1016/j.expneurol.2008.12.012

Cox, J. J., Reimann, F., Nicholas, A. K., Thornton, G., Roberts, E., Springell, K., et al. (2006). An SCN9A channelopathy causes congenital inability to experience pain. Nature 444, 894-898. doi: 10.1038/nature05413

Cross, J. H., Arora, R., Heckemann, R. A., Gunny, R., Chong, K., Carr, L., et al. (2013). Neurological features of epilepsy, ataxia, sensorineural deafness, tubulopathy syndrome. Dev. Med. Child. Neurol. 55, 846-856. doi: $10.1111 / \mathrm{dmcn} .12171$

D’Adamo, M. C., Gallenmüller, C., Servettini, I., Hartl, E., Tucker, S. J., Arning, L., et al. (2015a). Novel phenotype associated with a mutation in the KCNA1(Kv1.1) gene. Front. Physiol. 5:525. doi: 10.3389/fphys.2014.00525

D’Adamo, M. C., Hasan, S., Guglielmi, L., Servettini, I., Cenciarini, M., Catacuzzeno, L., et al. (2015b). New insights into the pathogenesis and therapeutics of episodic ataxia type 1. Front. Cell. Neurosci. 9:317. doi: $10.3389 /$ fncel.2015.00317

Davies, N. P., Imbrici, P., Fialho, D., Herd, C., Bilsland, L. G., Weber, A., et al. (2005). Andersen-Tawil syndrome: new potassium channel mutations and possible phenotypic variation. Neurology 65, 1083-1089. doi: 10.1212/01.wnl.0000178888.03767.74

Davis, M. D., and Sandroni, P. (2005). Lidocaine patch for pain of erythromelalgia: follow-up of 34 patients. Arch. Dermatol. 141, 1320-1321.

De Bellis, M., De Luca, A., Desaphy, J. F., Carbonara, R., Heiny, J. A., Kennedy, A., et al. (2013). Combined modifications of mexiletine pharmacophores for new lead blockers of Nav1.4 channels. Biophys. J. 104, 344-354. doi: 10.1016/j.bpj.2012.11.3830

De Franco, E., Flanagan, S. E., Houghton, J. A., Lango, A. H., Mackay, D. J., Temple, I. K., et al. (2015). The effect of early, comprehensive genomic testing on clinical care in neonatal diabetes: an international cohort study. Lancet 386, 957-963. doi: 10.1016/S0140-6736(15)60098-8 
de Lera Ruiz, M., and Kraus, R. L. (2015). Voltage-gated sodium channels: structure, function, pharmacology, and clinical indications. J. Med. Chem. 58, 7093-7118. doi: 10.1021/jm501981g

De Luca, A. (2012). Pre-clinical drug tests in the $\mathrm{mdx}$ mouse as a model of dystrophinopathies: an overview. Acta Myol. 31, 40-47.

De Luca, A., Pierno, S., Liantonio, A., Camerino, C., and Conte Camerino, D. (1998). Phosphorylation and IGF-1-mediated dephosphorylation pathways control the activity and the pharmacological properties of skeletal muscle chloride channels. Br. J. Pharmacol. 125, 477-482. doi: 10.1038/sj.bjp. 0702107

De Luca, A., Pierno, S., Liantonio, A., Cetrone, M., Camerino, C., Fraysse, B., et al. (2003). Enhanced dystrophic progression in $\mathrm{mdx}$ mice by exercise and beneficial effects of taurine and insulin-like growth factor-1. J. Pharmacol. Exp. Ther. 304, 453-463. doi: 10.1124/jpet.102.041343

De Luca, A., Pierno, S., Liantonio, A., Desaphy, J. F., Natuzzi, F., Didonna, M. P., et al. (2004). New potent mexiletine and tocainide analogues evaluated in vivo and in vitro as antimyotonic agents on myotonic ADR mouse. Neuromuscul. Disord. 14, 405-416. doi: 10.1016/j.nmd.2004. 04.006

De Luca, A., Tricarico, D., Wagner, R., Bryant, S. H., Tortorella, V., and Conte Camerino, D. (1992). Opposite effects of enantiomers of clofibric acid derivative on rat skeletal muscle chloride conductance: antagonism studies and theoretical modeling of two different receptor site interactions. J. Pharmacol. Exp. Ther. 260, 364-368.

de Pablos, A. L., García-Nieto, V., López-Menchero, J. C., Ramos-Trujillo, E., González-Acosta, H., and Claverie-Martín, F. (2014). Severe manifestation of Bartter syndrome Type IV caused by a novel insertion mutation in the BSND gene. Clin. Nephrol. 81, 363-368. doi: 10.5414/CN107687

Depienne, C., Bugiani, M., Dupuits, C., Galanaud, D., Touitou, V., Postma, N., et al. (2013). Brain white matter oedema due to $\mathrm{ClC}-2$ chloride channel deficiency: an observational and alytical study. Lancet Neurol. 12, 659-668. doi: 10.1016/S1474-4422(13)70053-X

Desaphy, J.-F., Carbonara, R., Costanza, T., and Conte Camerino, D. (2014). Preclinical evaluation of marketed sodium channel blockers in a rat model of myotonia discloses new promising antimyotonic drugs. Exp. Neurol. 255, 96-102. doi: 10.1016/j.expneurol.2014.02.023

Desaphy, J. F., Carbonara, R., Costanza, T., Lentini, G., Cavalluzzi, M. M., Bruno, C., et al. (2013a). Molecular dissection of lubeluzole use-dependent block of voltage-gated sodium channels discloses new therapeutic potentials. Mol. Pharmacol. 83, 406-415. doi: 10.1124/mol.112. 080804

Desaphy, J. F., De Luca, A., Didonna, M. P., George, A. L. Jr., and Conte Camerino, D. (2004). Different flecainide sensitivity of hNav1.4 channels and myotonic mutants explained by state-dependent block. J. Physiol. 554, 321-334. doi: 10.1113/jphysiol.2003.046995

Desaphy, J. F., De Luca, A., Tortorella, P., De Vito, D., George, A. L. Jr., and Conte, C. D. (2001). Gating of myotonic Na channel mutants defines the response to mexiletine and a potent derivative. Neurology 57, 1849-1857. doi: 10.1212/WNL.57.10.1849

Desaphy, J. F., Gramegna, G., Altamura, C., Dinardo, M. M., Imbrici, P., George Jr., et al. (2013b). Functional characterization of ClC-1 mutations from patients affected by recessive myotonia congenita presenting with different clinical phenotypes. Exp. Neurol. 248, 530-540. doi: 10.1016/j.expneurol.2013. 07.018

Desaphy, J. F., Modoni, A., Lomonaco, M., and Conte Camerino, D. (2013c). Dramatic improvement of myotonia permanens with flecainide: a two-case report of a possible bench-to-bedside pharmacogenetics strategy. Eur. J. Clin. Pharmacol. 69, 1037-1039. doi: 10.1007/s00228-0121414-3

Dichgans, M., Freilinger, T., Eckstein, G., Babini, E., Lorenz-Depiereux, B., Biskup, S., et al. (2005). Mutation in the neuronal voltage-gated sodium channel SCN1A in familial hemiplegic migraine. Lancet 366, 371-377. doi: 10.1016/S0140-6736(05)66786-4

Diener, H. C., Solbach, K., Holle, D., and Gaul, C. (2015). Integrated care for chronic migraine patients: epidemiology, burden, diagnosis and treatment options. Clin. Med. (Lond). 15, 344-350. doi: 10.7861/clinmedicine.15-4-344

Diep, V., and Seaver, L. H. (2015). Long QT syndrome with craniofacial, digital, and neurologic features: is it useful to distinguish between timothy syndrome types 1 and 2? Am. J. Med. Genet. A. 167A, 2780-2785. doi: 10.1002/ajmg.a. 37258

Dinardo, M. M., Camerino, G., Mele, A., Latorre, R., Conte Camerino, D., and Tricarico, D. (2012). Splicing of the rSlo gene affects the molecular composition and drug response of $\mathrm{Ca}^{2+}$-activated $\mathrm{K}^{+}$channels in skeletal muscle. PLoS ONE 7:e40235. doi: 10.1371/journal.pone.0040235

Duarri, A., Jezierska, J., Fokkens, M., Meijer, M., Schelhaas, H. J., den Dunnen, W. F., et al. (2012). Mutations in potassium channel kcnd3 cause spinocerebellar ataxia type 19. Ann. Neurol. 72, 870-880. doi: 10.1002/ana.23700

Eckle, V. S., Shcheglovitov, A., Vitko, I., Dey, D., Yap, C. C., Winckler, B., et al. (2014). Mechanisms by which a CACNA1H mutation in epilepsy patients increases seizure susceptibility. J. Physiol. 592, 795-809. doi: 10.1113/jphysiol.2013.264176

Eguchi, H., Tsujino, A., Kaibara, M., Hayashi, H., Shirabe, S., Taniyama, K., et al. (2006). Acetazolamide acts directly on the human skeletal muscle chloride channel. Muscle Nerve 34, 292-297. doi: 10.1002/mus.20585

El-Sherif, N., and Boutjdir, M. (2015). Role of pharmacotherapy in cardiac ion channelopathies. Pharmacol. Ther. 155, 132-142. doi: 10.1016/j.pharmthera.2015.09.002

Estacion, M., Vohra, B. P., Liu, S., Hoeijmakers, J., Faber, C. G., Merkies, I. S., et al. (2015). Ca2 ${ }^{+}$toxicity due to reverse $\mathrm{Na}^{+} / \mathrm{Ca}^{2+}$ exchange contributes to degeneration of neurites of DRG neurons induced by a neuropathyassociated Nav1.7 mutation. J. Neurophysiol. 114, 1554-1564. doi: 10.1152/jn. 00195.2015

Estévez, R., Boettger, T., Stein, V., Birkenhäger, R., Otto, E., Hildebrandt, F., et al. (2001). Barttin is a Cl- channel beta-subunit crucial for renal Cl- reabsorption and inner ear $\mathrm{K}^{+}$secretion. Nature 414, 558-561. doi: 10.1038/35107099

Faber, C. G., Hoeijmakers, J. G., Ahn, H. S., Cheng, X., Han, C., Choi, J. S., et al. (2012a). Gain of function $\mathrm{Na}(\mathrm{V}) 1.7$ mutations in idiopathic small fiber neuropathy. Ann. Neurol. 71, 26-39. doi: 10.1002/ana. 22485

Faber, C. G., Lauria, G., Merkies, I. S., Cheng, X., Han, C., Ahn, H. S., et al. (2012b). Gain-of-function Nav1.8 mutations in painful neuropathy. Proc. Natl. Acad. Sci. U.S.A. 109, 19444-19449. doi: 10.1073/pnas.1216080109

Feng, L., Campbell, E. B., Hsiung, Y., and MacKinnon, R. (2010). Structure of a eukaryotic CLC transporter defines an intermediate state in the transport cycle. Science 330, 635-641. doi: 10.1126/science.1195230

Fertleman, C. R., Baker, M. D., Parker, K. A., Moffatt, S., Elmslie, F. V., Abrahamsen, B., et al. (2006). SCN9A mutations in paroxysmal extreme pain disorder: allelic variants underlie distinct channel defects and phenotypes. Neuron 52, 767-774. doi: 10.1016/j.neuron.2006. 10.006

Fertleman, C. R., Ferrie, C. D., Aicardi, J., Bednarek, N. A., Eeg-Olofsson, O., Elmslie, F. V., et al. (2007). Paroxysmal extreme pain disorder (previously familial rectal pain syndrome). Neurology 69, 586-595. doi: 10.1212/ 01.wnl.0000268065.16865.5f

Finnerup, N. B., Attal, N., Haroutounian, S., McNicol, E., Baron, R., Dworkin, R. H., et al. (2015). Pharmacotherapy for neuropathic pain in adults: a systematic review and meta-analysis. Lancet Neurol. 14, 162-173. doi: 10.1016/S1474-4422(14)70251-0

Fischer, T. Z., Gilmore, E. S., Estacion, M., Eastman, E., Taylor, S., Melanson, M., et al. (2009). A novel Nav1.7 mutation producing carbamazepine-responsive erythromelalgia. Ann. Neurol. 65, 733-741. doi: 10.1002/ana.21678

Fratta, P., and Hanna, M. G. (2015). Neuromuscular diseases: progress in gene discovery drives diagnostics and therapeutics. Lancet Neurol. 14, 13-14. doi: 10.1016/S1474-4422(14)70239-X

Furby, A., Vicart, S., Camdessanché, J. P., Fournier, E., Chabrier, S., Lagrue, E., et al. (2014). Heterozygous CLCN1 mutations can modulate phenotype in sodium channel myotonia. Neuromuscul. Disord. 24, 953-959. doi: 10.1016/j.nmd.2014.06.439

Gaita, F., Giustetto, C., Bianchi, F., Schimpf, R., Haissaguerre, M., Calò, L., et al. (2004). Short QT syndrome: pharmacological treatment. J. Am. Coll. Cardiol. 43, 1494-1499.

Garcia, M. L., and Kaczorowski, G. J. (2014). Targeting the inward-rectifier potassium channel ROMK in cardiovascular disease. Curr. Opin. Pharmacol. 15, 1-6. doi: 10.1016/j.coph.2013.11.005

Garcia, M. L., Priest, B. T., Alonso-Galicia, M., Zhou, X., Felix, J. P., Brochu, R. M., et al. (2014). Pharmacologic inhibition of the renal outer 
medullary potassium channel causes diuresis and natriuresis in the absence of kaliuresis. J. Pharmacol. Exp. Ther. 348, 153-164. doi: 10.1124/jpet.113. 208603

Ghelardini, C., Desaphy, J. F., Muraglia, M., Corbo, F., Matucci, R., Dipalma, A., et al. (2010). Effects of a new potent analog of tocainide on hNav1.7 sodium channels and in vivo neuropathic pain models. Neuroscience 169, 863-873. doi: 10.1016/j.neuroscience.2010.05.019

Giudicessi, J. R., and Ackerman, M. J. (2013). Genotype- and phenotype-guided management of congenital long QT syndrome. Curr. Probl. Cardiol. 38, 417455. doi: 10.1016/j.cpcardiol.2013.08.001

Glauser, T. A., Cnaan, A., Shinnar, S., Hirtz, D. G., Dlugos, D., Masur, D., et al. (2013). Ethosuximide, valproic acid, and lamotrigine in childhood absence epilepsy: initial monotherapy outcomes at 12 months. Epilepsia 54, 141-155. doi: 10.1111/epi.12028

Graves, T. D., Imbrici, P., Kors, E. E., Terwindt, G. M., Eunson, L. H., Frants, R. R., et al. (2008). Premature stop codons in a facilitating EF-hand splice variant of CaV2.1 cause episodic ataxia type 2. Neurobiol. Dis. 32, 10-15. doi: 10.1016/j.nbd.2008.06.002

Grunnet, M., Strøbæk, D., Hougaard, C., and Christophersen, P. (2014). Kv7 channels as targets for anti-epileptic and psychiatric drugdevelopment. Eur. J. Pharmacol. 726, 133-137. doi: 10.1016/j.ejphar.2014. 01.017

Guglielmi, L., Servettini, I., Caramia, M., Catacuzzeno, L., Franciolini, F., D'Adamo, M. C., et al. (2014). Update on the implication of potassium channels in autism: $\mathrm{K}^{+}$channelautism spectrum disorder. Front. Cell. Neurosci. 9:34. doi: 10.3389/fncel.2015.00034

Habbout, K., Poulin, H., Rivier, F., Giuliano, S., Sternberg, D., Fontaine, B., et al. (2016). A recessive Nav1.4 mutation underlies congenital myasthenic syndrome with periodic paralysis. Neurology 86, 161-169. doi: 10.1212/WNL.0000000000002264

Habib, A. M., Wood, J. N., and Cox, J. J. (2015). Sodium Channels and Pain. Handb. Exp. Pharmacol. 227, 39-56. doi: 10.1007/978-3-662-46450-2_3

Han, C., Vasylyev, D., Macala, L. J., Gerrits, M. M., Hoeijmakers, J. G., Bekelaar, K. J., et al. (2014). The G1662S NaV1.8 mutation in small fibre neuropathy: impaired inactivation underlying DRG neuron hyperexcitability. J. Neurol. Neurosurg. Psychiatry 85, 499-505. doi: 10.1136/jnnp-2013306095

Havakuk, O., and Viskin, S. (2016). A Tale of 2 Diseases: the history of longQT syndrome and brugada syndrome. J. Am. Coll. Cardiol. 67, 100-108. doi: 10.1016/j.jacc.2015.10.020

Herson, P. S., Virk, M., Rustay, N. R., Bond, C. T., Crabbe, J. C., Adelman, J. P., et al. (2003). A mouse model of episodic ataxia type-1. Nat. Neurosci. 6, 378-383. doi: $10.1038 / \mathrm{nn} 1025$

Heyes, S., Pratt, W. S., Rees, E., Dahimene, S., Ferron, L., Owen, M. J., et al. (2015). Genetic disruption of voltage-gated calcium channels in psychiatric and neurological disorders. Prog. Neurobiol. 134, 36-54. doi: 10.1016/j.pneurobio.2015.09.002

Hibino, H., Inanobe, A., Furutani, K., Murakami, S., Findlay, I., and Kurachi, Y. (2010). Inwardly rectifying potassium channels: their structure, function, and physiological roles. Physiol. Rev. 90, 291-366. doi: 10.1152/physrev.00021. 2009

Hodgin, J. B., Corey, H. E., Kaplan, B. S., and D’Agati, V. D. (2008). Dent disease presenting as partial Fanconi syndrome and hypercalciuria. Kidney Int. 73, 1320-1323. doi: 10.1038/sj.ki.5002785

Hoegg-Beiler, M. B., Sirisi, S., Orozco, I. J., Ferrer, I., Hohensee, S., Auberson, M., et al. (2014). Disrupting MLC1 and GlialCAM and ClC-2 interactions in leukodystrophy entails glial chloride channel dysfunction. Nat. Commun. 5:3475. doi: $10.1038 /$ ncomms 4475

Hoffmann, E. K., Sørensen, B. H., Sauter, D. P., and Lambert, I. H. (2015). Role of volume-regulated and calcium-activated anion channels in cell volume homeostasis, cancer and drug resistance. Channels (Austin) 9, 380-396. doi: 10.1080/19336950.2015.1089007

Huang, J., Han, C., Estacion, M., Vasylyev, D., Hoeijmakers, J. G., Gerrits, M. M., et al. (2014). Gain-of-function sodium channel Nav1.9 mutations in painful neuropathy. Brain 137, 1627-1642. doi: 10.1093/brain/awu079

Humphries, E. S., and Dart, C. (2015). Neuronal and cardiovascular potassium channels as therapeutic drug targets: promise and pitfalls. J. Biomol. Screen. 20, 1055-1073. doi: 10.1177/1087057115601677
Igelström, K. M., and Heyward, P. M. (2012). The antidepressant drug fluoxetine inhibits persistent sodium currents and seizure-like events. Epilepsy Res. 101, 174-181. doi: 10.1016/j.eplepsyres.2012.03.019

Ilg, W., Bastian, A. J., Boesch, S., Burciu, R. G., Celnik, P., Claaßen, J., et al. (2014). Consensus paper: management of degenerative cerebellar disorders. Cerebellum 13, 248-268. doi: 10.1007/s12311-013-0531-6

Imbrici, P., Altamura, C., Pessia, M., Mantegazza, R., Desaphy, J. F., and Conte Camerino, D. (2015a). ClC-1 chloride channels: state-of-the-art research and future challenges. Front. Cell. Neurosci. 9:156. doi: 10.3389/fncel.2015.00156

Imbrici, P., D’Adamo, M. C., Grottesi, A., Biscarini, A., and Pessia, M. (2011). Episodic ataxia type 1 mutations affect fast inactivation of $\mathrm{K}^{+}$ channels by a reduction in either subunit surface expression or affinity for inactivation domain. Am. J. Physiol. Cell. Physiol. 300, C1314-C1322. doi: 10.1152/ajpcell.00456.2010

Imbrici, P., Liantonio, A., Gradogna, A., Pusch, M., and Camerino, D. C. (2014). Targeting kidney CLC-K channels: pharmacological profile in a human cell line versus Xenopus oocytes. Biochim. Biophys. Acta 1838, 2484-2491. doi: 10.1016/j.bbamem.2014.05.017

Imbrici, P., Maggi, L., Mangiatordi, G. F., Dinardo, M. M., Altamura, C., Brugnoni, R., et al. (2015b). ClC-1 mutations in myotonia congenita patients: insights into molecular gating mechanisms and genotype-phenotype correlation. J. Physiol. 593, 4181-4199. doi: 10.1113/JP270358

Jan, L. Y., and Jan, Y. N. (2012). Voltage-gated potassium channels and the diversity of electrical congenita. J. Physiol. 590, 2591-2599. doi: 10.1113/jphysiol.2011.224212

Janssen, A. G., Scholl, U., Domeyer, C., Nothmann, D., Leinenweber, A., and Fahlke, C. (2009). Disease-causing dysfunctions of barttin in Bartter syndrome type IV. J. Am. Soc. Nephrol. 20, 145-153. doi: 10.1681/ASN.2008010102

Jarecki, B. W., Piekarz, A. D., Jackson, I. I. J. O., and Cummins, T. R. (2010). Human voltage-gated sodium channel mutations that cause inherited neuronal and muscle channelopathies increase resurgent sodium currents. J. Clin. Invest. 120, 369-378. doi: 10.1172/JCI40801

Jen, J. C. (2015). "Familial Hemiplegic Migraine," in GeneReviews [Internet], eds R. A. Pagon, M. P. Adam, H. H. Ardinger, H. H. Ardinger, S. E. Wallace, A. Amemiya, et al. (Seattle, WA: University of Washington).

Jen, J. C., Graves, T. D., Hess, E. J., Hanna, M. G., Griggs, R. C., Baloh, R. W., et al. (2007). Primary episodic ataxias: diagnosis, pathogenesis and treatment. Brain 130, 2484-2493. doi: 10.1093/brain/awm126

Jentsch, T. J. (2015). Discovery of CLC transport proteins: cloning, structure, function and pathophysiology. J. Physiol. 593, 4091-4109. doi: 10.1113/JP270043

Jongjaroenprasert, W., Phusantisampan, T., Mahasirimongkol, S., Mushiroda, T., Hirankarn, N., Snabboon, T., et al. (2012). A genome-wide association study identifies novel susceptibility genetic variation for thyrotoxic hypokalemicperiodic paralysis. J. Hum. Genet. 57, 301-304. doi: 10.1038/jhg.2012.20

Kaneko, Y., and Szallasi, A. (2014). Transient receptor potential (TRP) channels: a clinical perspective. Br. J. Pharmacol. 171, 2474-2507. doi: 10.1111/bph.12414

Kasper, D., Planells-Cases, R., Fuhrmann, J. C., Scheel, O., Zeitz, O., Ruether, K., et al. (2005). Loss of the chloride channel ClC-7 leads to lysosomal storage disease and neurodegeneration. EMBO J. 24, 1079-1091. doi: 10.1038/sj.emboj.7600576

Kearney, J. A. (2011). Genetic modifiers of neurological disease. Curr. Opin. Genet. Dev. 21, 349-353. doi: 10.1016/j.gde.2010.12.007

Key, L. L. Jr., Rodriguiz, R. M., Willi, S. M., Wright, N. M., Hatcher, H. C., Eyre, D. R., et al. (1995). Long-term treatment of osteopetrosis with recombinant human interferon gamma. N. Engl. J. Med. 332, 1594-1599. doi: 10.1056/NEJM199506153322402

Khogali, S., Lucas, B., Ammar, T., Dejong, D., Barbalinardo, M., Hayward, L. J., et al. (2015). Physiological basis for muscle stiffness and weakness in a knockin M1592V mouse model of hyperkalemic periodic paralysis. Physiol. Rep. 3:e12656. doi: 10.14814/phy2.12656

Kim, J. B., Kim, M. H., Lee, S. J., Kim, D. J., and Lee, B. C. (2007). The genotype and clinical phenotype of Korean patients with familial hypokalemic periodic paralysis. J. Korean Med. Sci. 22, 946-951. doi: 10.3346/jkms.2007.22.6.946

Kokunai, Y., Nakata, T., Furuta, M., Sakata, S., Kimura, H., Aiba, T., et al. (2014). A Kir3.4 mutation causes Andersen-Tawil syndrome by an inhibitory effect on Kir2.1. Neurology 82, 1058-1064. doi: 10.1212/WNL.0000000000000239 
Kornak, U., Kasper, D., Bösl, M. R., Kaiser, E., Schweizer, M., Schulz, A., et al. (2001). Loss of the ClC-7 chloride channel leads to osteopetrosis in mice and man. Cell 104, 205-215. doi: 10.1016/S0092-8674(01)00206-9

Kornilov, P., Peretz, A., and Attali, B. (2013). Channel gating pore: a new therapeutic target. Cell Res. 23, 1067-1068. doi: 10.1038/cr. 2013.89

Krämer, B. K., Bergler, T., Stoelcker, B., and Waldegger, S. (2008). Mechanisms of Disease: the kidney-specific chloride channels ClCKA and ClCKB, the Barttin subunit, and their clinical relevance. Nat. Clin. Pract. Nephrol. 4, 38-46. doi: 10.1038/ncpneph0689

Kremeyer, B., Lopera, F., Cox, J. J., Momin, A., Rugiero, F., Marsh, S., et al. (2010). A gain-of-function mutation in TRPA1 causes familial episodic pain syndrome. Neuron 66, 671-680. doi: 10.1016/j.neuron.2010. 04.030

Krey, J. F., Pasca, S. P., Shcheglovitov, A., Yazawa, M., Schwemberger, R., and Rasmusson, R. (2013). Timothy syndrome is associated with activity-dependent dendritic retraction in rodent and human neurons. Nat. Neurosci. 16, 201-209. doi: $10.1038 / \mathrm{nn} .3307$

Kullmann, D. M., and Waxmann, S. G. (2010). Neurological channelopathies: new insights into disease mechanisms and ion channel function. J. Physiol. 588, 1823-1827. doi: 10.1113/jphysiol.2010.190652

Lampert, A., Eberhardt, M., and Waxman, S. G. (2014). Altered sodium channel gating as molecular basis of pain: contribution of activation, inactivation, and resurgent currents. Handb. Exp. Pharmacol. 221, 91-110. doi: 10.1007/978-3642-41588-3_5

Larsen, J., Carvill, G. L., Gardella, E., Kluger, G., Schmiedel, G., Barisic, N., et al. (2015). The phenotypic spectrum of SCN8A encephalopathy. Neurology 84, 480-489. doi: 10.1212/wnl.0000000000001211

Lau, E., Correia, C., Freitas, P., Nogueira, C., Costa, M., Saavedra, A., et al. (2015). Permanent neonatal diabetes by a new mutation in KCNJ11: unsuccessful switch to sulfonylurea. Arch. Endocrinol. Metab. 59, 559-561. doi: 10.1590/2359-3997000000076

Lee, Y. C., Durr, A., Majczenko, K., Huang, Y. H., Liu, Y. C., Lien, C. C., et al. (2012). Mutations in KCND3 cause spinocerebellar ataxia type 22. Ann. Neurol. 72, 859-869. doi: 10.1002/ana.23701

Leipold, E., Hanson-Kahn, A., Frick, M., Gong, P., Bernstein, J. A., Voigt, M., et al. (2015). Cold-aggravated pain in humans caused by a hyperactive NaV1.9 channel mutant. Nat. Commun. 6:10049. doi: 10.1038/ncomms10049

Leipold, E., Liebmann, L., Korenke, G. C., Heinrich, T., Giesselmann, S., Baets, J., et al. (2013). A de novo gain-of-function mutation in SCN11A causes loss of pain perception. Nat. Genet. 45, 1399-1404. doi: 10.1038/ng.2767

Leisle, L., Ludwig, C. F., Wagner, F. A., Jentsch, T. J., and Stauber, T. (2011). ClC7 is a slowly voltage-gated $2 \mathrm{Cl}(-) / 1 \mathrm{H}(+)$-exchanger and requires Ostm 1 for transport activity. EMBO J. 30, 2140-2152. doi: 10.1038/emboj.2011.137

Li, P., Chen, Z., Xu, H., Sun, H., Li, H., Liu, H., et al. (2013). The gating charge pathway of an epilepsy-associated potassium channel accommodates chemical ligands. Cell Res. 23, 1106-1118. doi: 10.1038/cr.2013.82

Liantonio, A., Giannuzzi, V., Picollo, A., Babini, E., Pusch, M., and Conte Camerino, D. (2007). Niflumic acid inhibits chloride conductance of rat skeletal muscle by directly inhibiting the CLC-1 channel and by increasing intracellular calcium. Br. J. Pharmacol. 150, 235-247. doi: 10.1038/sj.bjp. 0706954

Liantonio, A., Gramegna, G., Camerino, G. M., Dinardo, M. M., Scaramuzzi, A., Potenza, M. A., et al. (2012). In-vivo administration of CLC-K kidney chloride channels inhibitors increases water diuresis in rats: a new drug target for hypertension? J. Hypertens. 30, 153-167. doi: 10.1097/HJH.0b013e328 34d9eb9

Liantonio, A., Imbrici, P., Camerino, G. M., Fracchiolla, G., Carbonara, G., Giannico, D., et al. (2016). Kidney CLC-K chloride channels inhibitors: structure-based studies and efficacy in hypertension and associated CLC-K polymorphisms. J. Hypertens. 34, 981-992. doi: 10.1097/HJH.0000000000000876

Liantonio, A., Picollo, A., Carbonara, G., Fracchiolla, G., Tortorella, P., Loiodice, F., et al. (2008). Molecular switch for CLC-K Cl- channel block/activation: optimal pharmacophoric requirements towards high-affinity ligands. Proc. Natl. Acad. Sci. U.S.A. 105, 1369-1373. doi: 10.1073/pnas.07089 77105
Liao, Y., Anttonen, A. K., Liukkonen, E., Gaily, E., Maljevic, S., Schubert, S., et al. (2010). SCN2A mutation associated with neonatal epilepsy, lateonset episodic ataxia, myoclonus, and pain. Neurology 75, 1454-1458. doi: 10.1212/WNL.0b013e3181f8812e

Lim, C. X., Ricos, M. G., Dibbens, L. M., and Heron, S. E. (2016). KCNT1 mutations in seizure disorders: the phenotypic spectrum and functional effects. J. Med. Genet. 53, 217-225. doi: 10.1136/jmedgenet-2015-103508

Lion-Francois, L., Mignot, C., Vicart, S., Manel, V., Sternberg, D., Landrieu, P., et al. (2010). Severe neonatal episodic laryngospasm due to de novo SCN4A mutations: a new treatable disorder. Neurology 75, 641-645. doi: 10.1212/WNL.0b013e3181ed9e96

Lloyd, S. E., Gunther, W., Pearce, S. H., Thomson, A., Bianchi, M. L., Bosio, M., et al. (1997). Characterisation of renal chloride channel, CLCN5, mutations in hypercalciuric nephrolithiasis (kidney stones) disorders. Hum. Mol. Genet. 6, 1233-1239. doi: 10.1093/hmg/6.8.1233

Lo Monaco, M., D’Amico, A., Luigetti, M., Desaphy, J. F., and Modoni, A. (2015). Effect of mexiletine on transitory depression of compound motor action potential in recessive myotonia congenita. Clin. Neurophysiol. 126, 399-403. doi: 10.1016/j.clinph.2014.06.008

López-Hernández, T., Ridder, M. C., Montolio, M., Capdevila-Nortes, X., Polder, E., Sirisi, S., et al. (2011). Mutant GlialCAM causes megalencephalic leukoencephalopathy with subcortical cysts, benign familial macrocephaly, and macrocephaly with retardation and autism. Am. J. Hum. Genet. 88, 422-432. doi: 10.1016/j.ajhg.2011.02.009

Loudon, K. W., and Fry, A. C. (2014). The renal channelopathies. Ann. Clin. Biochem. 51(Pt 4), 441-458. doi: 10.1177/0004563214531403

Mall, M. A., and Galietta, L. J. (2015). Targeting ion channels in cystic fibrosis. J. Cyst. Fibros. 14, 561-570. doi: 10.1016/j.jcf.2015.06.002

Mansour-Hendili, L., Blanchard, A., Le Pottier, N., Roncelin, I., Lourdel, S., Treard, C., et al. (2015). Mutation update of the CLCN5 gene responsible for dent disease 1. Hum. Mutat. 36, 743-752. doi: 10.1002/humu. 22804

Markhorst, J. M., Stunnenberg, B. C., Ginjaar, I. B., Drost, G., Erasmus, C. E., and Sie, L. T. (2014). Clinical experience with long-term acetazolamide treatment in children with nondystrophic myotonias: a three-case report. Pediatr. Neurol. 51, 537-541. doi: 10.1016/j.pediatrneurol.2014.05.027

Matthews, E., and Hanna, M. G. (2010). Muscle channelopathies: does the predicted channel gating pore offer new treatment insights for hypokalaemic periodic paralysis? J. Physiol. 588, 1879-1886. doi: 10.1113/jphysiol.2009.186627

Matthews, E., and Hanna, M. G. (2014). Repurposing of sodium channel antagonists as potential new anti-myotonic drugs. Exp. Neurol. 261, 812-815. doi: 10.1016/j.expneurol.2014.09.003

McCarthy, R. J., Kerns, J. M., Nath, H. A., Shulman, M., and Ivankovich, A. D. (2002). The antinociceptive and histologic effect of sciatic nerve blocks with 5\% butamben suspension in rats. Anesth. Analg. 94, 711-716. doi: 10.1097/00000539-200203000-00043

McCormack, K., Santos, S., Chapman, M. L., Krafte, D. S., Marron, B. E., West, C. W., et al. (2013). Voltage sensor interaction site for selective small molecule inhibitors of voltage-gated sodium channels. Proc. Natl. Acad. Sci. U.S.A. 110, E2724-E2732. doi: 10.1073/pnas.1220844110

McTaggart, J. S., Clark, R. H., and Ashcroft, F. M. (2010). The role of the KATP channel in glucose homeostasis in health and disease: more than meets the islet. J. Physiol. 588, 3201-3209. doi: 10.1113/jphysiol.2010. 191767

Mele, A., Calzolaro, S., Cannone, G., Cetrone, M., Conte, D., and Tricarico, D. (2014). Database search of spontaneous reports and pharmacological investigations on the sulfonylureas and glinides-induced atrophy in skeletal muscle. Pharmacol. Res. Perspect. 2:e00028. doi: 10.1002/ prp2.28

Miceli, F., Soldovieri, M. V., Ambrosino, P., De Maria, M., Manocchio, L., Medoro, A., et al. (2015a). Molecular pathophysiology and pharmacology of the voltage-sensing module of neuronal ion channels. Front. Cell Neurosci. 9:259. doi: 10.3389/fncel.2015.00259

Miceli, F., Soldovieri, M. V., Ambrosino, P., De Maria, M., Migliore, M., Migliore, R., et al. (2015b). Early-onset epileptic encephalopathy caused by gain-of-function mutations in the voltage sensor of Kv7.2 and Kv7.3 potassium 
channel subunits. J. Neurosci. 35, 3782-3793. doi: 10.1523/JNEUROSCI.442314.2015

Miceli, F., Vargas, E., Bezanilla, F., and Taglialatela, M. (2012). Gating currents from Kv7 channels carrying neuronal hyperexcitability mutations in the voltagesensing domain. Biophys. J. 102, 1372-1382. doi: 10.1016/j.bpj.2012.02.004

Milanesi, R., Bucchi, A., and Baruscotti, M. (2015). The genetic basis for inherited forms of sinoatrial dysfunction and atrioventricular node dysfunction. J. Interv. Card. Electrophysiol. 43, 121-134. doi: 10.1007/s10840-015-9998-z

Miller, I. O., and Sotero de Menezes, M. A. (2014). SCN1A-Related Seizure Disorders. Seattle, WA: University of Washington.

Minassian, N. A., Lin, M. C., and Papazian, D. M. (2012). Altered Kv3.3 channel gating in early-onset spinocerebellar ataxia type 13. J. Physiol. 590, 1599-1614. doi: 10.1113/jphysiol.2012.228205

Moreau, A., Gosselin-Badaroudine, P., and Chahine, M. (2014). Biophysics, pathophysiology, and pharmacology of ion channel gating pores. Front. Pharmacol. 5:53. doi: 10.3389/fphar.2014.00053

Moscatelli, I., Thudium, C. S., Flores, C., Schulz, A., Askmyr, M., Gudmann, N. S., et al. (2013). Lentiviral gene transfer of TCIRG1 into peripheral blood CD34(+) cells restores osteoclast function in infantile malignant osteopetrosis. Bone 57, 1-9. doi: 10.1016/j.bone.2013.07.026

Moss, A. J., Zareba, W., Schwarz, K. Q., Rosero, S., McNitt, S., and Robinson, J. L. (2008). Ranolazine shortens repolarization in patients with sustained inward sodium current due to type-3 long-QT syndrome. J. Cardiovasc. Electrophysiol. 19, 1289-1293. doi: 10.1111/j.1540-8167.2008. 01246.x

Muraglia, M., De Bellis, M., Catalano, A., Carocci, A., Franchini, C., Carrieri, A., et al. (2014). N-Aryl-2,6-dimethylbenzamides, a new generation of tocainide analogues as blockers of skeletal muscle voltage-gated sodium channels. J. Med. Chem. 57, 2589-2600. doi: 10.1021/jm401864b

Nakamura, K., Yoshida, K., Miyazaki, D., Morita, H., and Ikeda, S. (2009). Spinocerebellar ataxia type 6 (SCA6): Clinical pilot trial with gabapentin. J. Neurol. Sci. 278, 107-111. doi: 10.1016/j.jns.2008. 12.017

Nascimento, C. L., Garcia, C. L., Schvartsman, B. G., and Vaisbich, M. H. (2014). Treatment of Bartter syndrome. Unsolved issue. J. Pediatr. 90, 512-517. doi: 10.1016/j.jped.2014.01.012

Nguyen, H. L., Pieper, G. H., and Wilders, R. (2013). Andersen-Tawil syndrome: clinical and molecular aspects. Int. J. Cardiol. 170, 1-16. doi: 10.1016/j.ijcard.2013.10.010

Niemeyer, M. I., Cid, L. P., Sepúlveda, F. V., Blanz, J., Auberson, M., and Jentsch, T. J. (2010). No evidence for a role of CLCN2 variants in idiopathic generalized epilepsy. Nat. Genet. 42:3. doi: 10.1038/ng0110-3

Nilius, B., and Voets, T. (2013). The puzzle of TRPV4 channelopathies. EMBO Rep. 14, 152-163. doi: 10.1038/embor.2012.219

Novak, K. R., Norman, J., Mitchell, J. R., Pinter, M. J., and Rich, M. M. (2015). Sodium channel slow inactivation as a therapeutic target for myotonia congenita. Ann. Neurol. 77, 320-332. doi: 10.1002/ana.24331

Novarino, G., Weinert, S., Rickheit, G., and Jentsch, T. J. (2010). Endosomal chloride-proton exchange rather than chloride conductance is crucial for renal endocytosis. Science 328, 1398-1401. doi: 10.1126/science.1188070

Oakley, J. C., Cho, A. R., Cheah, C. S., Scheuer, T., and Catterall, W. A. (2013). Synergistic GABA-enhancing therapy against seizures in a mouse model of Dravet syndrome. J. Pharmacol. Exp. Ther. 345, 215-224. doi: 10.1124/jpet.113.203331

Ogiwara, I., Ito, K., Sawaishi, Y., Osaka, H., Mazaki, E., Inoue, I., et al. (2009). De novo mutations of voltage-gated sodium channel alphaII gene SCN2A in intractable epilepsies. Neurology 73, 1046-1053. doi: 10.1212/WNL.0b013e3181b9cebc

Ohgi, K., Okamoto, F., Kajiya, H., Sakagami, R., and Okabe, K. (2011). Antibodies against $\mathrm{ClC} 7$ inhibit extracellular acidification-induced $\mathrm{ClC}$ currents and bone resorption activity in mouse osteoclasts. Naunyn Schmiedebergs Arch. Pharmacol. 383, 79-90. doi: 10.1007/s00210-010-0576-8

O'Malley, H. A., and Isom, L. L. (2015). Sodium channel $\beta$ subunits: emerging targets in channelopathies. Annu. Rev. Physiol. 77, 481-504. doi: 10.1146/annurev-physiol-021014-071846

Omata, T., Takanashi, J., Wada, T., Arai, H., and Tanabe, Y. (2011). Genetic diagnosis and acetazolamide treatment of familial hemiplegic migraine. Brain Dev. 33, 332-334. doi: 10.1016/j.braindev.2010.05.006
Orchard, P. J., Fasth, A. L., Le Rademacher, J., He, W., Boelens, J. J., Horwitz, E. M., et al. (2015). Hematopoietic stem cell transplantation for infantile osteopetrosis. Blood 126, 270-276. doi: 10.1182/blood-2015-01-625541

Paşca, S. P., Panagiotakos, G., and Dolmetsch, R. E. (2014). Generating human neurons in vitro and using them to understand neuropsychiatric disease. Annu. Rev. Neurosci. 37, 479-501. doi: 10.1146/annurev-neuro-062012-170328

Pedersen, S. F., Okada, Y., and Nilius, B. (2016). Biophysics and physiology of the volume-regulated anion channel (VRAC)/volume-sensitive outwardly rectifying anion channel (VSOR). Pflugers Arch. doi: 10.1007/s00424-015-17816 [Epub ahead of print].

Peretz, A., Pell, L., Gofman, Y., Haitin, Y., Shamgar, L., Patrich, E., et al. (2010). Targeting the voltage sensor of Kv7.2 voltage-gated $\mathrm{K}^{+}$channels with a new gating-modifier. Proc. Natl. Acad. Sci. U.S.A. 107, 15637-15642. doi: 10.1073/pnas.0911294107

Picollo, A., and Pusch, M. (2005). Chloride/proton antiporter activity of mammalian CLC proteins ClC-4 and ClC-5. Nature 436, 420-423. doi: 10.1038 /nature03720

Pierno, S., De Luca, A., Desaphy, J.-F., Fraysse, B., Liantonio, A., Didonna, M. P., et al. (2003). Growth hormone secretagogues modulate the electrical and contractile properties of rat skeletal muscle through a ghrelin-specific receptor. Br. J. Pharmacol. 139, 575-584. doi: 10.1038/sj.bjp.0705284

Pierno, S., Tricarico, D., De Luca, A., Campagna, F., Carotti, A., Casini, G., et al. (1994). Effects of taurine analogues on chloride channel conductance of rat skeletal muscle fibers: a structure-activity relationship investigation. Naunyn Schmiedebergs Arch. Pharmacol. 349, 416-421. doi: 10.1007/BF001 70889

Pietrobon, D. (2010). CaV2.1 channelopathies. Pflugers Arch. 460, 375-393. doi: 10.1007/s00424-010-0802-8

Pietrobon, D., and Moskowitz, M. A. (2013). Pathophysiology of migraine. Annu. Rev. Physiol. 75, 365-391. doi: 10.1146/annurev-physiol-030212-183717

Pini, J., Rouleau, M., Desnuelle, C., Sacconi, S., and Bendahhou, S. (2016). Modeling andersen's syndrome in human induced pluripotent stem cells. Stem Cells Dev. 25, 151-159. doi: 10.1089/scd.2015.0258

Piwon, N., Günther, W., Schwake, M., Bösl, M. R., and Jentsch, T. J. (2000). ClC5 Cl- -channel disruption impairs endocytosis in a mouse model for Dent's disease. Nature 408, 369-373. doi: 10.1038/35042597

Portaro, S., Altamura, C., Licata, N., Camerino, G. M., Imbrici, P., Musumeci, O., et al. (2015). Clinical, molecular, and functional characterization of CLCN1 mutations in three families with recessive myotonia congenita. Neuromol. Med. 17, 285-296. doi: 10.1007/s12017-015-8356-8

Priori, S. G., Napolitano, C., Memmi, M., Colombi, B., Drago, F., Gasparini, M., et al. (2002). Clinical and molecular characterization of patients with catecholaminergic polymorphic ventricular tachycardia. Circulation 106, 6974. doi: 10.1161/01.CIR.0000020013.73106.D8

Priori, S. G., Wilde, A. A., Horie, M., Cho, Y., Behr, E. R., Berul, C., et al. (2013). Executive summary: HRS/EHRA/APHRS expert consensus statement on the diagnosis and management of patients with inherited primary arrhythmia syndromes. Europace 15, 1389-1406. doi: 10.1093/europace/eut272

Prunetti, P., and Perucca, E. (2011). New and forthcoming anti-epileptic drugs. Curr. Opin. Neurol. 24, 159-164. doi: 10.1097/WCO.0b013e3283 $4479 \mathrm{a} 7$

Pusch, M., Liantonio, A., Bertorello, L., Accardi, A., De Luca, A., Pierno, S., et al. (2000). Pharmacological characterization of chloride channels belonging to the $\mathrm{ClC}$ family by the use of chiral clofibric acid derivatives. Mol. Pharmacol. 58, 498-507.

Pusch, M., and Zifarelli, G. (2015). ClC-5: Physiological role and biophysical mechanisms. Cell Calcium 58, 57-66. doi: 10.1016/j.ceca.2014.09.007

Raja, K. A., Schurman, S., D’mello, R. G., Blowey, D., Goodyer, P., Van Why, S., et al. (2002). Responsiveness of hypercalciuria to thiazide in Dent's disease. J. Am. Soc. Nephrol. 13, 2938-2944. doi: 10.1097/01.ASN.0000036869.82685.F6

Remme, C. A., and Wilde, A. A. M. (2014). Targeting sodium channels in cardiac arrhythmia. Curr. Opin. Pharmacol. 15, 53-60. doi: 10.1016/j.coph.2013. 11.014

Rogawski, M. A., Tofighy, A., White, H. S., Matagne, A., and Wolff, C. (2015). Current understanding of the mechanism of action of the antiepileptic drug lacosamide. Epilepsy Res. 110, 189-205. doi: 10.1016/j.eplepsyres.2014.11.021

Rolim, A. L., Lindsey, S. C., Kunii, I. S., Crispim, F., Moisés, R. C., Maciel, R. M., et al. (2014). The insulin-sensitivity sulphonylurea receptor variant 
is associated with thyrotoxic paralysis. J. Mol. Endocrinol. 53, 295-301. doi: 10.1530/JME-14-0083

Rolland, J. F., Tricarico, D., Laghezza, A., Loiodice, F., Tortorella, V., and Camerino, D. C. (2006). A new benzoxazine compound blocks KATP channels in pancreatic beta cells: molecular basis for tissue selectivity in vitro and hypoglycaemic action in vivo. Br. J. Pharmacol. 149, 870-879. doi: 10.1038/sj.bjp.0706895

Romano, S., Coarelli, G., Marcotulli, C., Leonardi, L., Piccolo, F., Spadaro, M., et al. (2015). Riluzole in patients with hereditary cerebellar ataxia: a randomised, double-blind, placebo-controlled trial. Lancet Neurol. 14, 985-991. doi: 10.1016/S1474-4422(15)00201-X

Roussel, J., Labarthe, F., Thireau, J., Ferro, F., Farah, C., Roy, J., et al. (2016). Carnitine deficiency induces a short QT syndrome. Heart Rhythm 13, 165-174. doi: 10.1016/j.hrthm.2015.07.027

Ruan, Y., Denegri, M., Liu, N., Bachetti, T., Seregni, M., Morotti, S., et al. (2010). Trafficking defects and gating abnormalities of a novel SCN5A mutation question gene-specific therapy in long QT syndrome type 3. Circ. Res. 106, 1374-1383. doi: 10.1161/CIRCRESAHA.110. 218891

Ruan, Y., Liu, N., Bloise, R., Napolitano, C., and Priori, S. G. (2007). Gating properties of SCN5A mutations and the response to mexiletine in long-QT syndrome type 3 patients. Circulation 116, 1137-1144. doi: 10.1161/CIRCULATIONAHA.107.707877

Rubinstein, M., Han, S., Tai, C., Westenbroek, R. E., Hunker, A., Scheuer, T., et al. (2015). Dissecting the phenotypes of Dravet syndrome by gene deletion. Brain 138, 2219-2233. doi: 10.1093/brain/awv142

Rusconi, R., Scalmani, P., Cassulini, R. R., Giunti, G., Gambardella, A., Franceschetti, S., et al. (2007). Modulatory proteins can rescue a trafficking defective epileptogenic NaV1.1 $\mathrm{Na}^{+}$channel mutant. J. Neurosci. 27, 1103711046. doi: 10.1523/JNEUROSCI.3515-07.2007

Russo, R., Caroleo, M. C., Cione, E., Perri, M., Paparo, M. T., and Russo, A. (2015). Dual effect of ziconotide in primary erythromelalgia. Case Rep. Med. 2015, 592170. doi: 10.1155/2015/592170

Ryan, D. P., da Silva, M. R., Soong, T. W., Fontaine, B., Donaldson, M. R., Kung, A. W. C., et al. (2010). Mutations in potassium channel Kir2.6 cause susceptibility to thyrotoxic hypokalemic periodic paralysis. Cell 140, 88-98. doi: 10.1016/j.cell.2009.12.024

Saint-Martin, C., Gauvain, G., Teodorescu, G., Gourfinkel-An, I., Fedirko, E., Weber, Y. G., et al. (2009). Two novel CLCN2 mutations accelerating chloride channel deactivation are associated with idiopathic generalized epilepsy. Hum. Mutat. 30, 397-405. doi: 10.1002/humu.20876

Sala-Rabanal, M., Kucheryavykh, L. Y., Skatchkov, S. N., Eaton, M. J., and Nichols, C. G. (2010). Molecular mechanisms of EAST/SeSAME syndrome mutations in Kir4.1 (KCNJ10). J. Biol. Chem. 285, 36040-36048. doi: 10.1074/jbc.M110.163170

Sansone, V. A., Burge, J., McDermott, M. P., Smith, P. C., Herr, B., Tawil, R., et al. (2016). Randomized, placebo-controlled trials of dichlorphenamide in periodic paralysis. Neurology doi: 10.1212/WNL.0000000000002416 [Epub ahead of print].

Schoonjans, A. S., Lagae, L., and Ceulemans, B. (2015). Low-dose fenfluramine in the treatment of neurologic disorders: experience in Dravet syndrome. Ther. Adv. Neurol. Disord. 8, 328-338. doi: 10.1177/1756285615607726

Sheets, P. L., Jackson, J. O. II, Waxman, S. G., Dib-Hajj, S. D., and Cummins, T. R. (2007). A Nav1.7 channel mutation associated with hereditary erythromelalgia contributes to neuronal hyperexcitability and displays reduced lidocaine sensitivity. J. Physiol. 581, 1019-1031. doi: 10.1113/jphysiol.2006. 127027

Shulman, M., Harris, J. E., Lubenow, T. R., Nath, H. A., and Ivankovich, A. D. (2000). Comparison of epidural butamben to celiac plexus neurolytic block for the treatment of the pain of pancreatic cancer. Clin. J. Pain 16, 304-309.

Shulman, M., Lubenow, T. R., Nath, H. A., Blazek, W., McCarthy, R. J., and Ivankovich, A. D. (1998). Nerve blocks with 5\% butamben suspension for the treatment of chronic pain syndromes. Reg. Anesth. Pain. Med. 23, 395-401. doi: 10.1016/S1098-7339(98)90014-1

Sicca, F., Imbrici, P., D'Adamo, M. C., Moro, F., Bonatti, F., Brovedani, P., et al. (2011). Autism with seizures and intellectual disability: possible causative role of gain-of-function of the inwardly-rectifying K+ channel Kir4.1. Neurobiol. Dis. 43, 239-247. doi: 10.1016/j.nbd.2011.03.016
Simon, D. B., Bindra, R. S., Mansfield, T. A., Nelson-Williams, C., Mendonca, E., Stone, R., et al. (1997). Mutations in the chloride channel gene, CLCNKB, cause Bartter's syndrome type III. Nat. Genet. 17, 171-178. doi: 10.1038/ng1097-171

Simon, D. B., Karet, F. E., Rodriguez-Soriano, J., Hamdan, J. H., DiPietro, A., Trachtman, H., et al. (1996). Genetic heterogeneity of Bartter's syndrome revealed by mutations in the $\mathrm{K}^{+}$channel, ROMK. Nat. Genet. 14, 152-156. doi: $10.1038 /$ ng $1096-152$

Skalova, S., Svadlakova, T., Shaikh Qureshi, W. M., Dev, K., and Mokry, J. (2015). Induced pluripotent stem cells and their use in cardiac and neural regenerative medicine. Int. J. Mol. Sci. 16, 4043-4067. doi: 10.3390/ijms160 24043

Smart, S. L., Lopantsev, V., Zhang, C. L., Robbins, C. A., Wang, H., Chiu, S. Y., et al. (1998). Deletion of the K(V)1.1 potassium channel causes epilepsy in mice. Neuron 20, 809-819. doi: 10.1016/S0896-6273(00)81018-1

Snowball, A., and Schorge, S. (2015). Changing channels in pain and epilepsy: exploiting ion channel gene therapy for disorders of neuronal hyperexcitability. FEBS Lett. 589, 1620-1634. doi: 10.1016/j.febslet.2015.05.004

Soares-da-Silva, P., Pires, N., Bonifácio, M. J., Loureiro, A. I., Palma, N., and Wright, L. C. (2015). Eslicarbazepine acetate for the treatment of focal epilepsy: an update on its proposed mechanisms of action. Pharmacol. Res. Perspect. 3:e00124. doi: 10.1002/prp2.124

Sobacchi, C., Schulz, A., Coxon, F. P., Villa, A., and Helfrich, M. H. (2013). Osteopetrosis: genetics, treatment and new insights into osteoclast function. Nat. Rev. Endocrinol. 9, 522-536. doi: 10.1038/nrendo.2013.137

Sokolov, S., Scheuer, T., and Catterall, W. A. (2007). Gating pore current in an inherited ion channelopathy. Nature 446, 76-78. doi: 10.1038/nature 05598

Sokolov, S., Scheuer, T., and Catterall, W. A. (2010). Ion permeation and block of the gating pore in the voltage sensor of NaV1.4 channels with hypokalemic periodic paralysis. J. Gen. Physiol. 136, 225-236. doi: 10.1085/jgp.201010414

Soldovieri, M. V., Miceli, F., and Taglialatela, M. (2011). Driving with no brakes: molecular pathophysiology of Kv7 potassium channels. Physiology (Bethesda) 26, 365-376. doi: 10.1152/physiol.00009.2011

Spears, D. A., and Gollob, M. H. (2015). Genetics of inherited primary arrhythmia disorders. Appl. Clin. Genet. 8, 215-233. doi: 10.2147/TACG.S55762

Spillane, J., Kullmann, D. M., and Hanna, M. G. (2016). Genetic neurological channelopathies: molecular genetics and clinical phenotypes. J. Neurol. Neurosurg. Psychiatry 87, 37-48. doi: 10.1136/jnnp-2015-311233

Splawski, I., Timothy, K. W., Sharpe, L. M., Decher, N., Kumar, P., Bloise, R., et al. (2004). $\mathrm{Ca}(\mathrm{V}) 1.2$ calcium channel dysfunction causes a multisystem disorder including arrhythmia and autism. Cell 119, 19-31. doi: 10.1016/j.cell.2004.09.011

Statland, J. M., Bundy, B. N., Wang, Y., Rayan, D. R., Trivedi, J. R., Sansone, V. A., et al. (2012). Mexiletine for symptoms and signs of myotonia in nondystrophic myotonia: a randomized controlled trial. JAMA 308, 1357-1365. doi: 10.1001/jama.2012.12607

Steinke, K. V., Gorinski, N., Wojciechowski, D., Todorov, V., Guseva, D., Ponimaskin, E., et al. (2015). Human CLC-K channels require palmitoylation of their accessory subunit barttin to be functional. J. Biol. Chem. 290, 1739017400. doi: 10.1074/jbc.M114.631705

Sternberg, D., Maisonobe, T., Jurkat-Rott, K., Nicole, S., Launay, E., Chauveau, D., et al. (2001). Hypokalaemic periodic paralysis type 2 caused by mutations at codon 672 in the muscle sodium channel gene SCN4A. Brain 124, 1091-1099. doi: 10.1093/brain/124.6.1091

Strupp, M., Zwergal, A., Feil, K., Bremova, T., and Brandt, T. (2015). Pharmacotherapy of vestibular and cerebellar disorders and downbeat nystagmus: translational and back-translational research. Ann. N. Y. Acad. Sci. 1343, 27-36. doi: 10.1111 /nyas. 12774

Struyk, A. F., and Cannon, S. C. (2007). A Na+ channel mutation linked to hypokalemic periodic paralysis exposes a proton-selective gating pore. J. Gen. Physiol. 130, 11-20. doi: 10.1085/jgp.200709755

Suetterlin, K. J., Bugiardini, E., Kaski, J. P., Morrow, J. M., Matthews, E., Hanna, M. G., et al. (2015). Long-term safety and efficacy of mexiletine for patients with skeletal muscle channelopathies. JAMA Neurol. 72, 1531-1533. doi: 10.1001/jamaneurol.2015.2338

Swaggart, K. A., and McNally, E. M. (2014). Modifiers of heart and muscle function: where genetics meets physiology. Exp. Physiol. 99, 621-626. doi: 10.1113/expphysiol.2013.075887 
Syrbe, S., Hedrich, U. B., Riesch, E., Djémié, T., Müller, S., Møller, R. S., et al. (2015). De novo loss- or gain-of-function mutations in KCNA2 cause epileptic encephalopathy. Nat. Genet. 47, 393-399. doi: 10.1038/ng.3239

Takahashi, M. P., and Cannon, S. C. (2001). Mexiletine block of disease-associated mutations in S6 segments of the human skeletal muscle $\mathrm{Na}^{+}$channel. J. Physiol. 537, 701-714. doi: 10.1113/jphysiol.2001.012541

Talon, S., De Luca, A., De Bellis, M., Desaphy, J. F., Lentini, G., Scilimati, A., et al. (2001). Increased rigidity of the chiral centre of tocainide favours stereoselectivity and use-dependent block of skeletal muscle $\mathrm{Na}+$ channels enhancing the antimyotonic activity in vivo. Br. J. Pharmacol. 134, 1523-1531. doi: 10.1038/sj.bjp.0704366

Tang, B., Dutt, K., Papale, L., Rusconi, R., Shankar, A., Hunter, J., et al. (2009). A BAC transgenic mouse model reveals neuron subtypespecific effects of a Generalized Epilepsy with Febrile Seizures Plus (GEFS+) mutation. Neurobiol. Dis. 35, 91-102. doi: 10.1016/j.nbd.2009. 04.007

Tang, Q. Y., Zhang, F. F., Xu, J., Wang, R., Chen, J., Logothetis, D. E., et al. (2016). Epilepsy-related slack channel mutants lead to channel over-activity by two different mechanisms. Cell Rep. 14, 129-139. doi: 10.1016/j.celrep.2015.12.019

Tawil, R., Ptacek, L. J., Pavlakis, S. G., DeVivo, D. C., Penn, A. S., Ozdemir, C., et al. (1994). Andersen's syndrome: potassium-sensitive periodic paralysis, ventricular ectopy, and dysmorphic features. Ann. Neurol. 35, 326-330. doi: 10.1002/ana.410350313

Theile, J. W., and Cummins, T. R. (2011). Recent developments regarding voltage-gated sodium channel blockers for the treatment of inherited and acquired neuropathic pain syndromes. Front. Pharmacol. 2:54. doi: 10.3389/fphar.2011.00054

Thériault, O., Poulin, H., Sculptoreanu, A., de Groat, W. C., O'Leary, M. E., and Chahine, M. (2014). Modulation of peripheral $\mathrm{Na}^{+}$channels and neuronal firing by n-butyl-p-aminobenzoate. Eur. J. Pharmacol. 727, 158-166. doi: 10.1016/j.ejphar.2014.01.036

Tikhonov, D. B., and Zhorov, B. S. (2012). Architecture and pore block of eukaryotic voltage-gated sodium channels in view of NavAb bacterial sodium channel structure. Mol. Pharmacol. 82, 97-104. doi: 10.1124/mol.112. 078212

Tottene, A., Conti, R., Fabbro, A., Vecchia, D., Shapovalova, M., Santello, M., et al. (2009). Enhanced excitatory transmission at cortical synapses as the basis for facilitated spreading depression in $\mathrm{Ca}(\mathrm{v}) 2.1$ knockin migraine mice. Neuron 61 , 762-773. doi: 10.1016/j.neuron.2009.01.027

Tricarico, D., and Camerino, D. C. (2011). Recent advances in the pathogenesis and drug action in periodic paralyses and related channelopathies. Front Pharmacol. 2:8. doi: 10.3389/fphar.2011.00008

Tricarico, D., Mele, A., Calzolaro, S., Cannone, G., Camerino, G. M., Dinardo, M. M., et al. (2013). Emerging role of calcium-activated potassium channel in the regulation of cell viability following potassium ions challenge in HEK293 cells and pharmacological modulation. PLOS ONE 8:e69551. doi: 10.1371/journal.pone.0069551

Tricarico, D., Mele, A., Camerino, G. M., Laghezza, A., Carbonara, G., Fracchiolla, G., et al. (2008a). Molecular determinants for the activating/blocking actions of the 2H-1,4-benzoxazine derivatives, a class of potassium channel modulators targeting the skeletal muscle KATP channels. Mol. Pharmacol. 74, 50-58. doi: 10.1124/mol.108. 046615

Tricarico, D., Mele, A., and Conte Camerino, D. (2006). Carbonic anhydrase inhibitors ameliorate the symptoms of hypokalaemic periodic paralysis in rats by opening the muscular $\mathrm{Ca}^{2+}$-activated- $\mathrm{K}^{+}$channels. Neuromuscul. Disord. 16, 39-45. doi: 10.1016/j.nmd.2005.10.005

Tricarico, D., Mele, A., Liss, B., Ashcroft, F. M., Lundquist, A. L., Desai, R. R., et al. (2008b). Reduced expression of Kir6.2/SUR2A subunits explains KATP deficiency in $\mathrm{K}^{+}$-depleted rats. Neuromuscul. Disord. 18, 74-80. doi: 10.1016/j.nmd.2007.07.009

Tricarico, D., Montanari, L., and Conte Camerino, D. (2003). Involvement of $3 \mathrm{Na}+/ 2 \mathrm{~K}+\mathrm{ATP}$-ase and Pi-3 kinase in the response of skeletal muscle ATPsensitive $\mathrm{K}^{+}$channels to insulin. Neuromuscul. Disord. 13, 712-719. doi: 10.1016/S0960-8966(03)00095-6

Tricarico, D., Rolland, J. F., Cannone, G., Mele, A., Cippone, V., Laghezza, A., et al. (2012). Structural nucleotide analogs are potent activators / inhibitors of pancreatic $\beta$ cell KATP channels: an emerging mechanism supporting their use as antidiabetic drugs. J. Pharmacol. Exp. Ther. 340, 266-276. doi: 10.1124/jpet.111.185835

Trudell, R. G., Kaiser, K. K., and Griggs, R. C. (1987). Acetazolamide-responsive myotonia congenita. Neurology 37, 488-491. doi: 10.1212/WNL.37.3.488

Unwin, R. J., and Capasso, G. (2006). Bartter's and Gitelman's syndromes: their relationship to the actions of loop and thiazide diuretics. Curr. Opin. Pharmacol. 6, 208-213. doi: 10.1016/j.coph.2006.01.002

van der Knaap, M. S., and Scheper, G. C. (2011). "Megalencephalic Leukoencephalopathy with Subcortical Cysts," in GeneReviews[Internet], eds R. A. Pagon, M. P. Adam, H. H. Ardinger, S. E. Wallace, A. Amemiya, L. J. H. Bean, et al. (Seattlem, WA: University of Washington).

Vanoye, C. G., Gurnett, C. A., Holland, K. D., George, A. L. Jr., and Kearney, J. A. (2013). Novel SCN3A variants associated with focal epilepsy in children. Neurobiol. Dis. 62, 313-322. doi: 10.1016/j.nbd.2013.10.015

Verkman, A. S., and Galietta, L. J. (2009). Chloride channels as drug targets. Nat. Rev. Drug Discov. 8, 153-171. doi: 10.1038/ $\operatorname{nrd} 2780$

Wagnon, J. L., and Meisler, M. H. (2015). Recurrent and non-recurrent mutations of SCN8A in epileptic encephalopathy. Front. Neurol. 6:104. doi: 10.3389/fneur.2015.00104

Walker, L. E., Mirza, N., Yip, V. L., Marson, A. G., and Pirmohamed, M. (2015). Personalized medicine approaches in epilepsy. J. Intern. Med. 277, 218-234. doi: 10.1111/joim. 12322

Walter, J. T., Alviña, K., Womack, M. D., Chevez, C., and Khodakhah, K. (2006). Decreases in the precision of Purkinje cell pacemaking cause cerebellar dysfunction and ataxia. Nat. Neurosci. 9, 389-397. doi: 10.1038/nn1648

Wang, G., Bochorishvili, G., Chen, Y., Salvati, K. A., Zhang, P., Dubel, S. J., et al. (2015). CaV3.2 calcium channels control NMDA receptor-mediated transmission: a new mechanism for absence epilepsy. Genes Dev. 29, 1535-1551. doi: $10.1101 /$ gad.260869.115

Wang, Q., Curran, M. E., Splawski, I., Burn, T. C., Millholland, J. M., VanRaay, T. J., et al. (1996). Positional cloning of a novel potassium channel gene: KVLQT1 mutations cause cardiac arrhythmias. Nat. Genet. 12, 17-23. doi: 10.1038/ng0196-17

Wang, S. S., Devuyst, O., Courtoy, P. J., Wang, X. T., Wang, H., Wang, Y., et al. (2000). Mice lacking renal chloride channel, CLC-5, are a model for Dent's disease, a nephrolithiasis disorder associated with defective receptormediated endocytosis. Hum. Mol. Genet. 9, 2937-2945. doi: 10.1093/hmg/9. 20.2937

Watson, L. M., Wong, M. M., and Becker, E. B. (2015). Induced pluripotent stem cell technology for modelling and therapy of cerebellar ataxia. Open Biol. 5:150056. doi: 10.1098/rsob.150056

Waxman, S. G., Merkies, I. S., Gerrits, M. M., Dib-Hajj, S. D., Lauria, G., Cox, J. J., et al. (2014). Sodium channel genes in pain-related disorders: phenotypegenotype associations and recommendations for clinical use. Lancet Neurol. 13, 1152-1160. doi: 10.1016/S1474-4422(14)70150-4

Weinert, S., Jabs, S., Hohensee, S., Chan, W. L., Kornak, U., and Jentsch, T. J. (2014). Transport activity and presence of ClC-7/Ostm1 complex account for different cellular functions. EMBO Rep 15, 784-791. doi: $10.15252 / \mathrm{embr} .201438553$

Welling, P. A., and Ho, K. (2009). A comprehensive guide to the ROMK potassium channel: form and function in health and disease. Am. J. Physiol. Renal. Physiol. 297, F849-F863. doi: 10.1152/ajprenal.00181.2009

Welters, A., Lerch, C., Kummer, S., Marquard, J., Salgin, B., Mayatepek, E., et al. (2015). Long-term medical treatment in congenital hyperinsulinism: a descriptive analysis in a large cohort of patients from different clinical centers. Orphanet. J. Rare Dis. 10:150. doi: 10.1186/s13023-015-0367-x

Wheeler, A., Wang, C., Yang, K., Fang, K., Davis, K., Styer, A. M., et al. (2008). Coassembly of different sulfonylurea receptor subtypes extends the phenotypic diversity of ATP-sensitive potassium (KATP) channels. Mol. Pharmacol. 74, 1333-1344. doi: 10.1124/mol.108.048355

Wu, F., Mi, W., and Cannon, S. C. (2013). Beneficial effects of bumetanide in a CaV1.1-R528H mouse model of hypokalaemic periodic paralysis. Brain $136(\mathrm{Pt}$ 12), 3766-3774. doi: 10.1093/brain/awt280

Wuttke, T. V., Jurkat-Rott, K., Paulus, W., Garncarek, M., LehmannHorn, F., and Lerche, H. (2007). Peripheral nerve hyperexcitability due to dominant-negative KCNQ2 mutations. Neurology 9, 2045-2053. doi: 10.1212/01.wnl.0000275523.95103.36 
Yamamoto, S., Kita, S., Iyoda, T., Yamada, T., and Iwamoto, T. (2011). New molecular mechanisms for cardiovascular disease: cardiac hypertrophy and cell-volume regulation. J. Pharmacol. Sci. 116, 343-349. doi: 10.1254/jphs.10R31FM

Yang, Y., Dib-Hajj, S. D., Zhang, J., Zhang, Y., Tyrrell, L., Estacion, M., et al. (2012). Structural modelling and mutant cycle analysis predict pharmacoresponsiveness of a Nav1.7 mutant channel. Nat. Commun. 3:1186. doi: $10.1038 /$ ncomms 2184

Yang, Y., Wang, Y., Li, S., Xu, Z., Li, H., Ma, L., et al. (2004). Mutations in SCN9A, encoding a sodium channel alpha subunit, in patients with primary erythermalgia. J. Med. Genet. 41, 171-174. doi: 10.1136/jmg.2003.012153

Yazawa, M., and Dolmetsch, R. E. (2013). Modeling Timothy syndrome with iPS cells. J. Cardiovasc. Transl. Res. 6, 1-9. doi: 10.1007/s12265-012-9444-x

Yuan, J., Matsuura, E., Higuchi, Y., Hashiguchi, A., Nakamura, T., Nozuma, S., et al. (2013). Hereditary sensory and autonomic neuropathy type IID caused by an SCN9A mutation. Neurology 80, 1641-1649. doi: 10.1212/WNL.0b013e3182904fdd

Zaharieva, I. T., Thor, M. G., Oates, E. C., van Karnebeek, C., Hendson, G., Blom, E., et al. (2015). Loss-of-function mutations in SCN4A cause severe foetal hypokinesia or 'classical' congenital myopathy. Brain doi: 10.1093/brain/awv352 [Epub ahead of print].

Zamponi, G. W., Striessnig, J., Koschak, A., and Dolphin, A. C. (2015). The physiology, pathology, and pharmacology of voltage-gated calcium channels and their future therapeutic potential. Pharmacol. Rev. 67, 821-870. doi: 10.1124/pr.114.009654

Zhang, X. Y., Wen, J., Yang, W., Wang, C., Gao, L., Zheng, L. H., et al. (2013). Gainof-function mutations in SCN11A cause familial episodic pain. Am. J. Hum. Genet. 93, 957-966. doi: 10.1016/j.ajhg.2013.09.016

Zhao, Q., Wei, Q., He, A., Jia, R., and Xiao, Y. (2009). CLC-7: a potential therapeutic target for the treatment of osteoporosis and neurodegeneration. Biochem. Biophys. Res. Commun. 384, 277-279. doi: 10.1016/j.bbrc.2009.04.088

Zou, B. (2015). Ion channel profiling to advance drug discovery and development. Drug Discov. Today Technol. 18, 18-23. doi: 10.1016/j.ddtec.2015. 10.003

Conflict of Interest Statement: The authors declare that the research was conducted in the absence of any commercial or financial relationships that could be construed as a potential conflict of interest.

Copyright (c) 2016 Imbrici, Liantonio, Camerino, De Bellis, Camerino, Mele, Giustino, Pierno, De Luca, Tricarico, Desaphy and Conte. This is an open-access article distributed under the terms of the Creative Commons Attribution License (CC BY). The use, distribution or reproduction in other forums is permitted, provided the original author(s) or licensor are credited and that the original publication in this journal is cited, in accordance with accepted academic practice. No use, distribution or reproduction is permitted which does not comply with these terms. 